\title{
Interaction of maize root associated fungi and the western corn rootworm
}

\author{
Dissertation \\ zur Erlangung des Doktorgrades \\ der Fakultät für Agrarwissenschaften \\ der Georg-August-Universität Göttingen
}

\author{
vorgelegt von \\ Benedikt Kurtz \\ geboren in Frankfurt am Main
}

Göttingen, im Mai 2010 
D 7

1. Referent: Prof. Dr. Stefan Vidal..

2. Korreferent: Prof. Dr. Petr Karlovsky.

Tag der mündlichen Prüfung: 15.07. 2010 


\section{Table of contents}

Summary

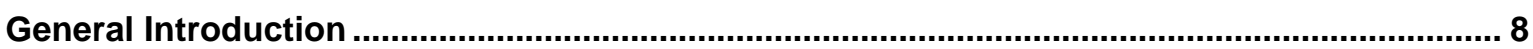

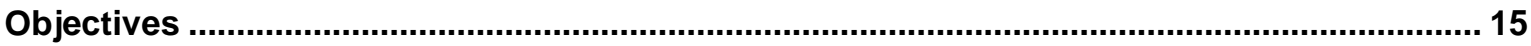

Chapter 1: Effects of soil type and maize cultivar on the development of western corn

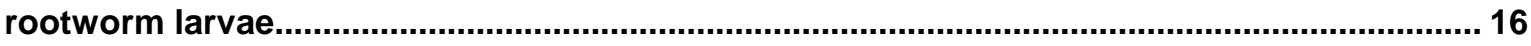

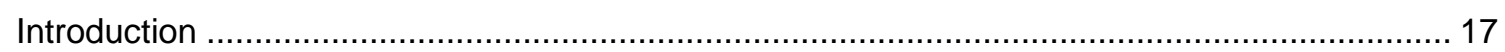

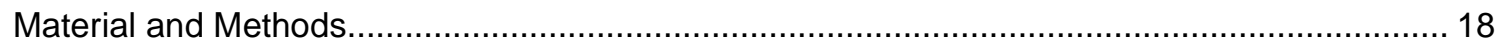

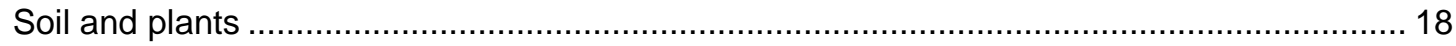

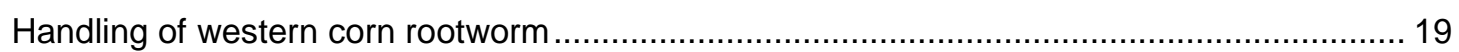

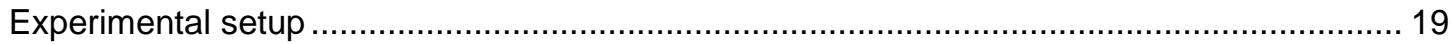

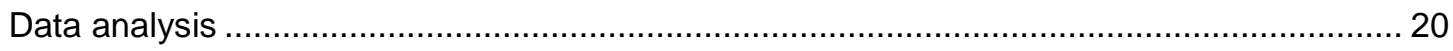

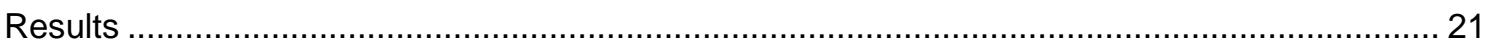

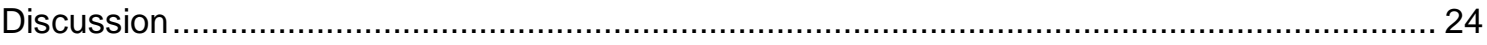

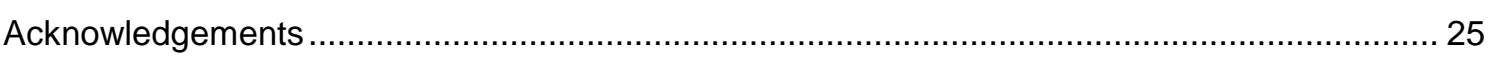

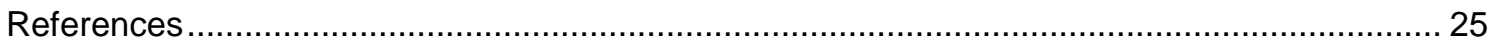

Chapter 2: Interaction between western corn rootworm (Coleoptera: Chrysomelidae) larvae

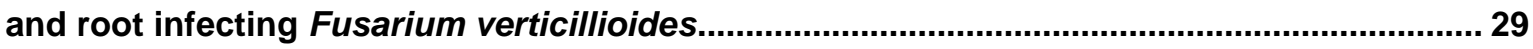

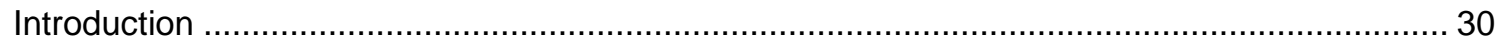

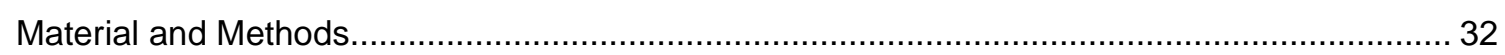

Cultivation of Fusarium verticillioides and handling of western corn rootworm ...................... 32

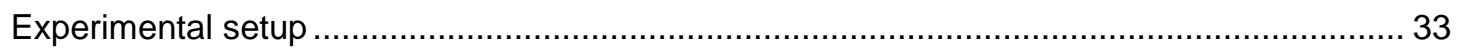

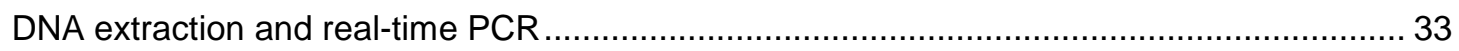

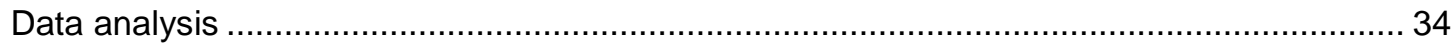

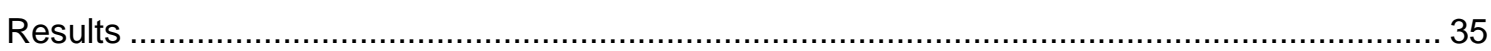

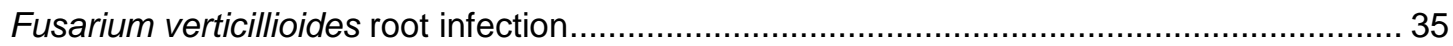

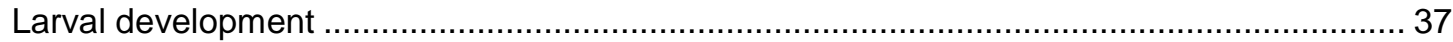

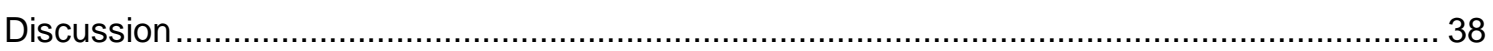

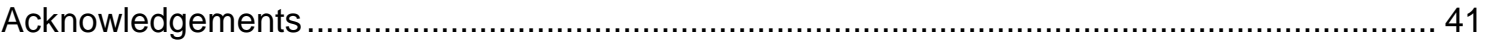

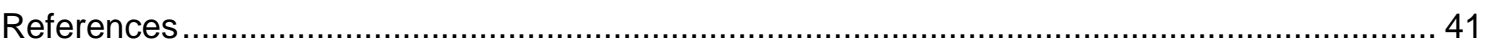

Chapter 3: Belowground feeding of western corn rootworm increases aboveground

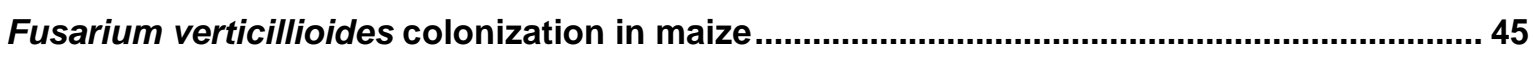

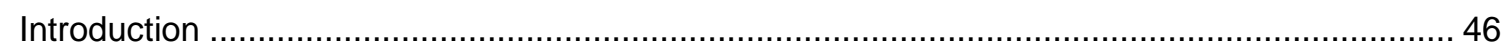

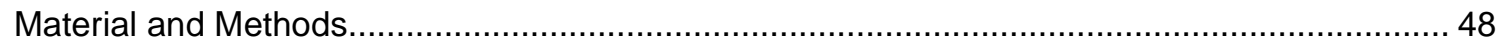

Plants, cultivation of Fusarium verticillioides and handling of western corn rootworm ........... 48

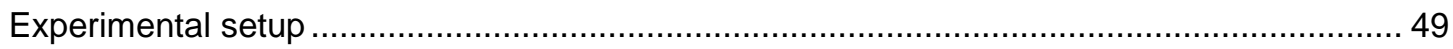




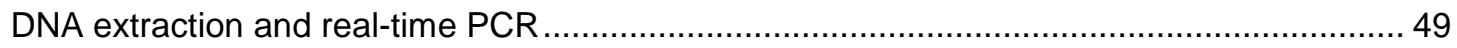

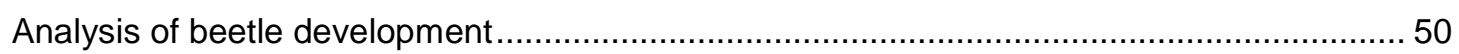

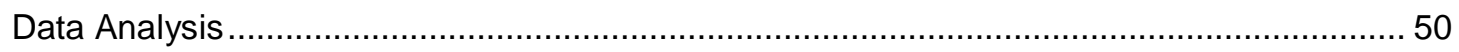

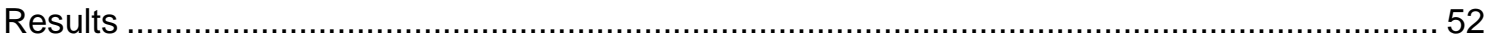

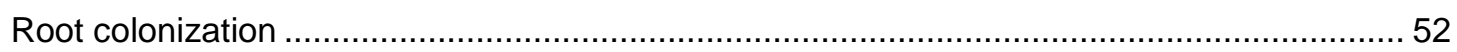

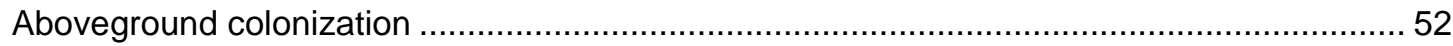

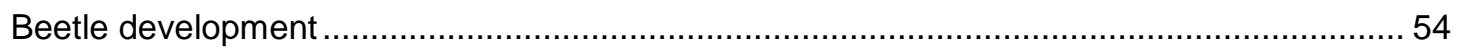

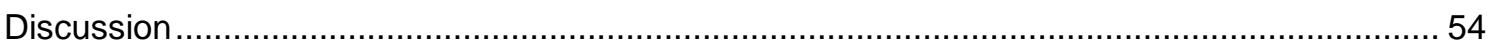

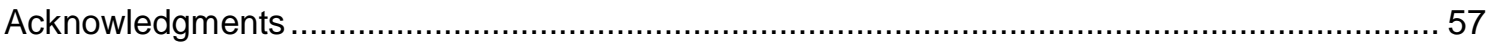

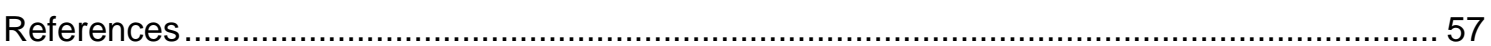

Chapter 4: Can western corn rootworm larvae orientate towards, transport and transmit root

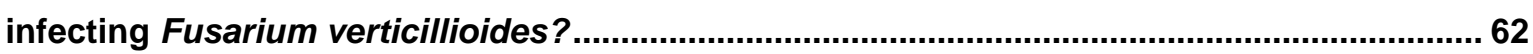

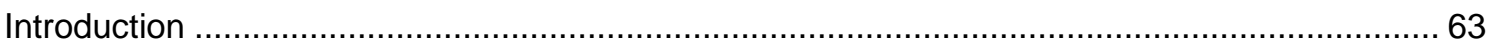

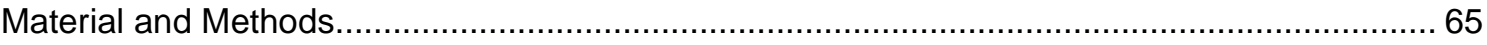

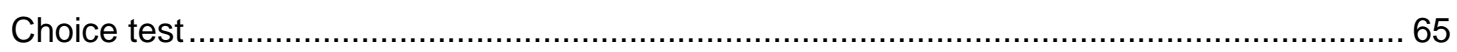

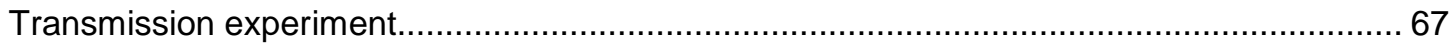

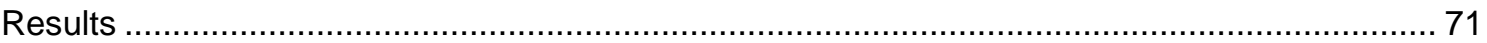

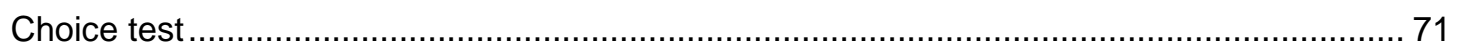

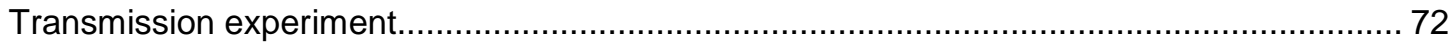

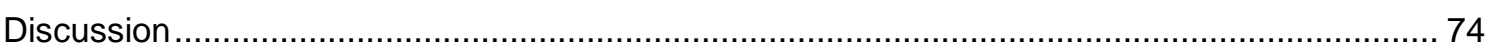

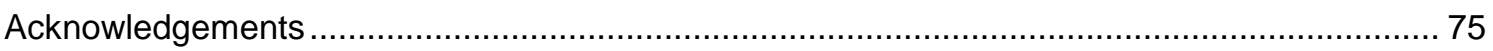

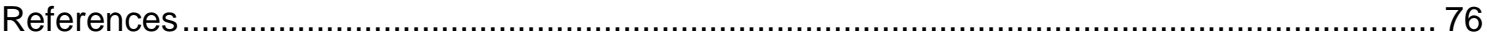

Chapter 5: Interaction between western corn rootworm (Coleoptera; Chrysomelidae) and the

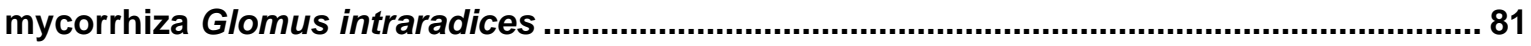

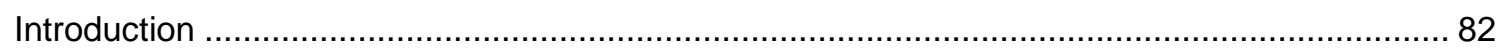

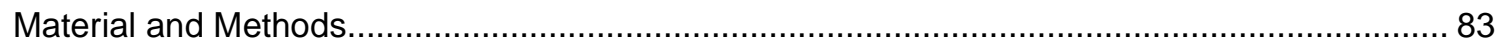

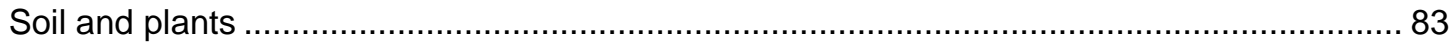

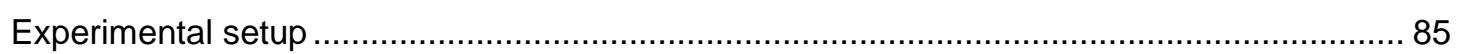

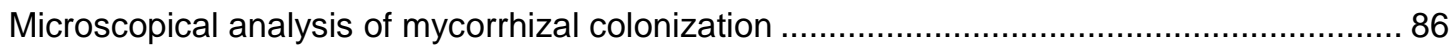

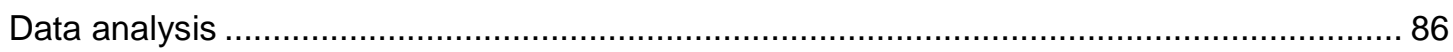

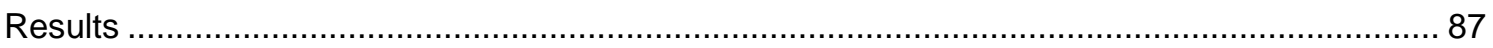

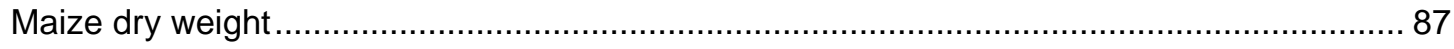

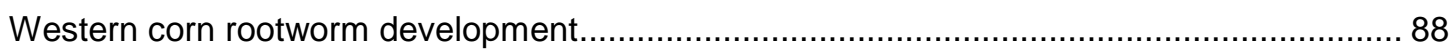

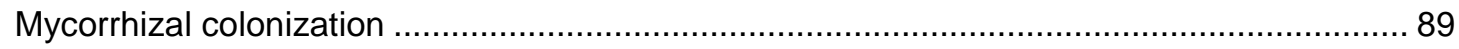

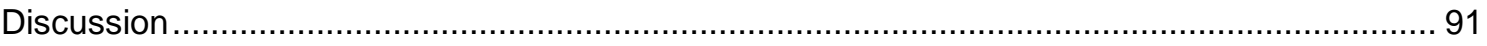

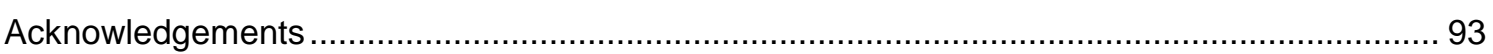

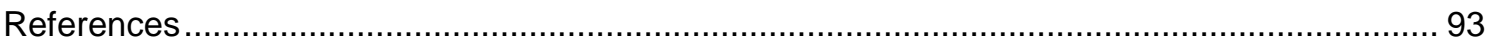

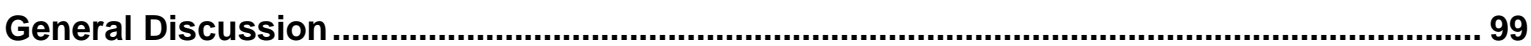


References cited in general introduction and discussion .............................................. 106

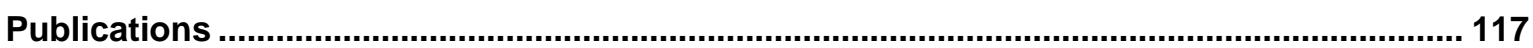

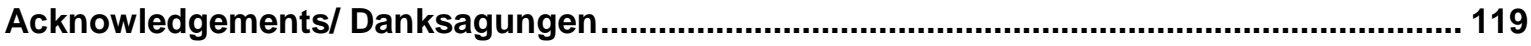

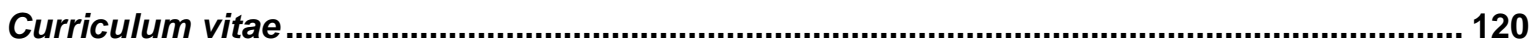

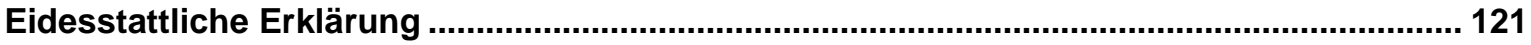




\section{Summary}

The chrysomelid beetle western corn rootworm (Diabrotica virgifera virgifera Le Conte) is an important maize pest and an invasive species in Europe. The larvae feed on the roots of maize and may cause severe damage. Knowledge of the ecology of a pest is a key requirement for developing a successful integrated pest management strategy. In this respect belowground insect pests have been specifically neglected in the past, because of difficulties in working with them. This study aimed at understanding the interaction of western corn rootworm (WCR) larvae with maize root associated fungi. It provides information on the influence of soil types and maize cultivars on WCR development, the potential of WCR larvae to transmitt and to enhance colonization by a root infecting plant pathogen, and on the interaction of WCR larvae with mutualistic mycorrhiza.

(1) We analyzed the development of western corn rootworm larvae in different soil types and on different maize cultivars.

- Soil type influenced the biomass production of different maize cultivars, but had no effect on the suitability of maize cultivar for larval development.

- Even maize cultivars considered to be susceptible to WCR, differed in their suitability for larval development.

(2) We tested different treatments to investigate the influence of different chronological appearances of western corn rootworm larvae, and the root infecting fungus Fusarium verticillioides (Saccardo) Nirenberg (synonym=F. moniliforme Sheldon) on their interaction.

- Larval damage enhanced the colonization of the roots by F. verticillioides depending on the fungal inoculum density and the chronological appearance of larvae and fungus. The level of colonization was higher the more time $F$. verticillioides had to colonize the root before the appearance of the larvae.

- Larvae were delayed in their development when F. verticillioides was applied. This effect appeared independently of the tested timing treatments. 
(3) We investigated the influence of western corn rootworm larval damage on above ground colonization of maize plants by $F$. verticillioides for conventional and a genetically modified maize cultivar. In addition we investigated the influence of F. verticillioides colonization on the development of WCR beetles.

- Larval feeding increased F. verticillioides colonization of lower stem parts in conventional cultivars.

- Larval feeding did not enhance $F$. verticillioides colonization in the transgenic cultivar MON 88017.

- Beetles emerging from fungus colonized plants were in one of the two tested conventional cultivars significantly smaller than beetles from the control treatment.

(4) We investigated transport and transmission of $F$. verticillioides by western corn rootworm larvae from colonized to non colonized plants. In choice tests we analyzed the orientation of larvae towards fungus colonized plants.

- Larvae were deterred by F. verticillioides colonized plants.

- Larvae transported vital F. verticillioides after having fed on inoculated plants.

- The transmitted inoculum was not sufficient to induce F. verticillioides colonization of previously non colonized plants.

(5) We tested the influence of western corn rootworm larval damage on the mycorrhization by Glomus intraradices, and the influence of $G$. intraradices on WCR larval development

- WCR larvae did not influence the colonization of maize roots by G. intraradices.

- Larval development was significantly delayed when feeding on plants colonized by $G$. intraradices. 


\section{"The first law of ecology: Everything is connected to everything else." Barry Commoner, 1971}

\section{General Introduction}

Root herbivores play an important role in the succession of natural vegetation, diversity of plant communities, competitive interactions between plants and in yield production of agronomic and forest systems (Hunter 2001, van Dam 2009). This is not surprising as belowground plant tissues contribute $50-90 \%$ of total plant biomass (Brown and Gange 1990). The effects of root herbivory on individual host plants include changes in plant root shoot ratio, changes in carbon and nitrogen allocation, production of secondary metabolites, emission of volatiles and plant architecture (Steinger and Mullerscharer 1992, Rasmann et al. 2005, Erb et al. 2009, Gerber et al. 2007).

The high impact of root feeding insects is best exemplified in their use as biological control agents against weeds, where they have been even more successful than above ground insect control agents (Blossey and Tamaru 2003). Despite the fact that belowground feeding insects can have such a strong impact on individual plants and plant community structure, studies on belowground insect herbivores comprise less than $2 \%$ of all insect-plant studies (Hunter 2001). This low attention that has been directed towards belowground herbivory is due to experimental limitations: the relative difficulty to directly assess and observe root feeders, their often clumped distributions, and their long life cycles (Brown and Gange 1990). However in the last decade interest regarding root feeding insects and their interaction with plants and above ground herbivores has increased, focusing mainly on economically important pests (van Dam 2009, Johnson and Murray 2009). This is due to the development of new molecular, analytical and visual techniques, now being used to study the ecological importance of belowground herbivores.

One economically important root feeding insect is the western corn rootworm (WCR) Diabrotica virgifera virgifera LeConte (Coleoptera Chrysomelidea). The eggs of this univoltine beetle diapause during the winter and larvae hatch in 
spring. The three larval instars feed on the roots of maize, but are also able to survive on some grass species (Moeser and Vidal 2004, Spencer 2009). The larval feeding results in reduced water and nutrient uptake and heavily attacked plants are prone to lodging (Levine and Oloumi-Sadeghi 1991, Godfrey et al. 1993). The western corn rootworm was first described by LeConte in 1865 in Kansas. With the increase in maize production in the middle of the $20^{\text {th }}$ century, WCR extended its distribution range in the USA and became an economically significant pest (Meinke et al. 2009). Today the western corn rootworm is the most important maize pest in the USA causing control costs of around 1 billion $\$$ US per year (Rice 2004, Sappington et al. 2006). In the early 1990`s WCR was introduced into Europe, and has since spread from Eastern to Central Europe, with first findings in Germany in 2007 (Kiss et al. 2005, Gray et al. 2009, Fig. 1). In Europe control measures and yield losses are expected to sum up to 472 millions $€$ per year (Wesseler and Fall 2009).

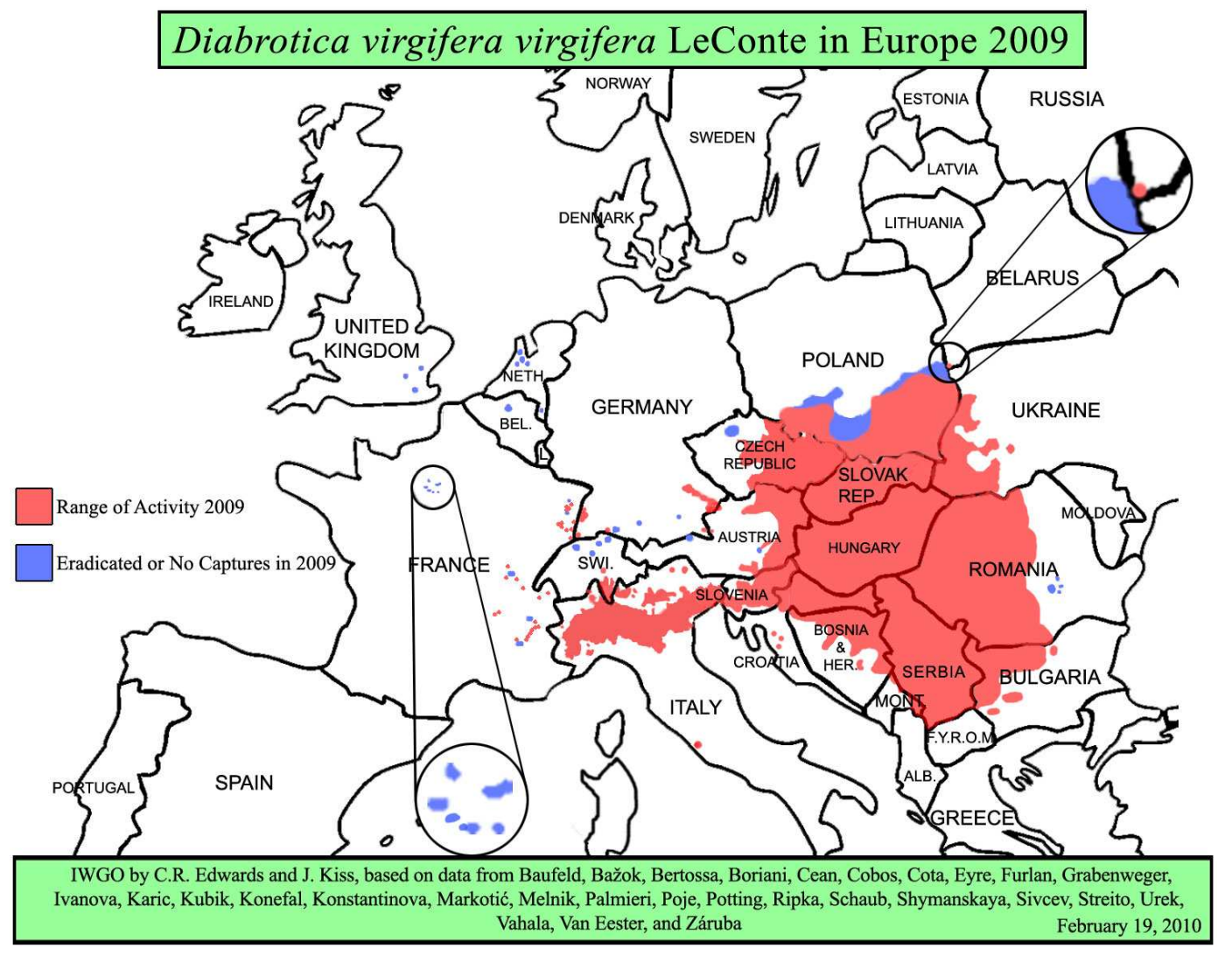

Fig. 1 Distribution of western corn rootworm (Diabrotica v. virgifera LeConte) in Europe 2009. 
The knowledge of the ecology and the interactions of a pest with its biotic and abiotic environment form the basis for successful integrated pest management (IPM) strategies (Kogan 1998). Invasive species impose a special challenge in this context, because they colonize new favourable areas and show a high adaptability to new environments (Moeser and Guillemaud 2009).

How do invasive root feeders interact with micro-organisms that they encounter in their new habitat? Grayston et al. (2001) suggested that root feeding insects could impact nutrient cycling in the soil by influencing the given microbial communities. In that way an invasive root feeder could cause severe changes in ecosystem processes. Because the western corn rootworm has been an important pest in the USA since the second half of the last century, many studies have been carried out investigating various aspects of its biology and ecology (Meinke et al. 2009, Spencer et al. 2009). However, there is no information available on the interactions of larvae with micro-organisms colonizing the roots of maize. Different studies have shown that micro-organisms colonizing the plant are able to influence insect behaviour, development and fitness (Vicari et al. 2002, Röder et al. 2007, Mondy and Corio-Costet 2004). With regard to root feeding insects, this has been investigated in several studies focussing on the interactions with mycorrhizal fungi (Gange 1994, Gange 2001, Koricheva et al. 2009). Furthermore it has been shown that root feeding change the composition of the microbial community colonizing the plant (Denton et al. 1998, Grayston et al. 2001, Dawson et al. 2004). Soil living arthropods transport and transmit fungi through the soil, but most of these studies concentrated on collembolans and mites (Visser et al. 1987, Whipps and Budge 1993, Thimm et al. 1998, Williams et al. 1998). Insects enhance infections of plants by plant pathogenic fungi (Rostas et al. 2003); however, studies concentrating on insect root feeders are rare, but indicate that root feeders influence the colonization of roots by plant pathogens (Palmer and Kommedahl 1969, Kalb et al. 1994). Due to the unknown impact of WCR invasion on root associated fungi in Europe, we focused on the following three main functional aspects in this thesis. 


\section{Influence of soil type and maize cultivar on western corn rootworm development (Chapter1)}

Soil type and maize cultivar are crucial factors influencing the development of the western corn rootworm larvae and the fungal community colonizing the maize root. Maize cultivars differ in their suitability for WCR development and the soil type directly influences the mobility of the larvae, but also the water content and the nutritional status of the plant (Branson et al. 1983, Prischmann et al. 2007, Tollefson 2007, Gustin and Schumacer 1989, Strnad and Bergman 1987 a, b). Additionally, soil types differ in their microbial community colonizing the root (Singh et al. 2007), which may then interact with western corn rootworm larval feeding. We therefore analyzed the development of WCR larvae on different maize cultivars and in different soil types, to assess the influence of these two factors on WCR larval development (Chapter 1). In the general discussion we will refer to results by our cooperating partners Flavia Dematheis and Prof. Dr. Cornelia Smalla (Institute of Plant Epidemiology and Pathogen Diagnostics, Julius-Kühn Institute, Braunschweig), who analyzed the fungal communities colonizing the roots in this experiment, by using denaturing gradient gel electrophoresis (DGGE). This research compiles information on the variability of fungal communities colonizing the roots, and the influence of the root feeding herbivore on the fungal community structure. The data presented provides information on the influence of soil type on the suitability of maize cultivars to support WCR larval development.

\section{Interaction of western corn rootworm with the root infecting plant pathogen Fusarium verticillioides (Chapter2-4)}

Studies investigating the interactions of herbivorous insects and plant pathogens mainly concentrate on aboveground insect pests (Agrios 2004). Although evidence exists that root feeding insect pests can enhance infections and transmit plant pathogens (Phytium, Fusarium, Sclerotium) only very few studies have investigated these interactions (Palmer and Kommedahl 1969, Leath and Hower 1993, Kalb et al. 1994, Agrios 2004). The main focus of the present work was therefore directed towards understanding the interactions between WCR larvae and the soil borne plant-pathogenic fungus Fusarium verticillioides.

F. verticillioides is an ubiquitous mycotoxin producing fungus causing seedling 
blight, root rot, stalk rot, kernel rot, ear rot or systemic infection of maize (Danielsen and Jensen 1998, Munkvold et al. 1999, Munkvold 2003).

F. verticillioides produces several mycotoxins, including fusaric acids, fusarins and fumonisins (Nelson 1992). Fumonisins have been associated with diseases in mammals, such as fatal leucoencephalomalacia in horses, pulmonary edema in swine, esophageal cancer in humans and cancer promoting activity in rats (Munkvold and Desjardins 1997, Voss et al. 2002, Mouhoube et al. 2003). Palmer and Kommedahl (1969) reported increased incidence of root infections by Fusarium spp. in fields infested by Diabrotica longicornis (Say), the northern corn rootworm larvae, but did not quantify the intensity of Fusarium spp. colonization. In addition, Palmer and Kommedahl (1969) concluded that northern corn rootworms acted as vectors of Fusarium spp., but did not test the mechanism underlying their observations. We therefore asked the following questions:

(i) Do WCR larvae not only increase the incidence but also the quantity of Fusarium spp. colonization in maize plants?

(ii) Does increased colonization of the roots also lead to a systemic infection of above ground parts?

(iii) Is the increased colonization caused because the larvae create wounds the fungus uses to enter, or do they also transmit Fusarium spp. to previously non colonized plants?

We examined the effects of WCR damage on the colonization quantity of maize roots by $F$. verticillioides, and the influence of different chronological appearance of the fungus and the insect (Chapter 2.). Furthermore we investigated the influence of $F$. verticillioides colonization of the roots on WCR larval and adult development (Chapter 2 and Chapter 3). Additionally we quantified the above ground colonization of maize plants by $F$. verticillioides, as it is important to consider the potential mycotoxin contaminations of maize (Chapter 3 ).

We also carried out choice tests to understand, whether WCR larvae prefer F. verticillioides colonized plants compared to non colonized plants, and whether they are able to transport $F$. verticillioides from colonized to uncolonized plants (Chapter 4). 


\section{Interaction of western corn rootworm with the mutualistic mycorrhiza}

\section{Glomus intraradices (Chapter5)}

Arbuscular mycorrhiza (AM) occur in 75\% of the world's flowering plants, but only a relative small number of fungal species ( 150 taxa) from the order Glomales (Zygomycota) are responsible for these associations (Hodge 2000). AM are known to change root morphology and function and increase the productivity of maize plants by providing plants with mineral nutrients (mainly phosphate, but also nitrogen, zinc and copper), and increase water uptake through their hyphal network (Berta et al. 1992, Kothari et al. 1990, Sylvia et al. 1993, Smith and Reed 2008). Therefore, AM play an important role in plant nutrition, specifically in soils with a low or unbalanced nutrient status (Jeffries 1987, Smith and Reed 2008). Goverde et al. (2000) demonstrated that the butterfly Polyommatus icarus Rottemburg (Lycaenidae) had a higher lipid content when larvae were feeding on mycorrhized plants. Insect lack the ability to synthesize sterols that they require for lipid synthesis (Behmer and Nes 2003), but mycorrhiza have the potential to alter sterol content in the plants (Fontaine et al. 2001). Apart from changing the nutritional status of the plant, mycorrhiza can modulate molecular and biochemical response in the plant influencing plant defence related genes and production of allelochemicals (reviewed by Bi et al. 2007). In general, studies on the interaction between mycorrhiza and insects have focused on aboveground insect herbivores. Gange et al. (1994) documented, being one of the few papers dealing with root feeding insects and mycorrhiza, that the growth of root feeding larvae of Otiorhynchus sulcatus Fabricius (black vine weevil) was reduced when feeding on plants colonized by the mycorrhizal fungus Glomus mosseae (Nicol. \& Gerd.). Koricheva (2009) carried out a meta-analysis on the effects of mycorrhizal fungi on insect herbivores. This study found that root feeders tend to be negatively influenced by mycorrhizal colonization. Brown and Gange (1990) suggested that root feeders might decrease the colonization of roots by mycorrhiza by feeding on colonized roots, while Currie et al. (2006) showed that root herbivory can enhance the colonization by AM fungi.

In greenhouse experiments we investigated the influence of colonization by the mycorrhiza Glomus intraradices (Schenk \& Smith) on WCR larval development, and the influence of larval feeding on mycorrhizal colonization (Chapter 5). In the discussion we will relate the results found in these experiments to the analyzis of 
fungal community structure at the roots of maize that was simultaneously carried out by Flavia Dematheis.

This work covers a range of different aspects of two functional groups of root colonizing fungi, a pathogen and a mutualist. The interaction of WCR with these fungi delivers basic ecological information which is relevant to the invasiveness and the management of WCR (Chapter1), plant health (Chapter 2-4) and plant nutrition (Chapter 5). 


\section{Objectives}

The aim of this work was to investigate the interaction of western corn rootworm (WCR-Diabrotic virgifera virgifera LeConte) larvae with root associated fungi. The focus was laid on the interaction of WCR with a plant pathogen (Fusarium verticillioides) and a mutualistic mycorrhiza (Glomus intraradices).

1.) The development of western corn rootworm larvae in different soil types and at different maize cultivars was analyzed to examine the influence of these crucial factors on WCR development.

2.) Different chronological appearances of WCR and F. verticillioides were tested to analyze the enhancement of fungal colonization of the roots caused by WCR damage. Additionally the influence of fungal colonization on larval development was examined.

3.) The systemic colonization of different maize cultivars by $F$. verticillioides was analyzed, to assess the enhancement of systemic colonization caused by WCR larval damage.

4.) Experiments were carried out to investigate the ability of WCR larvae to act as a vector of root infecting $F$. verticillioides.

5.) The mycorrhization of maize plants and the development of WCR larvae were analyzed, to investigate the interactions between $G$. intraradices and WCR. 


\title{
Chapter 1: Effects of soil type and maize cultivar on the development of western corn rootworm larvae
}

\author{
B. Kurtz and S. Vidal
}

Georg-August University Göttingen, Department of Crop Science, Agricultural Entomology, Grisebachstrasse 6, 37077 Goettingen, Germany, phone:++49(0)551-393728, Email: bkurtz@wdg.de

Corresponding author: S. Vidal address as above, phone: +49(0)551-39 9744, fax:+49(0)551 -39 12105, Email: svidal@gwdg.de

\section{Abstract}

Soil type and maize cultivar are crucial factors influencing the performance of the invasive ground-dwelling maize pest Diabrotica virgifera virgifera LeConte (western corn rootworm, WCR). We examined both soil type and maize cultivar and the interactions between these parameters on development of WCR larvae. In a greenhouse experiment, four maize cultivars were grown in three soil types, and WCR eggs were added at V3 growth stage. Twenty days later, the larvae were extracted from soil, counted by instar, and weighed (in the case of $3^{\text {rd }}$ instars); plant dry biomass was also measured. Soil type did influence the growth of cultivars but had only limited influence on the development of WCR larvae. Plant biomass was not correlated with larval numbers or $3^{\text {rd }}$ instar weight. Soil type did not influence the interaction between maize cultivars and larval development. However, maize cultivars influenced the ratio between $2^{\text {nd }}$ and $3^{\text {rd }}$ instars as well as $3^{\text {rd }}$ instar weight. Our results demonstrate that soil type does not interact with maize cultivar to impact WCR development. Our results agree with those of other studies that larval development is influenced by maize cultivar. The quantity of biomass produced by the different cultivars had little or no effect on larval development.

KEY WORDS Diabrotica virgifera virgifera, western corn rootworm, maize cultivar, soil type, larval development 


\section{INTRODUCTION}

Diabrotica virgifera virgifera Le Conte (the western corn rootworm, WCR) is an invasive maize pest in Europe that has spread from southeast to Central Europe in the last 18 years (Miller et al. 2005). Yield loss and control costs attributed to rootworms are 1 billion \$ per year in the USA (Rice 2004) and 472 million $€$ per year are expected in Europe (Wesseler and Fall 2009).

The ground-dwelling larvae feed on the roots of maize plants, thereby reducing water and nutrient uptake (Godfrey et al. 1993), and intensive root feeding can result in lodging (Levine and Oloumi-Sadeghi 1991). The ongoing spread of the WCR in Europe has generated substantial interest in its biology and ecology because knowledge of these traits is regarded as a key requirement for successful management (Spencer et al. 2009).

Feeding by WCR larvae is affected by the suitability of maize cultivars (Branson et al. 1982). Although several studies have shown that conventional maize cultivars have resistance against WCR larval feeding (Branson et al. 1983; Prischmann et al. 2007; Tollefson 2007), only a few characteristics of maize cultivars have been identified that might explain the cultivar differences with regard to WCR larval development. High levels of hydroxamid acids in maize roots were reported to retard WCR development (Xie et al. 1990; Assabgui et al. 1995) but this effect was not confirmed in a later study (Davis et al. 2000). Moeser and Vidal (2004) reported that larvae feeding on plants with high nitrogen content gained less weight and that the phytosterol content of maize plants influenced larval feeding behaviour.

The interaction between WCR and maize roots can also be affected by soil type. Soil type can influence the rootworm's oviposition decision (Dominique and Yule 1983) and can constrain the mobility of the larvae in the soil (Gustin and Schumacer 1989, Strnad and Bergman 1987a, b). WCR larvae are unable to burrow through soil and can only move through cracks or soil pores larger that $150 \mu \mathrm{m}$ (Gustin and Schumacer 1989). Soil type could also affect larval development indirectly by affecting plant nutritional and water status and by affecting the microbial community that colonizes the roots (Singh et al. 2007). For example, Kothari et al. (1990) demonstrated that mycorrhizal fungi and 
rhizosphere microorganisms can affect root growth, shoot growth, and water relations in maize plants.

In the present study, we determined whether WCR larval development is affected by the interaction between soil type and maize cultivar. The study included four cultivars (three conventional and one transgenic) and three soil types.

\section{MATERIAL AND METHODS}

\section{Soil and plants}

Tab. 1 Characteristics of the soils used in this study. Nomenclature follows Lt. FAO World Soil Resources Report, Food and Agriculture Organization of the UN, 1990.

\begin{tabular}{|c|c|c|c|}
\hline Soil & $\begin{array}{c}\text { Haplic Luvisol } \\
\text { (silt loam) }\end{array}$ & $\begin{array}{c}\text { Eutric Vertisol } \\
\text { (silt loam) }\end{array}$ & $\begin{array}{c}\text { Haplic Chernozem } \\
\text { (silt) }\end{array}$ \\
\hline \multirow[t]{2}{*}{ Coordinates } & $5129 ` 52.88 \mathrm{~N}$ & $51^{\circ} 28^{\prime} 26.99 \mathrm{~N}$ & $5130 ` 29.44 \mathrm{~N}$ \\
\hline & $95538.26 \mathrm{E}$ & $9599^{\circ} 5.13 \mathrm{E}$ & $95538.26 \mathrm{E}$ \\
\hline Sand content (\%) & 20.6 & 11.3 & 3.7 \\
\hline Silt content (\%) & 68.1 & 67.8 & 83.8 \\
\hline Clay content (\%) & 11.2 & 20.9 & 12.6 \\
\hline $\mathrm{pH}\left(\mathrm{H}_{2} \mathrm{O}\right)$ & 7.6 & 7.4 & 7.6 \\
\hline $\mathrm{C} / \mathrm{N}$ ratio & 15.8 & 13.2 & 16.3 \\
\hline
\end{tabular}

The soils were obtained from three fields near Goettingen, and each soil type was collected from one field at four different spots separated by $5 \mathrm{~m}$ and located on one transect. The soil was collected to a depth of $25 \mathrm{~cm}$. About $400 \mathrm{~kg}$ of each soil type was removed from the field and stored before use. Before the experiment began, each soil was homogenized using a "soil crusher" (Unifix 300, Moeschle, Ortenberg, Germany) and then passed through a 10-mm-mesh sieve. This procedure removed coarse material only and had minimal effect on soil composition. The study used three conventional maize cultivars (KWS13, KWS14, and KWS 15) from KWS company (Einbeck, Germany) and one transgenic cultivate (MON 88017) from Monsanto (St. Louis, USA). The KWS cultivars are 
hybrids and flint dent varieties classified as early (KWS13) and medium early varieties (KWS14 and KWS 15, maturity class 270). MON 88017 is a dent maize variety with the maturity class 440 .

\section{Handling of western corn rootworm}

WCR eggs from a non-diapausing strain were obtained from the USDA-ARS, North Central Agricultural Research Laboratory, Brookings, North Dakota, USA (Branson 1976). The eggs were stored in Petri dishes at $8^{\circ} \mathrm{C}$. Immediately before experiments were started, timing of larval hatch was determined using a hatch test as follows: eggs were kept at ${ }^{\circ} 6^{\circ} \mathrm{C}$ in $9-\mathrm{cm}$ diameter Petri dishes (100 eggs per dish) containing wet filter papers and were checked daily for larval hatching, which on average started after 14 days (data not shown). After maize plants were transplanted to the pots at the start of the experiment (see next section), the eggs were incubated at $2^{\circ} \mathrm{C}$ and $65 \%$ relative humidity an d checked for visible larvae inside the egg shells using a dissecting microscope. After 12 days, which was 2 days before hatching, the eggs were washed on a sieve $(250 \mu \mathrm{m})$ and then transferred onto a $0.15 \%$ agar solution. Thereafter, 60 eggs where applied per plant in $4 \mathrm{ml}$ of liquid agar; these eggs were applied $5 \mathrm{~cm}$ deep in the soil with a manual hand dispenser (Multipette Plus, Eppendorf, Hamburg, Germany). Additional eggs were added to Petri dishes (four dishes with 40 eggs per dish), as described for the hatch test above, to determine the hatch rate and to confirm that the neonates hatched on the date indicated by the initial hatch test.

\section{Experimental setup}

The experiment was carried out in four repetitions with one cultivar respectively. For each repetition, one cultivar of maize was planted in the greenhouse with 12 plants in each of three soil types. The seeds were sown in a plastic tray (34 $\mathrm{x}$ $26 \mathrm{~cm}$ ) with one tray for each soil type. After 1 week, the seedlings were transplanted into 13-cm diameter pots (one seedling per pot). The pots were prepared with gauze glued to the ground of the pots to prevent larval escape. Plants were placed randomly in the greenhouse with $16 \mathrm{~h}$ of illumination by sodium lamps (400W, HS2000, Hortilux Schréder, Monster, Netherlands). The 
relative humidity was $40 \%$ and the mean temperature was $2^{\circ} \mathrm{C}$. From the second week on, the plants were fertilized once each week by watering with $2.5 \%$ Hakaphos blau solution (Compo, Muenster, Germany). At the V3 growth stage (19 days after sowing), WCR eggs were applied to the soil as described in the previous section. After 20 days of feeding of the larvae on the plants (growth stage V6), plants were harvested and the aboveground biomass was dried (5 days at $60^{\circ} \mathrm{C}$ ) and then weighed. The larvae were extracted from the soil with a high gradient Kempson extraction system (Kempson et al. 1968). The head capsule width of the larvae, which was measured with a dissecting microscope fitted with an ocular micrometer, was used to classify larval stage (Hammack et al. 2003). Larvae were dried at $60^{\circ} \mathrm{C}$ for 2 days, and the dry w eight was determined using a micro scale (MC5, Sartorius, Goettingen, Germany).

\section{Data analysis}

All statistical tests and transformations were carried out using the software STATISTICA 8.0 (Statsoft, Tulsa, USA). The effect of soil type and maize cultivar on log-transformed plant dry biomass was determined with a multivariate ANOVA; a Tukey`s HSD test was used as a post-hoc test. Correlations were examined for $3^{\text {rd }}$ instar weight vs. aboveground biomass and larval number vs. aboveground biomass. The log-transformed biomass of maize plants was included as a covariant in all general linear models analysing larval development. The number of $2^{\text {nd }}$ and $3^{\text {rd }}$ instars and the dry weight of $3^{\text {rd }}$ instar larvae were used to assess the development of WCR. For analysis of $2^{\text {nd }}$ and $3^{\text {rd }}$ instar numbers in combination, the data were transformed using the formula (number $3^{\text {rd }}-$ number $2^{\text {nd }}$ ) $+K$; $K$ is a constant included to maintain positive values. These calculated values were analyzed in a general linear model combined with a Tukey`s HSD test. The data for the $3^{\text {rd }}$ instar weights were transformed to ranks to meet the assumptions of a normal distribution (Conover and Iman 1981) and analyzed in a general linear model combined with the Fisher LSD test. 


\section{RESULTS}

Maize dry weight varied among soil types and maize cultivars. Maize cultivar, soil type, and the interaction between soil type and maize cultivar influenced the final dry weight at harvest (Tab. 2, Fig. 1). No correlation was found between the weight of $3^{\text {rd }}$ instars and aboveground biomass $\left(p=0.681, r^{2}=0.001\right)$ or between larval number and aboveground biomass $\left(p=0.052, r^{2}=0.031\right)$.

Tab. 2 Influence of soil type, maize cultivar, and soil ${ }^{*}$ cultivar on maize dry weight, western corn rootworm larval number, larval instar composition ((numbers of $3^{\text {rd }}$ numbers of $2^{\text {nd }}$ instars) $+K$ ), and $3^{\text {rd }}$ instar weight. The data were analyzed using the general liner model with maize dry weight as a covariant.

\begin{tabular}{llcc} 
Maize dry weight & df & $\mathrm{F}$ & $\mathrm{p}$ \\
\hline Soil type & 2 & 244.6 & $\mathbf{0 . 0 0}$ \\
Cultivar & 3 & 151.7 & $\mathbf{0 . 0 0}$ \\
Soil type*cultivar & 6 & 12.8 & $\mathbf{0 . 0 0}$ \\
Larval number & & & \\
\hline Maize dry weight & 1 & 0.0 & 0.96 \\
Soil type & 2 & 0.9 & 0.40 \\
Cultivar & 3 & 27.9 & $\mathbf{0 . 0 0}$ \\
Soil type*cultivar & 6 & 1.9 & 0.07 \\
Larval instar & & & \\
composition & & & \\
\hline Maize dry weight & 1 & 513.8 & $\mathbf{0 . 0 0}$ \\
Soil type & 2 & 0.1 & 0.91 \\
Cultivar & 3 & 182.9 & $\mathbf{0 . 0 0}$ \\
Soil type*cultivar & 6 & 1.5 & 0.18 \\
3rd instar weight & & & \\
\hline Maize dry weight & 1 & 0.1 & 0.70 \\
Soil type & 2 & 2.3 & 0.09 \\
Cultivar & 3 & 11.0 & $\mathbf{0 . 0 0}$ \\
Soil type*cultivar & 6 & 1.3 & 0.27 \\
\hline
\end{tabular}


The composition of second and third larval instars was influenced by maize dry weight and maize cultivar but not by soil type or the interaction of soil type and cultivar (Tab. 2). The weight of $3^{\text {rd }}$ instar larvae was significantly influenced by maize cultivar but not by soil type or the interaction between cultivar and soil type (Tab. 2). The weight of $3^{\text {rd }}$ instar larvae did not differ among maize cultivars in Haplic Chernozem but did differ among cultivars in Haplic Luvisoil and Eutric Vertisoil (Fig. 2). In Haplic Luvisoil and Eutric Vertisoil, the $3^{\text {rd }}$ instar larvae weighed significantly less with cultivars KWS14 and Mon 88017 than with cultivars KWS13 and KWS15.

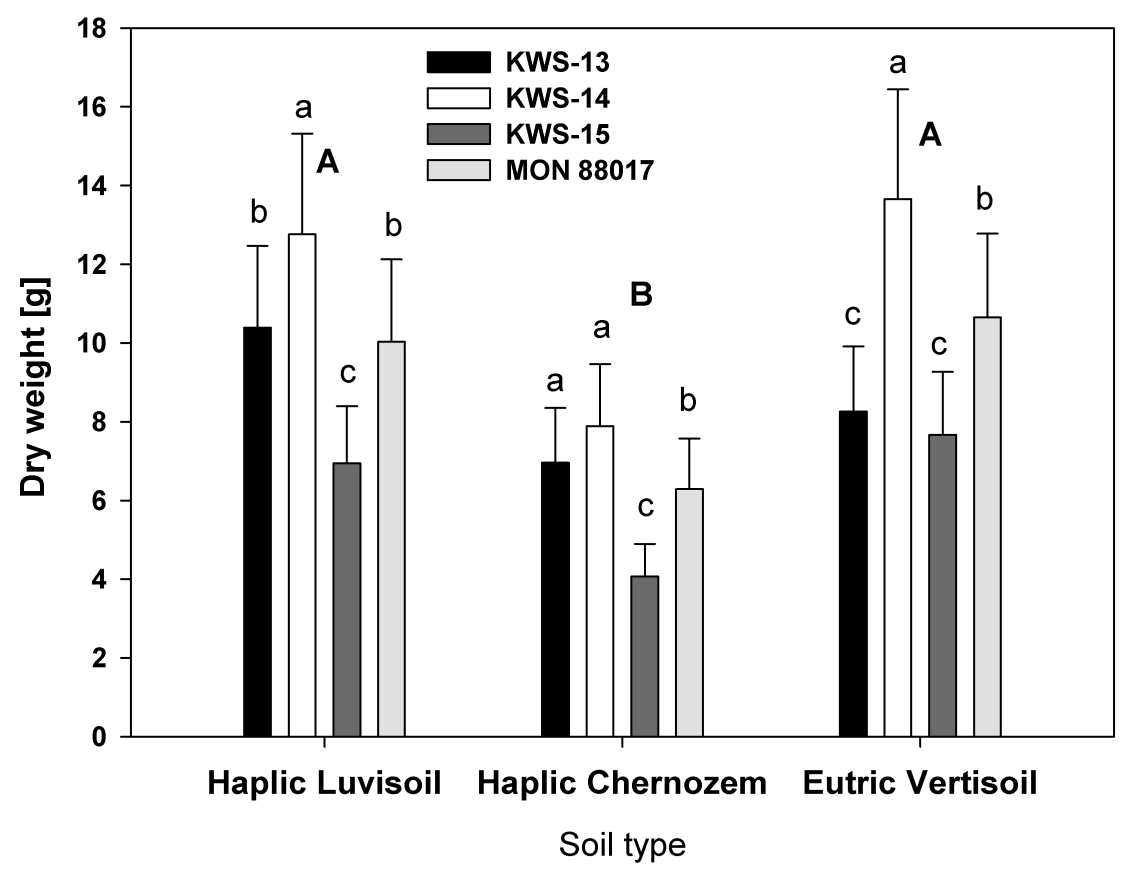

Fig. 1 Above ground dry weight (mean $+S E, n=12$ ) of four maize cultivars in three soil types (Haplic Luvisoil and Haplic Vertisoil, Haplic Chernozem). Lowercase letters indicate significant differences between cultivars within a soil type, and uppercase letters indicate significant differences among soil types (ANOVA; $p<0.05)$. 


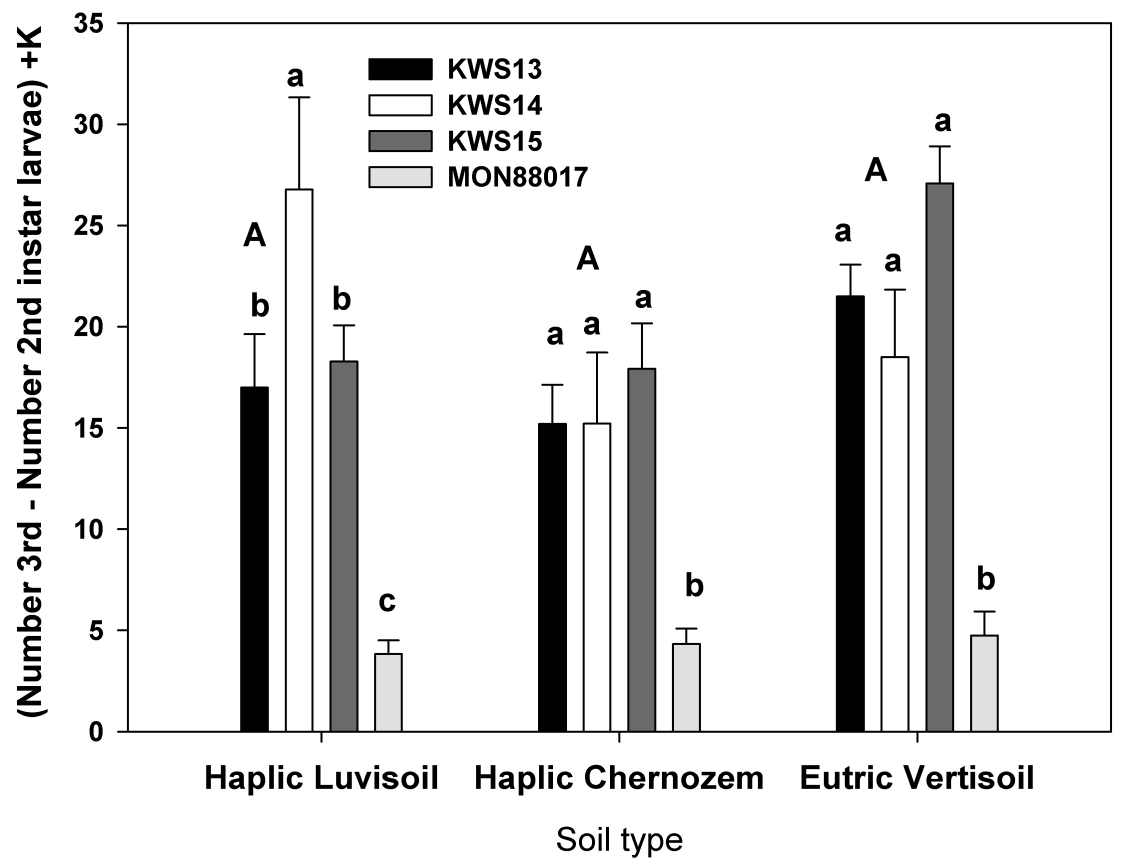

Fig. 2 Weight of $3^{\text {rd }}$ instar western corn rootworm larvae (mean + SE) after feeding on four maize cultivars in three soil types. Lowercase letters indicate significant differences between cultivars within each soil type, and uppercase letters indicate significant differences among soil types according to GLM $(p<0.05)$. The interaction between cultivar and soil type was not signififcant.

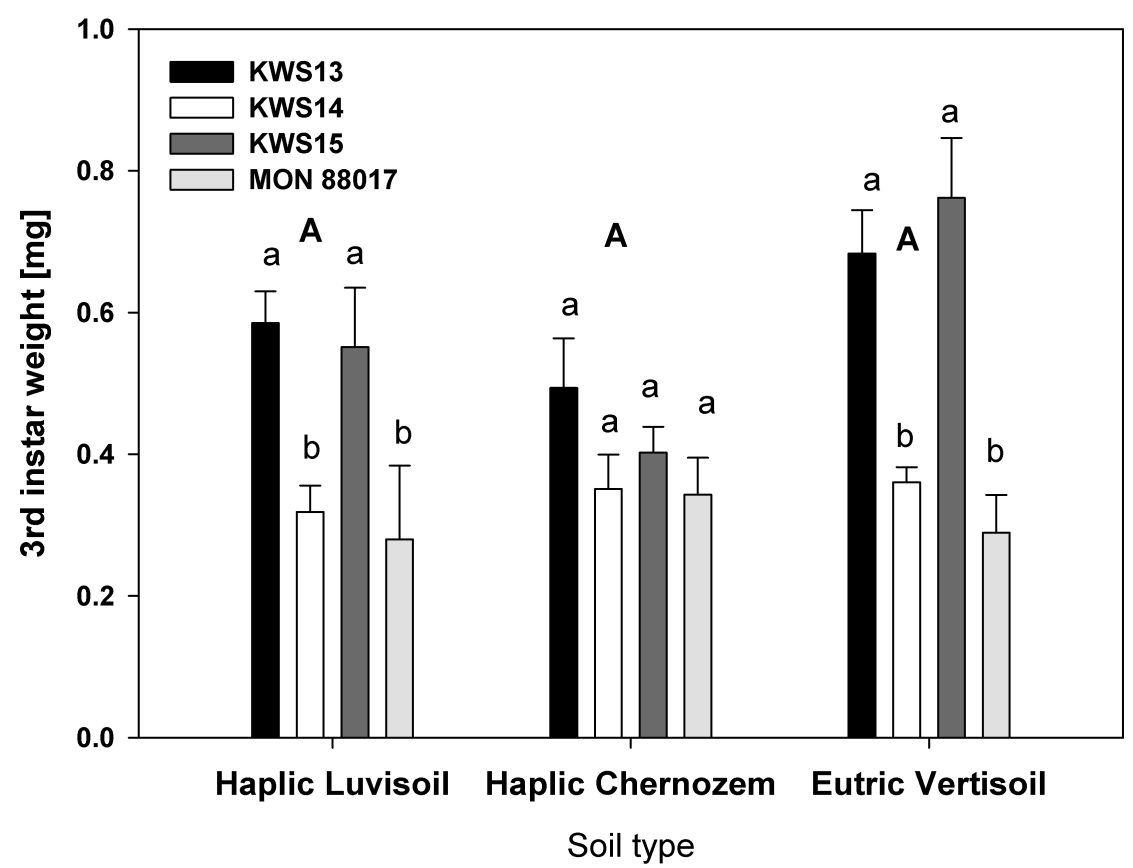

Fig. 3. Composition of $3^{\text {rd }}$ and $2^{\text {nd }}$ instar larvae of western corn rootworm ((number of $3^{\text {rd }}$ instars-number of $2^{\text {nd }}$ instars $\left.\left.+K\right)\right)+S E$, feeding on four maize cultivars in 
three soil types. Lowercase letters indicate significant differences among cultivars within soil types, and uppercase letters indicate significant differences among soil types according to GLM $(p<0.05)$. The interaction between cultivar and soil type was not signficant.

\section{DISCUSSION}

We found that soil type influenced biomass production by the maize plants but had only a small effect on WCR larval development. In addition, soil type did not interact with maize cultivar with regard to WCR development. The conventional maize cultivars used in the experiment significantly differed in their suitability to support western corn rootworm larval development, confirming results reported by Moeser and Vidal (2004). The published data regarding larval development on different maize cultivars are limited. In previous studies concerning the resistance and tolerance of maize cultivars against WCR larvae, larval survival was used as a measure for antibiosis or non-preference effects (Branson et al. 1982; Allee and Davis 1996; Prischmann et al. 2007; Tollefson 2007).

The current study might have underestimated the influence of soil type. Several studies have shown that WCR larvae are able to move quite long distances through the soil to reach host plant roots (Hibbard et al. 2003; Hibbard et al. 2005, Strnad and Bergman 1987). In the present study, however, eggs were applied close to the plants, and larvae therefore probably moved shorter distances in the experiment than in the field; this would reduce potential effects of soil type on larval survival during movement.

Soil type did affect plant biomass production, and plant biomass was correlated with the composition of larval instars. However, maize dry biomass was not correlated with the weight of $3^{\text {rd }}$ instar larvae or with the overall number of larvae. This corroborates results of Branson et al. (1982) and Allee and Davis (1996), who found no significant differences in the number of beetles emerging from plants with root systems of different sizes. Godfrey et al. (1993) reported that plants attacked by WCR larvae showed similar stress reactions regardless of soil type. These reports are consistent with our finding that soil type did not affect larval development. The three tested soil types had a high percentage of silt (67-83\%) and low percentage of sand (3-20\%) and could therefore by regarded as relatively 
heavy soils. In Europe, WCR population densities are usually much higher and plant lodging is more common in regions with heavy soils (I. Zseller pers. comm. 2008). Perhaps the experimental set-up in the current study reduced the potential effect of soil type on WCR larvae. Light, sandy soils can negatively affect WCR larvae by causing desiccation (Gustin and Schumacer 1989, Macdonald and Ellis 1990).

We conclude that soil type has no impact on the suitability of maize cultivars for WCR larval development. Because even susceptible cultivars differ in their suitability to support WCR development, the choice of a less suitable conventional cultivar could help in managing WCR.

\section{ACKNOWLEDGEMENTS}

We thank Dr. Joachim Moeser and Dr. Christian Ahl for assistance at various stages of this work and Dr. Christoph Scherber for support of the statistical analysis. The soil types were analyzed by Karin Schmidt from the Institute of Soil Science (Georg-August University, Goettingen). This work was funded by the DFG (German Research Foundation).

\section{REFERENCES}

Allee, L. L., and P. M. Davis. 1996. Effect of manure and corn hybrid on survival of western corn rootworm (Coleoptera: Chrysomelidae). Environ. Entomol. 25: 801-809.

Assabgui, R. A., T. J. Arnason, and R. I. Hamilton. 1995. Field evaluations of hydroxamic acids as antibiosis factors in elite maize inbreds to the western corn root worm (Coleoptera: Chrysomelidae). J. Econ. Entomol. 88: 14821493.

Branson, T. F. 1976. The selection of a non-diapause strain of Diabrotica virgifera (Coleoptera: Chrysomelidae). Entomol. exp. appl. 19: 148-154.

Branson, T. F., G. R. Sutter, and J. R. Fisher. 1982. Comparison of a tolerant and a susceptible maize inbred under artificial infestations of Diabrotica virgifera virgifera: Yield and adult emergence. Environ. Entomol. 11: 371372. 
Branson, T. F., V. A. Welch, G. R. Sutter, and J. R. Fisher. 1983. Resistance to larvae of Diabrotica virgifera virgifera in three experimental maize hybrids. Environ. Entomol. 12: 1509-1512.

Conover, W. J., and R. L. Iman. 1981. Rank transformations as a bridge between parametric and nonparametric statistics. Am. Stat. 35: 124-129.

Davis, C. S., X. Z. Ni, S. S. Quisenberry, and J. E. Foster. 2000. Identification and quantification of hydroxamic acids in maize seedling root tissue and impact on western corn rootworm (Coleoptera : Chrysomelidae) larval development. J. Econ. Entomol. 93: 989-992.

Dominique, C. R., and W. N. Yule. 1983. Influence of soil type, soil moisture, and soil surface conditions on oviposition preference of the northern corn rootworm, Diabrotica longicornis (coleoptera:chrysomelidae). Can. Entomol. 115: 1043-1046.

FAO. 1990. World Soil Resources Report 60, Food and Agriculture Organization of the United Nations, Rome, Italy

Godfrey, L. D., L. J. Meinke, and R. J. Wright. 1993. Vegetative and reproductive biomass accumulation in field corn: response to root injury by western corn rootworm (Coleoptera: Chrysomelidae). J. Econ. Entomol. 86: 1557-1573.

Gustin, R. D., and T. E. Schumacer. 1989. Relationship of some soil pore parameters to movement of first-instar western corn rootworm (Coleoptera: Chrysomelidae). Environ. Entomol. 18: 343-346.

Hammack, L., M. M. Ellsbury, R. L. Roehrdanz, and J. L. Pikul, Jr. 2003. Larval sampling and instar determination in field populations of northern and western corn rootworm (Coleoptera: Chrysomelidae). J. Econ. Entomol. 96: 1153-1159.

Hibbard, B. E., D. P. Duran, M. R. Ellersieck, and M. M. Ellsbury. 2003. Postestablishment movement of western corn rootworm larvae (Coleoptera: Chrysomelidae) in Central Missouri corn. J. Econ. Entomol. 96: 599-608.

Hibbard, B. E., T. T. Vaughn, I. O. Oyediran, T. L. Clark, and M. R. Ellersieck. 2005. Effect of Cry3Bb1-Expressing transgenic corn on plant-to-plant movement by western corn rootworm larvae (Coleoptera: Chrysomelidae). J. Econ. Entomol. 98: 1126-1138. 
Kempson, D., M. Lloyd, and R. Ghelardy. 1968. A new extractor for woodland litter. Pedobiologia 3: 1-30.

Kothari, S. K., H. Marschner, and E. George. 1990. Effect of Va Mycorrhizal Fungi and rhizosphere microorganisms on root and shoot morphology, growth and water relations in maize. New Phytol. 116: 303-311.

Levine, E., and H. Oloumi-Sadeghi. 1991. Management of Diabroticite rootworms in corn. Annu. Rev. Entomol. 36: 229-255.

Macdonald, P. J., and C. R. Ellis. 1990. Survival-time of unfed, 1st-Instar western corn-rootworm (Coleoptera, Chrysomelidae) and the effects of soil type, moisture, and compaction on their mobility in soil. Environ. Entomol. 19: 666-671.

Miller, N., A. Estoup, S. Toepfer, D. Bourguet, L. Lapchin, S. Derridj, K. Kim, P. Reynaud, L. Furlan, and T. Guillemaud. 2005. Multiple transatlantic introductions of the western corn rootworm. Science 310: 992.

Moeser, J., and S. Vidal. 2004. Response of larvae of the invasive maize pest Diabrotica virgifera virgifera (Coleoptera, Chrysomelidae) to carbon/nitrogen ration and phytosterol content of European maize varieties. J. Econ. Entomol. 97: 1335-1341.

Prischmann, D. A., K. E. Dashiell, D. J. Schneider, and B. E. Hibbard. 2007. Field screening maize germplasm for resistance and tolerance to western corn rootworms (Col.: Chrysomelidae). J. Appl. Entomol. 131: 406-415.

Rice, M. E. 2004. Transgenic rootworm corn: assessing potential agronomic, economic, and environmental benefits. Plant Health Prog.: 1-10.

Singh, B. K., S. Munro, J. M. Potts, and P. Millard. 2007. Influence of grass species and soil type on rhizosphere microbial community structure in grassland soils. Appl. Soil. Ecol. 36: 147-155.

Spencer, J. L., B. E. Hibbard, J. Moeser, and D. W. Onstad. 2009. Behaviour and ecology of the western corn rootworm (Diabrotica virgifera virgifera LeConte). Agr. Forest Entomol. 11: 9-27.

Strnad, S. P., and M. K. Bergman. 1987a. Distribution and orientation of western corn rootworm (Coleoptera: Chrysomelidae) larvae in corn roots. Environ. Entomol. 16: 1193-1198. 
Strnad, S. P., and M. K. Bergman. 1987b. Movement of first-instar western corn rootworms (Coleoptera: Chrysomelidae) in soil. Environ. Entomol. 16: 975978.

Tollefson, J. J. 2007. Evaluating maize for resistance to Diabrotica virgifera virgifera LeConte (Coleoptera: Chrysomelidae). Maydica 52: 311-318.

Wesseler, J., and E. Fall. 2009. Benefits and costs of Diabrotica virgifera virgifera control in Europe, 23rd IWGO Conference \& 2nd International Conference of Diabrotica Genetics, Munich.

Xie, Y. S., J. T. Arnason, B. J. R. Philogene, J. D. H. Lambert, J. Atkinson, and P. Morand. 1990. Role of 2,4-dihydroxy-7-methoxy-1,4-benzoxazin-3-one (DIMBOA) in the resistance of maize to western corn rootworm, Diabrotica virgifera virgifera (Leconte) (Coleoptera: Chrysomelidae). Can. Entomol. 122: 1177-1186. 


\section{Chapter 2: Interaction between western corn rootworm (Coleoptera: Chrysomelidae) larvae and root infecting} Fusarium verticillioides

B. Kurtz ${ }^{1}$, P. Karlovsky ${ }^{2}$ and S. Vidal ${ }^{1}$

${ }^{1}$ Department of Crop Sciences, Agricultural Entomology, ${ }^{2}$ Molecular Phytopathology and Mycotoxin Research, Georg August University Goettingen, Grisebachstrasse 6, 37077 Goettingen, Germany

Corresponding author: S. Vidal ${ }^{1}$, phone: $+49(0) 551-399744$, fax:+49(0)551 -39 12105, Email: svidal@gwdg.de

\section{Abstract}

A greenhouse experiment was conducted to evaluate the effect of soil-dwelling larvae of the western corn rootworm, Diabrotica virgifera virgifera LeConte, on infection of maize roots by the mycotoxin-producing plant-pathogenic fungus, Fusarium verticillioides (Saccardo) Nirenberg (synonym=Fusarium moniliforme Sheldon). The time and order of application of $F$. verticillioides and western corn rootworm were varied in three different treatments to investigate the influence of timing on root colonization of $F$. verticillioides and western corn rootworm larval development. Root feeding by western corn rootworm larvae accelerated root colonization by $F$. verticillioides (as determined by real-time PCR) up to 50 -fold when a high inoculum ( $10^{7}$ spores/plant) of $F$. verticillioides was applied before western corn rootworm eggs were added. This effect was stronger the earlier $F$. verticillioides was applied relative to the time of western corn rootworm egg application but was only significant for the high $F$. verticillioides inoculum density treatment; $F$. verticillioides colonization was not increased when a low $F$. verticillioides inoculum density $\left(10^{6}\right.$ spores/plant) was applied. F. verticillioides slightly suppressed larval development in that the ratio of second- to third-instar larvae was higher in treatments with $F$. verticillioides than without $F$. verticillioides. $F$. verticillioides reduced western corn rootworm head capsule width when applied before or simultaneously with western corn rootworm. The results of this study are 
discussed focussing on conditions that favour root colonization by $F$. verticillioides and its influence on western corn rootworm larval development.

KEY WORDS Diabrotica virgifera virgifera, western corn rootworm belowground interactions, root colonization, larval development

\section{INTRODUCTION}

In 1992, the ground-dwelling maize pest Diabrotica virgifera virgifera LeConte (the western corn rootworm, western corn rootworm) was found for the first time in Europe and has since spread from Eastern to Central Europe (Miller et al. 2005). In the USA, damage caused by rootworms has been calculated at over $\$ 1$ billion per year (Rice 2004); in Europe, costs for controlling the pest are expected to be $€$ 472 million per year (Wesseler and Fall 2009). The major damage to maize plants is caused by larval feeding on the roots, which disrupts water and nutrient uptake (Godfrey et al. 1993). Generally, insect herbivores damage the plants they feed on directly, by removing plant tissue, but also indirectly, by creating wounds or entry points used by plant-pathogenic fungus to colonize the damaged plant tissues (Stutz et al. 1985, Kalb et al. 1994, Munkvold et al. 1999). In addition to the direct damage caused by larval feeding, western corn rootworm may also transmit and accelerate belowground infections by plant-pathogenic fungi, but this indirect damage is not yet understood in detail.

One plant-pathogenic fungus that is likely to interact with western corn rootworm larvae is the fungus Fusarium verticillioides (Saccardo) Nirenberg (synonym=Fusarium moniliforme Sheldon). $F$ verticillioides is the most prevalent soilborne plant-pathogenic fungus of maize and causes corn seedling blight, root rot, stalk rot, kernel rot, ear rot, or systemic infection of maize (Danielsen and Jensen 1998, Munkvold et al. 1999, Munkvold 2003). Moreover, upon colonization of plant tissues, the fungus produces a wide range of mycotoxins including fusaric acids, fusarins, and fumonisins (Nelson 1992). Fumonisins have gained much attention because they have been associated with fatal leucoencephalomalacia in horses, pulmonary edema in swine, esophageal cancer in humans, and cancerpromoting activity in rats (Munkvold and Desjardins 1997, Voss et al. 2002, Mouhoube et al. 2003). Studies on the interactions between insect herbivore 
damage and mycotoxin contamination in maize plants have mainly focused on aboveground herbivores and especially on lepidopteran pest species like Ostrinia nubilalis (Hubner) and Mussidia nigrinivella (Ragonot). (Munkvold et al. 1999, Mouhoube et al. 2003). Gilbertson et al. (1986) investigated the interactions between western corn rootworm adults, which feed on silks and in the ear tips (as opposed to western corn rootworm larvae), and Fusarium spp. Moreover, recently published models that assess the risk for fumonisin contamination of maize following herbivore damage have only considered damage by aboveground insect pests (Maiorano et al. 2009). Palmer and Kommedahl (1969) found that maize plants growing in fields infested with northern corn rootworm Diabrotica longicornis (Say) exhibited a 1.4-fold increase in root infection by Fusarium spp. Since this pioneering work, no studies have been published investigating the interactions between western corn rootworm larvae and $F$. verticillioides in detail; more specifically, no study has quantified the potential risk of mycotoxin contamination resulting from larval damage to the roots. In cases where herbivorous insects and plant-pathogenic fungi share the same host plant, interactions ranging from competitive to mutualistic are possible (Röder et al. 2007). The colonization of the host by the fungus may alter the chemical composition of the host with positive (Mondy and Corio-Costet 2004) or negative effects (Laine 2004) on the development and the fitness of the herbivorous insects feeding simultaneously on these plants. Fusarium species or specific isolates, however, may negatively affect insect performance because some species are entomopathogenic (Majumdar et al. 2008, Wenda-Piesik et al. 2009) and some are known to produce secondary metabolites that inhibit insect defensive enzymes (Teetor-Barsch and Roberts 1983, Dowd 1999). For example, larvae of the European corn borer that were orally inoculated with isolates of $F$. verticillioides developed lesions of the digestive tract (Vago 1958). In the current study, we investigated how the timing of western corn rootworm larval damage and $F$. verticillioides inoculation affect the incidence and severity of root colonization. We also tested the effect of $F$. verticillioides infections on the development of western corn rootworm larvae. 


\section{MATERIAL AND METHODS}

\section{Cultivation of Fusarium verticillioides and handling of western corn rootworm}

We used a strain of $F$. verticillioides obtained from the German Resource Centre of Biological Material (DSMZ, Braunschweig, Germany, No. DSM6224). The fungus was previously maintained on potato extract glucose agar (39 g/l) and upon receipt was transferred to "Spezieller Nährstoffarmer Agar" (SNA, Nirenberg 1976) modified as liquid culture. SNA liquid culture induces $F$. verticillioides to produce spores, which were used as inoculum in the experiment. The culture was maintained for $3 \mathrm{wk}$ on a shaker at $100 \mathrm{rpm}$ and $25^{\circ} \mathrm{C}$. For inoculation of pots, spores were removed from the medium and suspended in water; spore concentrations were determined with a hemacytometer. Each plant that was inoculated with $F$. verticillioides received either $1 \times 10^{6}$ spores (designated 'low' inoculum) or $1 \times 10^{7}$ spores (designated 'high' inoculum) in $70 \mathrm{ml}$ of water. Plants that were not inoculated with $F$. verticillioides received $70 \mathrm{ml}$ of water without spores.

Western corn rootworm eggs from the non-diapausing strain were obtained from the USDA-ARS, North Central Agricultural Research Laboratory, Brookings, North Dakota USA (Branson 1976). The eggs were stored in Petri dishes at $8^{\circ} \mathrm{C}$. Before the experiment was started, the timing of larval hatch was determined with a hatch test as follows: eggs were kept at ${ }^{\circ} 6^{\circ} \mathrm{C}$ in 9 -cm dia meter Petri dishes (100 eggs per dish) with wet filter papers and were checked daily for larval hatching, which occurred after $14 \mathrm{~d}$ (data not shown). After the maize plants were transplanted at the start of the experiment, the eggs were incubated at $266^{\circ}$ and $65 \%$ relative humidity and checked for visible larvae inside the egg shells using a dissecting microscope. After $12 \mathrm{~d}$, which was $2 \mathrm{~d}$ before hatching, the eggs were washed using a sieve $(250 \mu \mathrm{m})$ and transferred into a $0.15 \%$ agar solution. Thereafter, 60 eggs where applied per plant in $2 \mathrm{ml}$ of liquid agar; the eggs were applied $5 \mathrm{~cm}$ deep in the soil with a manual hand dispenser (Multipette Plus, Eppendorf, Hamburg, Germany). Additional eggs were added to Petri dishes (six dishes with 30 eggs per dish) as described for the hatch test above to determine the hatch rate $(85 \%)$ and to confirm that the neonates hatched on the date indicated by the initial hatch test. 


\section{Experimental setup}

A flint $x$ dent maize cultivar (KWS13, KWS, Einbeck, Germany) was used in all experiments. Maize plants were sown in plastic trays $\left(34 \mathrm{~cm}{ }^{*} 26 \mathrm{~cm}\right)$ in a mixture of potting soil and sand (1:1) and transplanted to pots (diameter $13 \mathrm{~cm}) 1 \mathrm{wk}$ later. Gauze (Voile, 100 \% polyester, Alfatex, Goettingen, Germany) glued to the bottom of the pots prevented escape of the western corn rootworm larvae. Plants were kept in the greenhouse at $40 \%$ relative humidity and $24^{\circ} \mathrm{C}$ for six weeks with $16 \mathrm{hr}$ of illumination by sodium lamps (400W, HS2000, Hortilux Schréder, Monster, Netherlands). The maize plants were watered daily and fertilized once each week with a $2 \%$ Hakaphos blau solution (Compo, Münster, Germany).

Three weeks after transplanting, plants were inoculated with western corn rootworm eggs. In three different timing treatments, F. verticillioides was applied to the maize plants: (i) 2 wks before application of western corn rootworm eggs ('early treatment'), (ii) at the same time as western corn rootworm eggs were applied ('simultaneous treatment'), (iii) $1 \mathrm{wk}$ after the application of western corn rootworm eggs ('late treatment'). For each timing treatment we prepared three different controls that included applications with western corn rootworm only, with F. verticillioides only and without an application. Larvae of the western corn rootworm were allowed to feed for $20 \mathrm{~d}$ on the maize roots before they were extracted from the soil using a high-gradient Kempson extraction system (Kempson et al. 1968). Approximately $5 \mathrm{~g}$ of fresh root material was taken as a sample from near the bottom of the pot and were used for DNA extraction and quantification of $F$. verticillioides colonization of the root system. Larval instars were classified based on head capsule width (Hammack et al. 2003), which was measured using a dissecting microscope fitted with an ocular micrometer.

\section{DNA extraction and real-time PCR}

The root samples (approximately $5 \mathrm{~g}$ of fresh material per pot) were wrapped in aluminium foil, freeze-dried for $72 \mathrm{~h}$, and ground to a fine powder with a laboratory mill (Analysenmühle A10, IKA Labortechnik, Staufen, Germany). DNA was extracted from milled roots using a CTAB protocol described previously (Brandfass and Karlovsky 2008). Quality and quantity of DNA were assessed by electrophoresis in $0.8 \%(w / v)$ agarose gels (Biozym, Hess. Oldendorf, Germany) 
prepared in TAE buffer ( $40 \mathrm{mM}$ Tris, $1 \mathrm{mM}$ EDTA, pH set to 8.5 with acetic acid). The electrophoresis was carried out at $4 \mathrm{~V} / \mathrm{cm}$ for $60 \mathrm{~min}$. Double-stranded DNA was stained with ethidium bromide at $2 \mathrm{mg} / \mathrm{L}$. Gels were documented with a digital imaging system (Vilber Lourmat, Marne la Vallee, France).

Real-time PCR (qPCR) for F. verticillioides DNA was performed using primers VER1 and VER2 and SYBR Green fluorescence monitoring according to a protocol adapted from qPCR assays for $F$. culmorum and $F$. graminearum (Mulè et al. 2004, Brandfass and Karlovsky 2008, Nutz personal com.). One $\mu$ l of 10-times diluted maize root DNA was used for each $25-\mu l$ reaction. Standards were prepared from DNA of F. verticillioides FRC 8114 (Fusarium Research Center, Pennsylvania State University, Pennsylvania, USA), which was purified and quantified as described previously (Brandfass and Karlovsky 2006). Two sets of standards ranging from $0.3 \mathrm{pg}$ to $100 \mathrm{pg}$, dissolved in 10-times diluted maize DNA matrix, were analyzed with each sample set.

\section{Data analysis}

For the analysis of the amount of $F$. verticillioides DNA in the roots, a dilution factor was calculated based on the mass of the root sample analyzed and the dilutions used during and following DNA extraction (see CTAB protocol Brandfass and Karlovsky 2008). The concentration of $F$. verticillioides DNA in the root samples (pg F. verticillioides DNA per mg root material) was calculated by division of the DNA starting quantity given by the icycler software (Biorad, Hercules, USA) by the calculated dilution factor. The data were then log transformed and analyzed in a multivariate ANOVA using the concentration of $F$. verticillioides DNA as a dependent variable and timing and inoculum density as independent variables. The differences in root colonization of $F$. verticillioides in the timing treatments and between the inoculum densities were tested with a Tukey`s HSD test.

All statistical tests and transformations were carried out using the software STATISTICA 8.0 (Statsoft, Tulsa, Oklahoma, USA). The overall number of larvae was transformed into ranks because of outliers and was analyzed with univariate ANOVA, using the larval number as the dependent variable and the applications with and without $F$. verticillioides as independent variables. The Tukey`s HSD test was used for post hoc tests. The ratio of numbers of the $2^{\text {nd }}$ and $3^{\text {rd }}$ instar larvae 
was analyzed by transforming the data using the formula (number $3^{\text {rd }}$ instar larvaenumber $2^{\text {nd }}$ instar larvae) $+K$, where $K$ is a constant used to avoid negative values. The calculated values were analyzed using univariate general linear models with the ratio of $2^{\text {nd }}$ and $3^{\text {rd }}$ larval instar as a dependent variable and timing and inoculum density as independent variables. The head capsule widths were transformed into ranks and analyzed using univariate ANOVAs in combination with Tuke`s HSD test, for each timing treatment with the head capsule width as the dependent variable and inoculum density as independent variables. In addition different timing treatments were compared against each other in a univariate ANOVA using the third instar head capsule width as dependent and the timing treatment and the inoculum density as independent variable.

\section{RESULTS}

\section{Fusarium verticillioides root infection}

The effect of western corn rootworm larvae on $F$. verticillioides root colonization was significantly influenced by the timing of $F$. verticillioides inoculation (relative to western corn rootworm inoculation) and $F$. verticillioides inoculum density (timing, $F=6.3 ; \mathrm{df}=2,88 ; P<0.05$, inoculum, $F=22.5 ; \mathrm{df}=2,88 ; P<0.05)$. At the high $F$. verticillioides inoculum density, western corn rootworm feeding increased F. verticillioides root colonization by 50 -fold in the early timing treatment and by 10 -fold in the simultaneous timing treatment. Western corn rootworm did not affect $F$. verticillioides root colonization at the low $F$. verticillioides inoculum density and in the late timing treatment (Fig. 1). In the controls without western corn rootworm application, F. verticillioides colonization did not significantly differ between the timing treatments $(F=0.42 ; \mathrm{df}=2,28 ; P=0.65)$. 


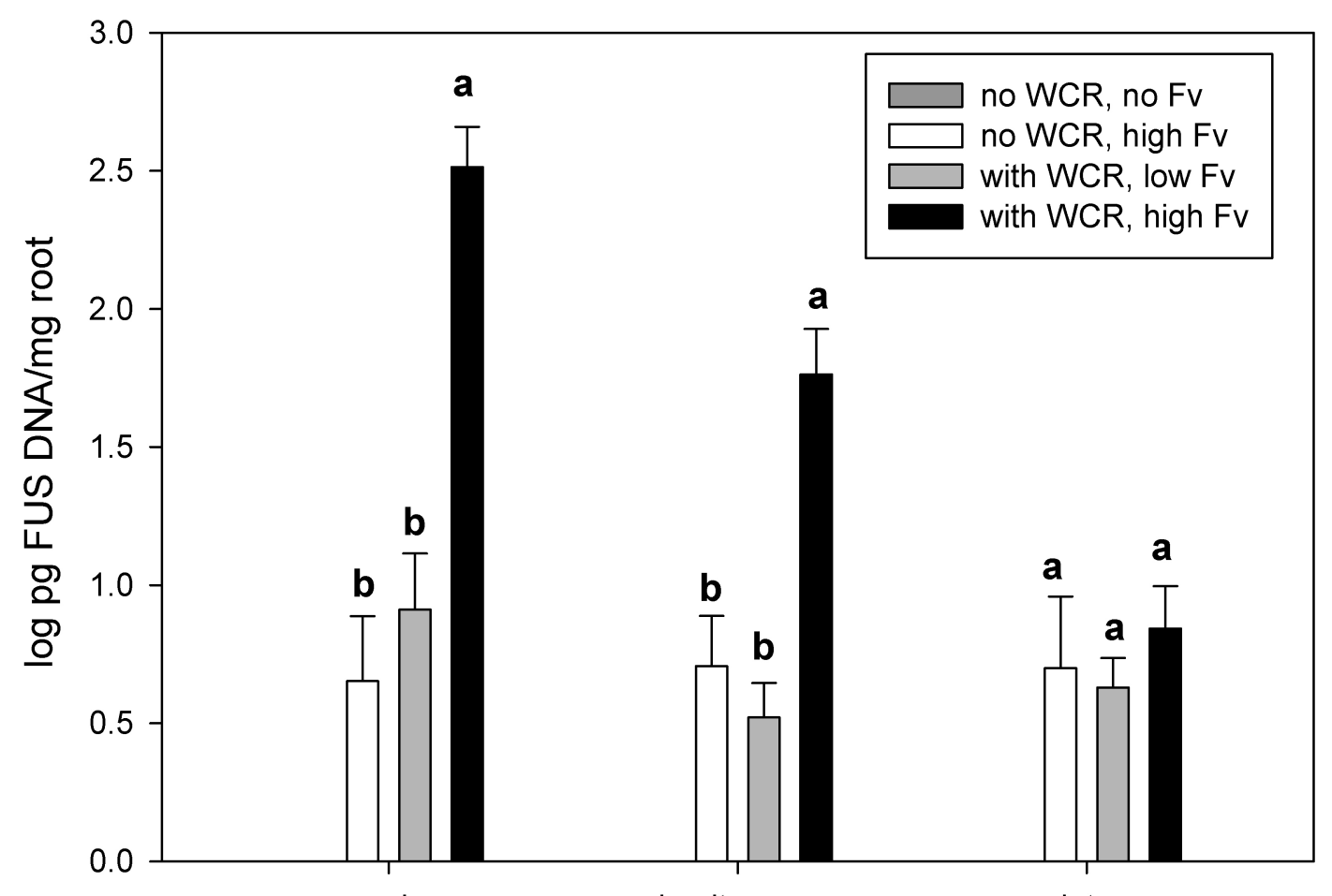

Fig. 1 The quantity of Fusarium verticillioides (Fv) DNA/mg root (mean + SE) as affected by three timing treatments, two inoculum densities of western corn rootworm (WCR; with and without WCR), and three inoculum densities of FV (no Fv, low Fv, or high Fv). Within each timing treatment, bars with different letters are significantly different according to ANOVA $p<0.05$. The data for "no WCR, no Fv" were excluded from the analysis (and the corresponding bars do not appear) because Fv DNA was not detected in this treatment combination regardless of the timing treatment. 


\section{Larval development}

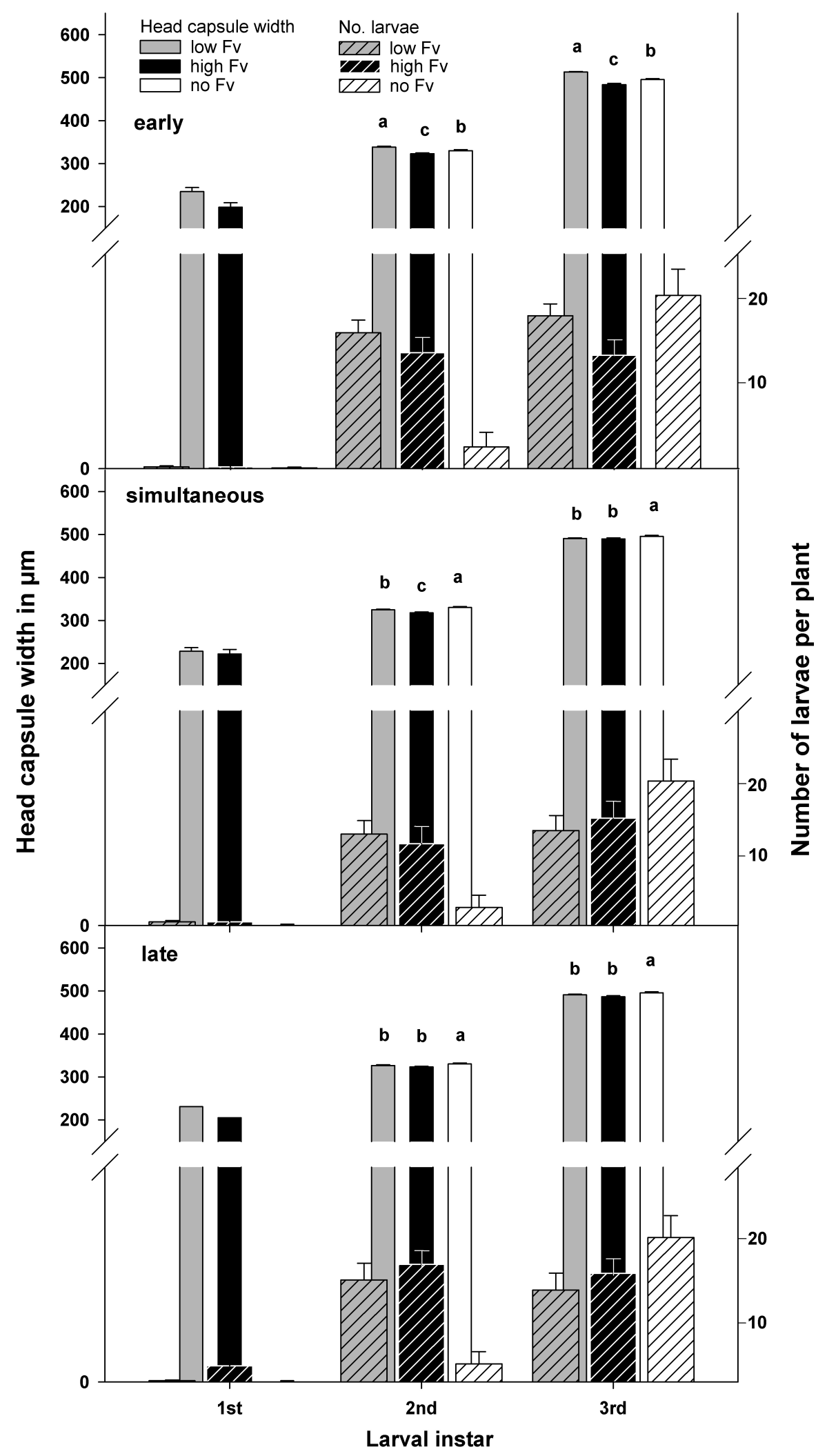

Fig. 2 Head capsule width (mean + SE, $n>100$ ) and numbers of three larval instars (mean $+\mathrm{SE}$ ) of the western corn rootworm as affected by three timing treatments 
and three inoculum densities of Fusarium verticillioides (Fv; no Fv, low Fv, and high Fv). No statistical analysis was carried out for $1^{\text {st }}$ instar larvae as numbers were low $(n<10)$. Within each timing treatment and for each larval instar, bars with different letters are significantly different according to the general linear model $P<0.05$.

The number of larvae recovered from the soil did not differ between treatments (Fig. 2). Neither timing of application nor amount of $F$. verticillioides applied influenced overall larval number (timing treatment $F=0.79 ; \mathrm{df}=2,66 ; P=0.46$, inoculum $F=0.70, \mathrm{df}=1,67 ; P=0.41)$. The ratio of larval instars did significantly differ between treatments with and without $F$. verticillioides application $(F=9.83$; $\mathrm{df}=2$, 102; $P<0.05$; Fig. 2). The timing treatments however did not significantly influence larval instar composition $(F=0.97 ; \mathrm{df}=2,102 ; P=0.37)$. Furthermore, the interaction between timing treatments and $F$. verticillioides inoculum density was not significant $(F=0.70 ; \mathrm{df}=4,100 ; P=0.59)$.

In two of the three timing treatments (simultaneous and late), the head capsule widths of $2^{\text {nd }}$ and $3^{\text {rd }}$ instar larvae were significantly smaller in treatments with F. verticillioides than in treatments without $F$. verticillioides (Fig. 2). In the early timing treatment, head capsule widths of $2^{\text {nd }}$ and $3^{\text {rd }}$ instar larvae were significantly smaller in the high $F$. verticillioides treatment than in the no $F$. verticillioides treatment, but significantly larger in the low $F$. verticillioides treatment than in the no $F$. verticillioides treatment.

\section{DISCUSSION}

We found that Fusarium verticillioides reduced the growth of western corn rootworm larvae and that feeding by western corn rootworm larvae increased root colonization by $F$. verticillioides up to 50 -fold. The time at which $F$. verticillioides was inoculated (before, simultaneous with, or after western corn rootworm) did not influence the effect of $F$. verticillioides on western corn rootworm larval development but did influence the enhancement of $F$. verticillioides colonization of roots caused by larval damage: larval damage increased $F$. verticillioides root colonization to a greater degree when F. verticillioides was applied earlier than the 
insect. This effect was not found when the fungus was applied later than the larvae (Fig. 1).

The earlier application of $F$. verticillioides could have enhanced the effect of western corn rootworm on $F$. verticillioides colonization by providing sufficient time for $F$. verticillioides to colonize the rhizosphere before the western corn rootworm larvae fed. This would have resulted in the $F$. verticillioides inoculum being present at the site of feeding injury when the injury occurred. Apparently, F. verticillioides was not able to invade older wounds, perhaps because of previous colonization by other micro-organisms. The low colonization of the roots in the late treatment cannot be explained by a lack of time for the fungus to colonize the roots, because $F$. verticillioides colonization did not differ among the timing treatments in the absence of western corn rootworm.

Interestingly, studies investigating the increase of fungal infections caused by plant-pathogenic nematodes showed a reverse trend from that in the current study (Powell 1971, Mai and Abawi 1987, Lamondia 1992). In a study by Lamondia (1992), wilt caused by $F$. oxysporum (Schlecht) increased when fungus was applied after the nematode. While Lamondia attributed this increase of symptoms by systemic effects caused by the nematodes, our results indicate that there is no similar phenomenon with regard to western corn rootworm and $F$. verticillioides. In our case, simple wounding by larval feeding could explain the observed increase in F. verticillioides colonization, as has been reported in other studies (Stutz et al. 1985, Kalb et al. 1994).

F. verticillioides colonization of roots (as indicated by the quantity of F. verticillioides DNA detected in roots) in the absence of the western corn rootworm was quite low as compared to unpublished data obtained in a similar experiment by Mario Schumann (pers. com. 2010; $10 \mathrm{pg} / \mathrm{mg}$ root biomass in the current study as compared to up to $200 \mathrm{pg} / \mathrm{mg}$ in Schumann's study). It is interesting to note that under this low infection pressure, western corn rootworm still had a strong impact on F. verticillioides infections in the current study. However, given that in the 'low' inoculum treatments western corn rootworm larvae did not cause increased colonization, a critical amount of $F$. verticillioides inoculum must be present for western corn rootworm damage to accelerate $F$. verticillioides colonization (Fig. 1). 
Srinivas and Pasalu (1990) identified F. verticillioides as a pathogen of the brown plant hopper Nilaparvata lugens (Stål), and Abbas and Mulrooney (1994) found that $F$. verticillioides and its metabolites reduced the growth of Heliothes virescens (Fabricius). In our study, F. verticillioides infection of the roots reduced head capsule width of $2^{\text {nd }}$ and $3^{\text {rd }}$ instar larvae and increased the ratio of $2^{\text {nd }}$ to $3^{\text {rd }}$ instars after 20 days of feeding. The early application of low F. verticillioides inoculum, however, increased head capsule width. Plant-pathogenic fungus (Solomon and Oliver 2001) or their metabolites (Wu et al. 2007) can increase the nitrogen and amino acid content of plant tissue, thus favouring insect development. Early colonization of the roots by $F$. verticillioides may improve the nutritional value of the roots for the larvae, and as long as the colonization of $F$. verticillioides is low, this positive indirect effect might exceed the negative direct influence of $F$. verticillioides on larval development. The delay of larval development in the simultaneous and late timing treatments indicates a direct negative effect of $F$. verticillioides on western corn rootworm larval development. Because the proportions of different larval instars were affected, $F$. verticillioides might have either influenced the ecdysis of the larvae, or delayed their development. Some isolates of $F$. verticillioides produce traces of beauvericin, which is toxic to insects (Logrieco et al. 2003). In general, production of beauvericin is commonly associated with infection of maize by F. proliferatum and F. subglutinans; studies dealing specifically with $F$. verticillioides have not reported beauvericin production (Munkvold et al. 1998, Shephard et al. 1999, Pascale et al. 2002). As mentioned previously, infection rates in our study were low, and $F$. verticillioides colonization might have had a stronger effect on western corn rootworm development had $F$. verticillioides inoculum densities or infection rates been higher.

The current greenhouse study demonstrates that western corn rootworm larval damage can increase root infection by $F$. verticillioides up to 50-fold, depending on the time when the plant-pathogenic fungus and the pest co-occur on the plant roots. The results also show that infection of the roots with $F$. verticillioides influences western corn rootworm larval development. It follows that fumonisin contamination of maize could increase with increasing western corn rootworm populations in Europe. 


\section{ACKNOWLEDGEMENTS}

We thank Dr. Joachim Moeser (SAATEN-UNION, Isernhagen, Germany) for ideas and advice, Patricia Bartoschek (Molecular Phytopathology and Mycotoxin Research, Georg August University Goettingen) for assistance carrying out the real-time PCR, and Wade French, (USDA-ARS, Brookings, SD) for providing the western corn rootworm eggs. We appreciate the comments of three reviewers which helped to improve the manuscript. This work was funded by the DFG (German Research Foundation).

\section{REFERENCES}

Abbas, H. K., and J. E. Mulrooney. 1994. Effect of some phytopathogenic fungi and their metabolites on growth of Heliothis virescens $(F)$ and its host plants. Biocontrol Sci. Technol. 4: 77-87.

Brandfass, C., and P. Karlovsky. 2006. Simultaneous detection of Fusarium culmorum and F. graminearum in plant material by duplex PCR with melting curve analysis. BMC Microbiol. 6: 4.

Brandfass, C., and P. Karlovsky. 2008. Upscaled CTAB-based DNA extraction and real-time PCR assays for Fusarium culmorum and F. graminearum DNA in Plant Material with reduced sampling error. Int. J. Mol. Sci. 9: 23062321.

Branson, T. F. 1976. The selection of a non-diapause strain of Diabrotica virgifera (Coleoptera: Chrysomelidae). Entomol. exp. appl. 19: 148-154.

Danielsen, S., and D. F. Jensen. 1998. Relationships between seed germination, fumonisin content and Fusarium verticilloides infection in selected maize samples from different regions of Costa Rica. Plant Pathol. 47: 609-614.

Dowd, P. F. 1999. Relative inhibition of insect phenoloxidase by cyclic fungal metabolites from insect and plant pathogens. Nat. Toxins 7: 337-341.

Gilbertson, R. L., W. M. J. Bronw, E. G. Ruppel, and J. L. Capinera. 1986. Association of corn stalk rot Fusarium spp. and western corn rootworm beetles in Colorado (USA). Phytopathology 76: 1309-1314.

Godfrey, L. D., L. J. Meinke, and R. J. Wright. 1993. Vegetative and reproductive biomass accumulation in field corn: response to root Injury by 
western corn rootworm (Coleoptera: Chrysomelidae). J. Econ. Entomol. 86: 1557-1573.

Hammack, L., M. M. Ellsbury, R. L. Roehrdanz, and J. L. Pikul, Jr. 2003. Larval sampling and instar determination in field populations of northern and western corn rootworm (Coleoptera: Chrysomelidae). J. Econ. Entomol. 96: 1153-1159.

Kalb, D. W., G. C. Bergstrom, and E. J. Shields. 1994. Prevalence, severity and association of fungal crown and root rots with injury by the clover root curculio in New York alfalfa. Plant Dis. 78: 491-495.

Kempson, D., M. Lloyd, and R. Ghelardy. 1968. A new extractor for woodland litter. Pedobiologia 3: 1-30.

Laine, A.-L. 2004. A powdery mildew infection on a shared host plant affects the dynamics of the Glanville fritillary butterfly populations. Oikos 107: 329-337.

Lamondia, J. A. 1992. Predisposition of broadleaf tobacco to fusarium-wilt by early infection with globodera-tabacum tabacum or Meloidogyne hapla. J. Nematol. 24: 425-431.

Logrieco, A., A. Bottalico, G. Mule, A. Moretti, and G. Perrone. 2003. Epidemiology of toxigenic fungi and their associated mycotoxins for some mediterranean crops. Eur. J. Plant Pathol.: 645-667.

Mai, W. F., and G. S. Abawi. 1987. Interactions among root-knot nematodes and Fusarium wilt fungi on host plants. Ann. Rev. Phytopathol. 25: 317-338.

Maiorano, A., A. Reyneri, D. Sacco, A. Magni, and C. Ramponi. 2009. A dynamic risk assessment model (FUMAgrain) of fumonisin synthesis by Fusarium verticilliides in maize grain in Italy. Crop Prot. 28: 243-256.

Majumdar, A., M. A. Boetel, and S. T. Jaronski. 2008. Discovery of Fusarium solani as a naturally occurring pathogen of sugarbeet root maggot (Diptera: Ulidiidae) pupae: prevalence and baseline susceptibility. J. Invertebr. Pathol. 97: 1-8.

Miller, N., A. Estoup, S. Toepfer, D. Bourguet, L. Lapchin, S. Derridj, K. Kim, P. Reynaud, L. Furlan, and T. Guillemaud. 2005. Multiple transatlantic introductions of the western corn rootworm. Science 310: 992.

Mondy, N., and M.-F. Corio-Costet. 2004. Feeding insects with a phytopathogenic fungus influences their diapause and population dynamics. Ecol. Entomol. 29: 711-717. 
Mouhoube, A., F. Schulthess, Y. D. Mawuena, K. F. Cardwell, and G. Cardwell. 2003. The effect of Fusarium verticilloides on oviposition behaviour and binomics of lepidopteran and coleopteran pests attacking the stem and cobs of maize in West Africa. Entomol. Exp. Appl. 106: 201-210.

Mulè, G., A. Susca, G. Stea, and A. Moretti. 2004. A species-specific PCR assay based on the calmodulin partial gene for identification of Fusarium verticillioides, F. proliferatum and F. Subglutinans. Eur. J. Plant Pathol. 110: 495-502.

Munkvold, G. P., and A. E. Desjardins. 1997. Fumonisins in maize - can we reduce their occurrence ? Plant Dis. 81: 556-565.

Munkvold, G., H. M. Stahr, A. Logrieco, A. Moretti, and A. Ritieni. 1998. Occurrence of fusaproliferin and beauvericin in Fusarium-contaminated livestock feed in lowa? Appl. Environ. Microbiol. 64: 3923-3926.

Munkvold, G. P., R. L. Hellmich, and L. G. Rice. 1999. Comparison of fumonisin concentration in kernels of transgenic bt maize hybrids and nontransgenic hybrids. Plant Dis. 83: 130-138.

Munkvold, G. P. 2003. Epidemiology of Fusarium diseases and their mycotoxinss in maize. Europ. J. Plant Pathol. 109: 705-713.

Nelson, P. E. 1992. Taxonomy and biology of Fusarium moniliforme. Mycopathologia 117: 29-36.

Nirenberg, H. I. 1976. Untersuchungen über die morphologische und biologische Differenzierung in der Fusarium-sektion Liseola. Mitteilungen aus der Biologischen Bundesanstalt fuer Land-und Forstwirtschaft (Berlin-Dahlem). 169: 1-117.

Palmer, L. T., and T. Kommedahl. 1969. Root-infecting fusarium species in relation to rootworm infestations in corn. Phytopathology 59: 1613-1617.

Pascale, M., A. Visconti, and J. Chelkowski. 2002. Ear rot susceptibility and mycotoxin contamination of maize hybrids inoculated with Fusarium species under field conditions. Eur. J. Plant Pathol. 108: 645-651.

Powell, N. T. 1971. Interactions between nematodes and fungi in disease complexes. Annu. Rev. Phytopathol. 9: 253-\&.

Rice, M. E. 2004. Transgenic rootworm corn: assessing potential agronomic, economic, and environmental benefits. Plant Health Prog.: 1-10. 
Röder, G., M. Rahier, and R. E. Naisbit. 2007. Coping with an antagonist: the impact of a phytopathogenic fungus on the development and behaviour of two species of alpine leaf beetle. Oikos 116: 1514-1523.

Shephard, G. S., V. Sewram, T. W. Nieuwoudt, W. F. O. Marasas, and A. Ritieni. 1999. Production of the mycotoxins fusaproliferin and beauvericin by south african isolates in the Fusarium section Liseola. J. Agr. Food Chem. 47: 5111-5115.

Srinivas, P. R., and I. C. Pasalu. 1990. Occurrence of a fungal disease on brown planthopper of rice. J. Biol. Control. 4: 67.

Solomon, P. S., and R. P. Oliver. 2001. The nitrogen content of the tomato leaf apoplast increases during infection by Cladosporium fulvum. Planta 213: 241-249.

Stutz, J. C., K. T. Leath, and W. A. Kendall. 1985. Wound-related modifications of penetration, development, and root-rot by Fusarium roseum in forage legumes. Phytopathology 75: 920-924.

Teetor-Barsch, G. T., and D. W. Roberts. 1983. Entomogenous Fusarium species. Mycopathologia 84: 3-16.

Vago, V. 1958. Virulence cryptogamique simultanée vis-a-vis d’n végétal et d’n insecte. Compt. rend. Acad. sci., Paris 247: 1651-1653.

Voss, K. A., P. C. Howard, R. T. Riley, R. P. Sharma, T. J. Bucci, and R. J. Lorentzen. 2002. Carcinogenicity and mechanism of action of fumonisin B1: a mycotoxin produced by Fusarium moniliforme (= F. verticillioides). Cancer Detect. Prev. 26: 1-9.

Wenda-Piesik, A., Z. T. Sun, W. E. Grey, D. K. Weaver, and W. L. Morrill. 2009. Mycoses of wheat stem sawfly (Hymenoptera: Cephidae) larvae by Fusarium spp. Isolates. Environ. Entomol. 38: 387-394.

Wesseler, J., and E. Fall. 2009. Benefits and costs of Diabrotica virgifera virgifera control in Europe, 23rd IWGO Conference \& 2nd International Conference of Diabrotica Genetics, Munich.

Wu, H. S., X. M. Yin, Y. Y. Zhu, S. W. Guo, C. L. Wu, Y. L. Lu, and Q. R. Shen. 2007. Nitrogen metabolism disorder in watermelon leaf caused by fusaric acid. Physiol. Mol. Plant Pathol. 71: 69-77. 


\title{
Chapter 3: Belowground feeding of western corn rootworm increases aboveground Fusarium verticillioides colonization in maize
}

\author{
B. Kurtz ${ }^{1}$, P. Karlovsky ${ }^{2}$ and S. Vidal ${ }^{1}$
}

${ }^{1}$ Department of Crop Sciences, Agricultural Entomology, ${ }^{2}$ Molecular Phytopathology and Mycotoxin Research, Georg August University Göttingen, Grisebachstrasse 6, 37077 Göttingen, Germany

Corresponding author: S. Vidal ${ }^{1}$, phone: $+49(0) 551-399744$, fax:+49(0)551 -39 12105, Email: svidal@gwdg.de

\section{Abstract}

Greenhouse and quarantine laboratory experiments were carried out to investigate the effect of the ground-dwelling maize pest western corn rootworm (WCR, Diabrotica v. virgifera LeConte) on systemic infections of maize plants by Fusarium verticillioides (Saccardo) Nirenberg. Different maize cultivars including a transgenic cultivar (MON88017) were artificially infested with F. verticillioides and WCR, and were grown until young cobs developed (growth stage R1). Emerging beetles were caught in gauze nets in the quarantine laboratory and analyzed for their development. Male beetles were significantly smaller when emerging from F. verticillioides inoculated plants for one of the two tested conventional cultivars. WCR larval damage enhanced the fungal colonization of roots and lowest stalk parts (as determined by real-time PCR). This effect was present in both tested conventional cultivars, but not in MON88017. In higher stem parts only little amounts of fungal DNA were found and no significant difference between cultivars and treatments occurred. This is the first study demonstrating that western corn rootworm larval feeding can significantly increase the systemic colonization of aboveground parts of maize by $F$. verticillioides. Because of that, root feeding by western corn rootworm might contribute to mycotoxin contamination in maize ears. 
KEY WORDS Diabrotica virgifera virgifera, western corn rootworm, Fusarium verticillioides, systemic colonization, aboveground colonization, Bt maize

\section{INTRODUCTION}

In 1992 the ground-dwelling maize pest Diabrotica virgifera virgifera LeConte (Western corn rootworm - WCR) was found in Europe close to Belgrade, and has since then spread from Eastern to Central Europe (Kiss et al. 2005, Miller et al. 2005). Rootworms are responsible for losses of 1 billion $\$$ per year in the USA (Rice 2004), and 472 million $€$ per year are expected in Europe (Wesseler and Fall 2009). Larval feeding at the roots reduces water and nutrient uptake and strongly attacked plants are susceptible to lodging (Levine and Oloumi-Sadeghi 1991, Godfrey et al. 1993). Generally, insect herbivores are not only damaging the plants they are feeding on, but also create wounds that plant pathogens use to colonize damaged plant tissues (Stutz and Leath 1981, Kalb et al. 1994). Fusarium verticillioides (Saccardo) Nirenberg (synonym $=$ Fusarium moniliforme J. Sheld.) is a ubiquitous plant pathogenic fungus and colonizes different developmental stages and parts of the maize plant (Danielsen and Jensen 1998, Munkvold et al. 1999, Munkvold 2003). F. verticillioides produces the fumonisins $\left(\mathrm{FB}_{1}, \mathrm{FB}_{2}\right)$ that have been associated with diseases in animals (fatal leucoencephalomalacia in horses, pulmonary edema in swine, cancer promoting activity in rats) and humans (esophageal cancer, neural tube defects) (Rajeev et al. 2009, Munkvold and Desjardins 1997, Voss et al. 2002, Mouhoube et al. 2003, Waes et al. 2005). A study by Palmer and Kommedahl (1969) documented an increased incidence of Fusarium rot root in the presence of Diabrotica longicornis (Say) northern corn rootworm larvae, but no quantification of the colonization by $F$. verticillioides in root or stem material was carried out.

The major pathway for kernel infection and mycotoxin contamination of maize ears by $F$. verticillioides are airborne spores that infect the silks, which are highly susceptible during the first 6 days after silk emergence (Munkvold 2003). The intensity of fungal colonization and mycotoxin contamination of maize ears can be increased by damage caused by lepidopteran pest species (Ostrinia nubilalis (Hbn.), Mussidia nigrinivella (Rag.)) (Munkvold et al. 1999, Mouhoube et al. 2003). 
A second pathway for the fungus to colonize the plant is the systemic infection of the plant through the seed (Foley 1962). Phenological growth stages of maize are closely related to the movement of $F$. verticillioides inside the plant, and colonization of aboveground tissues occurs primarily after pollination (Lawrence et al. 1981). Different studies have shown that the fungus can move from the seed to the stalk and into the kernels of the plant (Kedera et al. 1994, Munkvold et al. 1996, Munkvold and Carlton 1997, Bacon et al. 2001). Temperature and water availability have been found to influence the extent of $F$. verticillioides colonization with higher temperatures extending aboveground colonization (Marín et al. 1995, Doohan et al. 2003, Wilke et al. 2007, Murillo-Williams and Munkvold 2008). In comparison to the direct infection of maize ears, is the systemic infection generally of less importance (Munkvold and Carlton 1997, Munkvold 2003), but can contribute to mycotoxin contamination (Desjardin et al. 2000, Desjardin and Plattner 2002). Previous studies that investigated systemic infection of maize concentrated on early infection of seeds or young seedlings (Foley 1962, Bacon and Hinton 1996, Munkvold et al. 1996, Oren et al. 2003). However the influence of root feeding insects on systemic infections has not been investigated. We assume that feeding of WCR can enhance aboveground infection of maize by $F$. verticillioides, because we have already found increased root colonization due to WCR larval feeding (Kurtz et al. 2010). Recently published models aiming at assessing the risk for contamination of maize with fumonisins following herbivore damage, took into account damage by aboveground pests only (Maiorano et al. 2009). To estimate the importance of belowground feeders in that context, we investigate the importance of western corn rootworm larvae for systemic aboveground colonization of maize plants by $F$. verticillioides.

Additionally referring to results that found reduced larval development at plants colonized by $F$. verticillioides (Kurtz et al. 2010), we analyzed the development of WCR beetles emerging from $F$. verticillioides colonized plants. 


\section{MATERIAL AND METHODS}

\section{Plants, cultivation of Fusarium verticillioides and handling of western corn rootworm}

Seeds of MON 88017 (Monsanto, St. Louis, USA), Isoline (DKC 5143) and Prinz (KWS, Einbeck, Germany ) were germinated on a moist filter paper and planted in plastic trays $(34 \mathrm{~cm} \times 26 \mathrm{~cm})$ with a mixture of potting soil and sand (1:1). Plants were kept in the greenhouse under $16 \mathrm{~h}$ of illumination (400W, HS2000, Hortilux Schréder, Monster Netherlands) and $26^{\circ} \mathrm{C}, 50 \%$ relati ve humidity. After one week plants were transferred into pots $\left(16^{\star} 16^{*} 16 \mathrm{~cm}\right)$. Maize plants were watered daily and fertilized once a week using $2 \%$ Hakaphos blue solution (Compo, Münster, Germany).

We obtained an Italian strain of $F$. verticillioides from Katharina Doell (Molecular Phytopathology and Mycotoxin Research, Georg-August University Goettingen, Germany). The fungus was obtained on potato extract glucose agar (39 $\mathrm{g} / \mathrm{l})$ and a disc of the mycelium was used to inoculate a straw culture as described below. Wheat straw was grinded ( $4 \mathrm{~mm}$ ), $12 \mathrm{~g}$ filled in a $1 \mathrm{l}$ flask and filled up with $400 \mathrm{ml}$ distilled water. The flasks stayed over night at room temperature (appr. $20^{\circ} \mathrm{C}$ ) and were autoclaved the following day. After two days the flasks were autoclaved a second time and a disc of mycelium from $F$. verticillioides was added. Thereafter the flasks were transferred to a shaker at $25^{\circ} \mathrm{C}$ and $100 \mathrm{rpm}$ for four weeks. Successful colonization of the straw cultures was controlled by determining the spore concentration with a haemocytometer (data not shown). Finally the straw was filtered and seven grams mixed with $100 \mathrm{~g}$ dry soil which was placed onto the top soil in the pot.

WCR eggs from the non-diapausing strain were obtained from USDA-ARS, North Central Agricultural Research Laboratory, Brookings, USA (Branson 1976). The eggs were stored in Petri dishes in a fridge at $8^{\circ} \mathrm{C}$. Before starting the experiment hatch tests were carried out to assess the exact time of larval hatch. Therefore eggs were placed in Petri dishes with wet filter papers, incubated at $26{ }^{\circ}, 65 \%$ relative humidity daily checking larval hatching. After the start of the experiment the eggs were incubated at $26^{\circ} \mathrm{C}$ and $65 \%$ relative hu midity and checked for visible larvae inside the egg shells using a dissecting microscope. After twelve days, which was two days prior to hatching, the eggs were washed using a sieve 
$(250 \mu \mathrm{m})$ and transferred into $0.15 \%$ agar solution. Thereafter the eggs where applied to the pots, dispersed in $2 \mathrm{ml}$ of agar, $5 \mathrm{~cm}$ into the soil by using a manual hand dispenser (60 eggs/plant, Multipette Plus, Eppendorf, Hamburg, Germany). Hatch tests were prepared as described previously to test the hatch rate and to ensure the assumed date of hatch ( $n=6$, data no shown).

\section{Experimental setup}

Four different treatments were prepared (1) with WCR and F. verticillioides (2) with F. verticillioides (3) without $F$. verticillioides or WCR (4) with WCR only. Per treatment cultivar combination 8 plants were kept for 7 weeks and for 15 weeks in the greenhouse. In that way the fungal colonization of the plants at two different time points was analyzed. Plants treated with $F$. verticillioides were inoculated with $7 \mathrm{~g}$ of $F$. verticillioides straw two weeks after planting. WCR eggs (60eggs/plant) were applied 4 weeks (growth stage V5) after planting to the respective treatments. After 7 weeks 8 plants were harvested and root samples (approx. $5 \mathrm{~g}$ fresh weight) were taken near the bottom of the pot. In this way first effects caused by WCR larval feeding were obsereved. Nine weeks after planting the remaining plants had to be moved to the quarantine laboratory to secure the hatching of WCR beetles. So plants were kept for the last 6 weeks of the experiment at $23^{\circ} \mathrm{C}$, $60 \%$ relative humidity under $16 \mathrm{~h}$ of illumination by halogen mirror lamps (250W, E40, Lanzini, Italy). Self made gauze cages (Voile, $100 \%$ polyester, Alfatex, Goettingen, Germany) were placed around the base of the plants to catch emerging beetles.

After 15 weeks (growth stage R1) the final sampling was carried out. At this sampling only stalk samples were taken and divided into three sections: (1) lower stalk from $0-8 \mathrm{~cm}$ height (2) middle stalk $8-16 \mathrm{~cm}$ height (3) higher stalk $16-24 \mathrm{~cm}$ height $(n=8)$.

\section{DNA extraction and real-time PCR}

The root samples and stalk samples were wrapped in aluminium foil, freeze-dried for $72 \mathrm{~h}$ and ground by using a laboratory mill (Analysenmühle A10, IKA Labortechnik, Staufen, Germany). DNA was extracted from root and stalk samples 
milled to a fine powder using the CTAB protocol described by Brandfass and Karlovsky, (2008). Quality and quantity of DNA were assessed by electrophoresis in $0.8 \%(\mathrm{w} / \mathrm{v})$ agarose gels (Biozym, Hess. Oldendorf, Germany) prepared in TAE buffer (40 mM Tris, $1 \mathrm{mM}$ EDTA, $\mathrm{pH}$ set to 8.5 with acetic acid). The electrophoresis was carried out at $4 \mathrm{~V} / \mathrm{cm}$ for $60 \mathrm{~min}$. Double-stranded DNA was stained with ethidium (ethidium bromide, $2 \mathrm{mg} / \mathrm{L}$ ). Gels were documented with the help of a digital imaging system (Vilber Lourmat, Marne la Vallee, France).

Real-time PCR for $F$. verticillioides DNA was performed using primers VER1 and VER2 and SYBR Green fluorescence monitoring according to a protocol adapted from real-time PCR assays for F. culmorum and F. graminearum (Mulé et al. 2004, Brandfass and Karlovsky 2008; Nutz et al., in preparation). One microliter of 10times diluted maize root DNA was used for each $25-\mu$ reaction. Standards were prepared from DNA of Fusarium verticillioides FRC 8114 (Fusarium Research Centre, Penn State University, Pennsylvania, USA) which was purified and quantified as described previously (Brandfass and Karlovsky 2006). Two sets of standards ranging from $0.3 \mathrm{pg}$ to $100 \mathrm{pg}$, dissolved in 10-times diluted maize DNA matrix, were analyzed with each sample set.

\section{Analysis of beetle development}

Gauze cages were daily checked for emerging beetles and beetles were removed from the cages and stored in 70\% ethanol. Different morphological traits (head capsule width, pronotum width, pronotum length, elythron width, elythron length, tibia length) were measured under the dissecting microscope fitted with an ocular micrometer. Additionally the dry weight of each individual was measured by using a micro scale (MC5, Sartorius, Goettingen, Germany).

\section{Data Analysis}

All statistical tests and transformations were carried out using the software STATISTICA 8.0 (Statsoft, Tulsa, USA). For the analysis of the amount of $F$. verticillioides DNA in the roots, a dilution factor was calculated based on the mass of the root sample analyzed and the dilutions used during DNA extraction (see CTAB protocol Brandfass and Karlovsky 2008). The concentration of 
F. verticillioides DNA in the root samples (pg F. verticillioides DNA per mg root material) was calculated by division of the DNA starting quantity given by the iCycler software (Biorad, Hercules, USA) by the calculated dilution factor.

The data were then ranked because of non normal distribution (Conover and Iman 1981) and analyzed in a multivariate ANOVA using the concentration of F. verticillioides DNA as a dependent variable and cultivar and WCR application as independent variables. The differences in root colonization of $F$. verticillioides between the cultivars and WCR treatments were tested with a Fisher LSD test.

The different morphological traits were checked for correlations between each other. Therefore the data was displayed in a scatter plot and Pearson correlations were carried out for the various combinations of morphological traits.

As the different traits measured correlated with each other, the tibia length was used for further analysis. Male beetles were taken for the analysis as the two sexes differed significantly in size and more males were available. As transformation was not sufficient to cause a normalized distribution, the non parametric Man-Whitney-U test was used. 


\section{RESULTS}

\section{Root colonization}

The colonization of maize roots by $F$. verticillioides was significantly increased for the cultivars ISO and Prinz when WCR was present. In Bt maize no significant increase in root colonization occurred (Fig. 1).

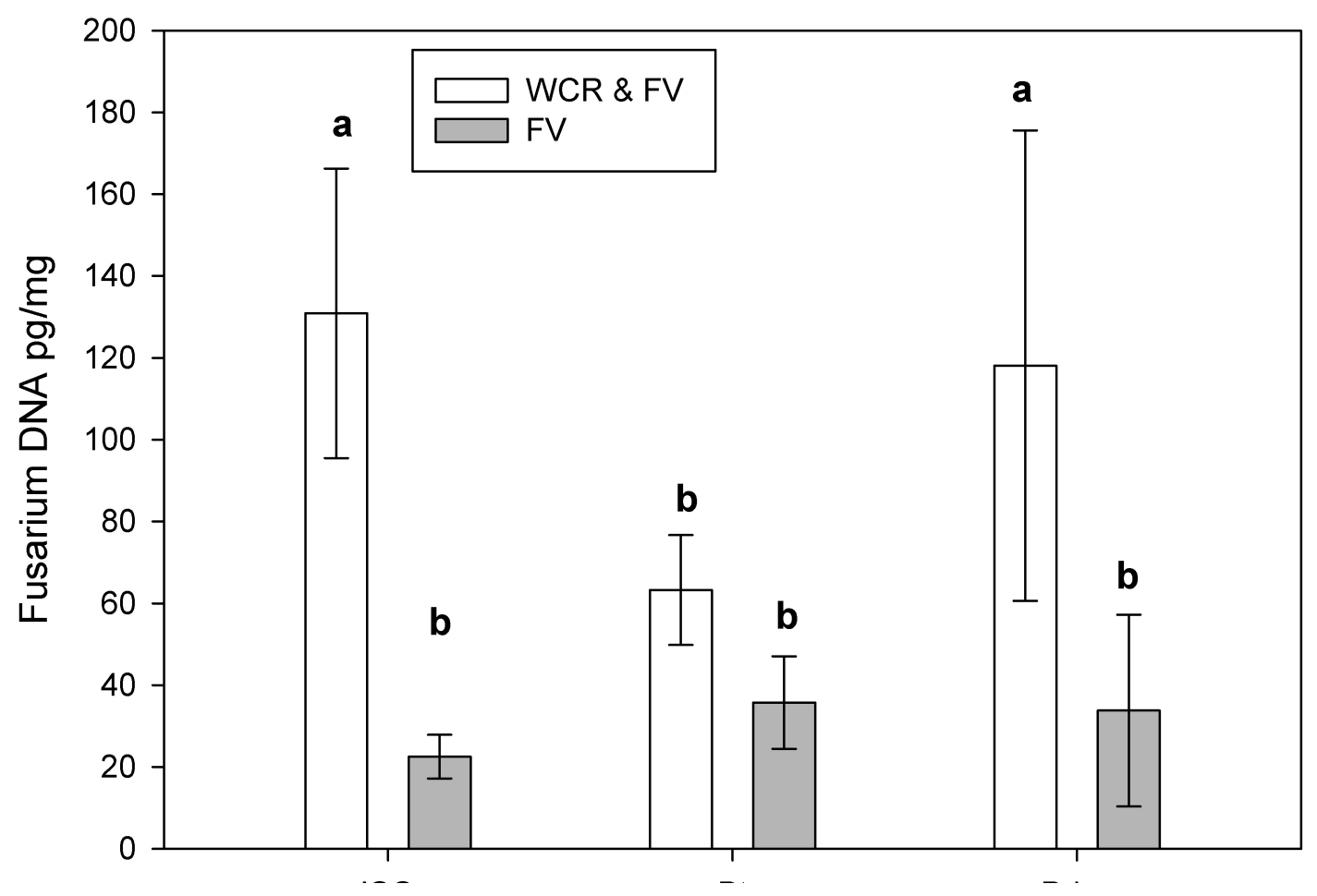

Fig. 1 Amount of Fusarium verticillioides DNA ( $F v$, mean $\pm S E, n=8$ ) in roots of different maize cultivars in the presence (white bars) and absence (grey bars) of western corn rootworm (WCR) larvae. Letters above columns indicate significance of difference according to ANOVA $<0.05$.

\section{Aboveground colonization}

WCR larval feeding had a significant influence on colonization of lower stalk in the used conventional cultivars (Fig. 2). In contrast no significant increase could be found in the Bt cultivar. In higher stem parts (stalk, higher stalk) amounts of found 
DNA fluctuated strongly (high standard error), and no significant difference between the treatments with or without WCR occurred (Fig. 2).

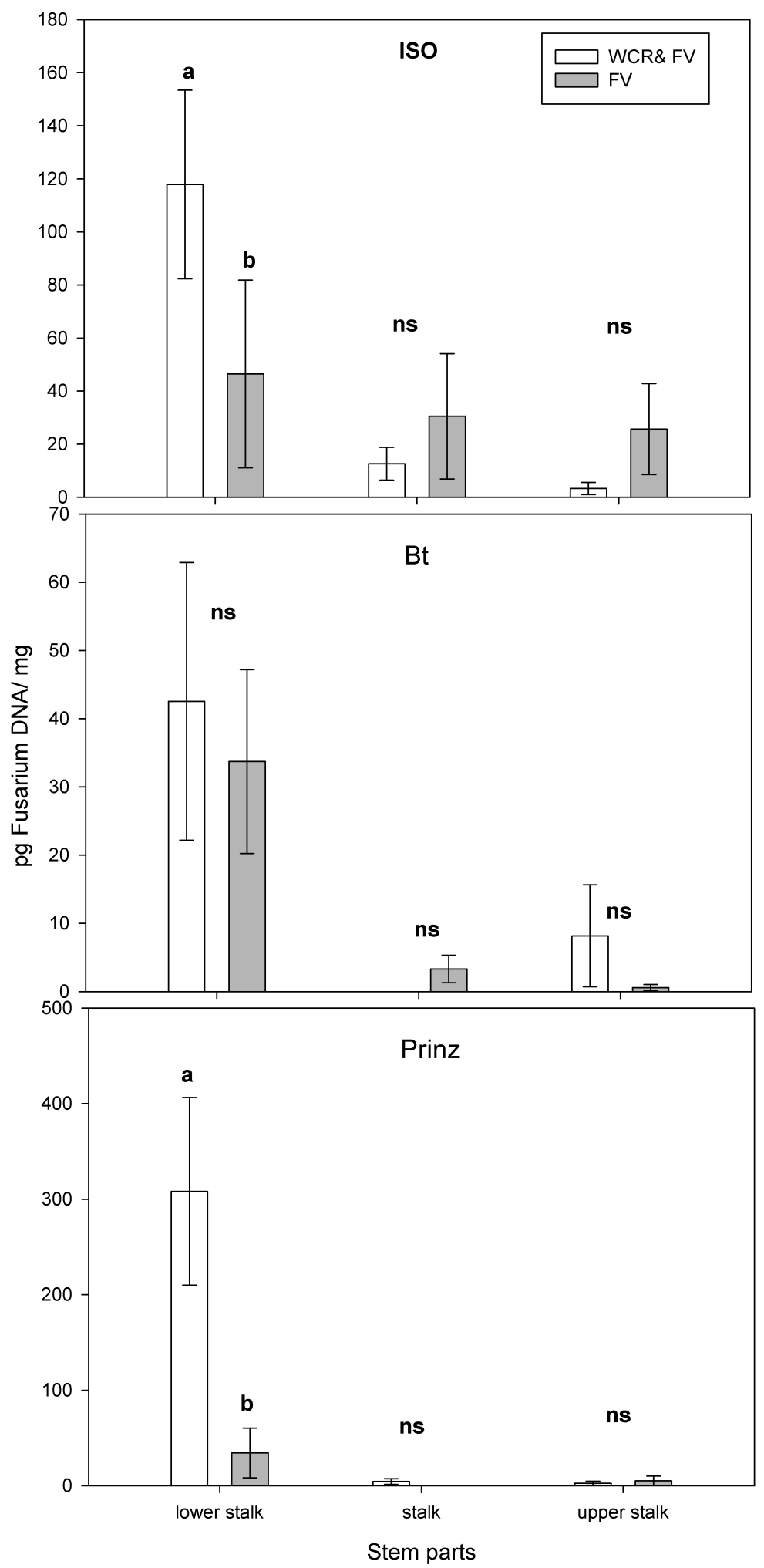

Fig. 2 Amount of Fusarium verticillioides DNA (mean $\pm S E, n=8$ ) in different stem parts (lower stalk=0-8cm height, stalk=8-16 cm height, upper stalk $=16-24 \mathrm{~cm}$ 
height) of different maize cultivars (ISO, Bt and Prinz) in the presence and absence of western corn rootworm (WCR) larvae. Letters above columns indicate significance of difference according to ANOVA $<0.05$.

\section{Beetle development}

Tibia weight and dry weight correlated with each other as also the other mentioned morphological traits (e.g. cultivar Prinz tibia length vs. dry weight $y=1.29+0.32^{*} x$, $r=0.80, p=0.00, n=22$, elythron length vs. tibia length $y=0.15+2.4^{*} \times r=0.90$, $\mathrm{p}=0.00$ ). In the cultivar Prinz males that emerged from $F$. verticillioides colonized plants had significantly smaller tibia lengths than males that emerged from not inoculated plants (see Tab. 1). In ISO no significant difference was detectable.

Tab. 1 Comparison of tibia lengths of male western corn rootworm beetles from two different maize cultivars and two different treatments (with and without Fusarium verticillioides, Man-Whitney U test).

\begin{tabular}{llllll}
\hline $\begin{array}{l}\text { Maize } \\
\text { cultivar }\end{array}$ & Comparison & $\begin{array}{l}\text { Tibia length } \\
\pm \text { s.d. }\end{array}$ & $\mathrm{P}$ & $\mathrm{Z}$ & $\mathrm{n}$ \\
\hline Prinz & No Fusarium & $1.73 \pm 0.1$ & $\mathbf{0 . 0 0 3}$ & 2.9 & $7 / 7$ \\
& vs. & & & \\
& With Fusarium & $1.58 \pm 0.1$ & & $5 / 5$ \\
ISO & No Fusarium & $1.78 \pm 0.22$ & 0.14 & 1.5 & \\
vs. & & & \\
& With Fusarium & $1.63 \pm 0.1$ & & & \\
\end{tabular}

\section{DISCUSSION}

This study demonstrates that belowground insect feeding can not only enhance belowground, but also aboveground colonization of a plant by a plant pathogenic fungus. The transgenic Bt cultivar MON88017 showed no significantly increased colonization of Fusarium verticillioides as it was found for the two conventional cultivars tested. Western corn rootworm (WCR) beetles were significantly reduced in size when emerging from the cultivar Prinz colonized by F. verticillioides. 
Schumann (2008) presented results in which root colonization of MON88017 by $F$. verticillioides was even higher in comparison to conventional cultivars, when WCR larvae were present. Schumann tested different inoculum densities of F: verticillioides and this increase appeared only, when the highest inoculum density was used. In our study we used higher amounts of straw for the inoculum than Schumann (2008) (7g vs. 3g Schumann et al.), but it was much less colonized $\left(2 * 10^{5}\right.$ spores $/ \mathrm{ml}$ vs. $2^{*} 10^{6}$ spores $/ \mathrm{ml}$, spores counted in the solution of the culture). Lastly the inoculum applied in our study is only comparable to the medium inoculum density used by Schumann (2008), and therefore coincide with the findings that at little and medium inoculum density colonization was not increased on MON88017. Under medium inoculum pressure the effect of MON88017 on WCR larvae is sufficient to prevent an increase in root colonization while especially at higher densities the inoculum pressure causes even higher colonization than in conventional cultivars. Schuman (2008) explained this fact with the change in feeding behaviour of the WCR larvae on Bt maize. Clark et al. (2006) documented that WCR larvae when feeding at the roots of Bt maize produce many little wounds while searching for a place to feed. At high Fusarium inoculum density these little wounds might be already sufficient to enhance the colonization of the root by the fungus. The presented experiment had to be stopped because of unfavourable growth conditions in the quarantine laboratory, preventing an analysis of further movement of the fungus. Other studies showed reduced frequencies of $F$. verticillioides with increasing height in the stalk (Munkvold and Carlton 1997, Murillo-Williams and Munkvold 2008). The presented results show a similar trend in the quantities of found $F$. verticillioides DNA. Munkvold et al. (1996) reported that the limiting step in the movement of the fungus is from the crown to the stalk and much less from stalk to ear. As we could show in our experiment, WCR can increase the colonization of the lower stalk bridging this limiting gap. So we expect that WCR can cause an increased colonization as well at higher internodes up to the maize kernels, as it has been found in other studies (Kedera et al. 1994, Munkvold et al. 1996, Munkvold and Carlton 1997). As a consequence this may affect mycotoxin contamination in maize ears.

From our knowledge no real-time PCR data of root colonization by F. verticillioides from natural field situation is available. So we can only compare our data to 
studies that have quantified Fusarium sp. in aboveground parts of maize. In Germany low amounts of $F$. verticillioides DNA have been found in naturally infested maize ears ( 1 ppb) (Nutz pers. com. 2009). In experiments by Sabine Nutz (Molecular Phytopathology and Mycotoxin Research, Georg-August University, Goettingen, Germany) naturally colonization by F. graminearum was measured in stalk right under the maize ears ( $450 \mathrm{ppb}$ ). In our experiments the amount of DNA in the lowest stalk samples was depending on the cultivar between 26-308 ppb.

We found that beetles emerging from $F$. verticillioides colonized plants were at one of the two conventional cultivars significantly smaller than beetles emerging from not inoculated plants. This coincides with results from previous studies that found reduced larval development on plants colonized by F. verticillioides (Chapter 2. , Chapter 5). In general stressed larvae produce inferior adults (Peters and Barbosa 1977), and this phenomenon has been already described for WCR testing different egg densities (Branson and Sutter 1985, Weiss et al. 1985). About how $F$. verticillioides reduces larval and following adult performance, we can only speculate. Results from previous work suggests that $F$. verticillioides affects WCR development relatively fast, as even if $F$. verticillioides was applied one week after application of ready to hatch WCR eggs, a significant influence on larval development could be observed (Chapter 2, Kurtz et al. 2010). Logrieco et al. (2003) mentioned that Italian isolates of $F$. verticillioides were able to produce traces of beauvericin which is known to have insecticidal properties. Also fusaric acid that is produced by $F$. verticillioides has shown to inhibit phenoloxidase (monophenol oxidase, catechol oxidase E.C. 1.10.3.1) activity, the enzyme responsible in wound healing and pathogen encapsulation in insects (Dowd 1999).

In this study we were able to demonstrate that systemic aboveground colonization by Fusarium verticillioides can be enhanced by western corn rootworm larval damage. An increased colonization of the kernels has not been proved, but other studies suggest this assumption (Munkvold and Carlton 1997, Murillio-Williams and Munkvold 2008). Mycotoxin production depends on various factors as maize cultivar susceptibility, fungal strain, environmental conditions or presence of other fungi (Marín et al. 1998, Munkvold 2003, Jurado et al. 2008, Mogensen et al. 
2009). Further studies have to show if WCR larval damage can contribute to mycotoxin contamination in maize kernels.

\section{ACKNOWLEDGMENTS}

We thank Patricia Bartoschek for support carrying out the real-time PCR and Wade French, (USDA-ARS, Brookings, SD) for providing the western corn rootworm eggs. This work was funded by the DFG (German Research Foundation).

\section{REFERENCES}

Bacon, C. W., and D. M. Hinton. 1996. Symptomless endophytic colonization of maize by Fusarium moniliforme. Can. J. Bot. 74: 1195-1202.

Bacon, C. W., I. E. Yates, D. M. Hinton, and F. Meredith. 2001. Biological control of Fusarium moniliforme in maize. Environ. Health Perspect. 109: 325-332.

Brandfass, C., and P. Karlovsky. 2006. Simultaneous detection of Fusarium culmorum and F. graminearum in plant material by duplex PCR with melting curve analysis. BMC Microbiol. 6: 4.

Brandfass, C., and P. Karlovsky. 2008. Upscaled CTAB-based DNA extraction and real-time PCR assays for Fusarium culmorum and F. graminearum DNA in Plant Material with reduced sampling error. Int. J. Mol. Sci. 9: 23062321.

Branson, T. F. 1976. The selection of a non-diapause strain of Diabrotica virgifera (Coleoptera: Chrysomelidae). Entomol. exp. appl. 19: 148-154.

Branson, T. F., and G. R. Sutter. 1985. Influence of population density of immatures on size, longevity, and fecundity of adult Diabrotica virgifera virgifera (Coleoptera: Chrysomelidae). Environ. Entomol. 14: 687-690.

Clark, P. L., T. T. Vaughn, L. J. Meinke, J. Molina-Ochoa, and J. E. Foster. 2006. Diabrotica virgifera virgifera (Coleoptera: Chrysomelidae) larval feeding behaviour on transgenic maize (MON 863) and its isoline. J. Econ. Entomol. 99: 722-727. 
Conover, W. J., and R. L. Iman. 1981. Rank transformations as a bridge between parametric and nonparametric statistics. Am. Stat. 35: 124-129.

Danielsen, S., and D. F. Jensen. 1998. Relationships between seed germination, fumonisin content and Fusarium verticilloides infection in selected maize samples from different regions of Costa Rica. Plant Pathol. 47: 609-614.

Desjardins, A. E., and R. D. Plattner. 2000. Fumonisin B-1-nonproducing strains of Fusarium verticillioides cause maize (Zea mays) ear infection and ear rot. J. Agric. Food Chem. 48: 5773-5780.

Desjardins, A. E., G. P. Munkvold, R. D. Plattner, and R. H. Proctor. 2002. FUM1 - A gene required for fumonisin biosynthesis but not for maize ear rot and ear infection by Gibberella moniliformis in field tests. Mol. PlantMicrobe Interact. 15: 1157-1164.

Doohan, F. M., J. Brennan, and B. M. Cooke. 2003. Influence of climatic factors on Fusarium species pathogenic to cereals. Eur. J. Plant Pathol. 109: 755768.

Dowd, P. F. 1999. Relative inhibition of insect phenoloxidase by cyclic fungal metabolites from insect and plant pathogens. Nat. Toxins 7: 337-341.

Foley, D. C. 1962. Systemic infection of corn by Fusarium moniliforme. Phytopathology 52: 870-872.

Godfrey, L. D., L. J. Meinke, and R. J. Wright. 1993. Vegetative and reproductive biomass accumulation in field corn: response to root injury by western corn rootworm (Coleoptera: Chrysomelidae). J. Econ. Entomol. 86: 1557-1573.

Jurado, M., P. Marin, N. Magan, and M. T. Gonzalez-Jaen. 2008. Relationship between solute and matric potential stress, temperature, growth, and FUM1 gene expression in two Fusarium verticillioides strains from Spain. Appl. Environ. Microbiol. 74: 2032-2036.

Kalb, D. W., G. C. Bergstrom, and E. J. Shields. 1994. Prevalence, severity and association of fungal crown and root rots with injury by the clover root curculio in New York alfalfa. Plant Dis. 78: 491-495.

Kedera, C. J., J. F. Leslie, and L. E. Claflin. 1994. Genetic diversity of Fusarium section liseola (Gibberella-Fujikuro) in individual maize stalks. Phytopathology 84: 603-607. 
Kiss, J., C. R. Edwards, H. K. Berger, P. Cate, M. Cean, S. Cheek, J. Derron, H. Festic, L. Furlan, J. Igrc-Barc ic', I. Ivanova, W. Lammers, V. Omelyuta, G. Princzinger, P. Reynaud, I. Sivcev, P. Sivicek, G. Urek, and O. Vahala. 2005. Monitoring of western corn rootworm (Diabrotica virgifera virgifera LeConte) in Europe 1992-2003, pp. 29-39. In U. K. S. Vidal, C. R. Edwards [ed.], Western Corn Rootworm: Ecology and Management, CABI, Wallingford.

Kurtz, B., Karlovsky P., and S. Vidal. 2010. Interaction between western corn rootworm (Coleoptera: Chrysomelidae) larvae and root-infecting Fusarium verticillioides. Environ. Entomol. (accepted for publication).

Lawrence, E. B., P. E. Nelson, and J. E. Ayeres. 1981. Histopathology of sweet corn seed and plants infected with Fusarium moniliforme and Fusarium oxysporum Phytopathology 71: 379-386.

Levine, E., and H. Oloumi-Sadeghi. 1991. Management of Diabroticite rootworms in corn. Annu. Rev. Entomol. 36: 229-255.

Logrieco, A., A. Bottalico, G. Mule, A. Moretti, and G. Perrone. 2003. Epidemiology of toxigenic fungi and their associated mycotoxins for some mediterranean crops. Eur. J. Plant Pathol.: 645-667.

Maiorano, A., A. Reyneri, D. Sacco, A. Magni, and C. Ramponi. 2009. A dynamic risk assessment model (FUMAgrain) of fumonisin synthesis by Fusarium verticillioides in maize grain in Italy. Crop Prot. 28: 243-256.

Marín, S., V. Sanchis, and N. Magan. 1995. Water activity, temperature, and $\mathrm{pH}$ effects on growth of Fusarium moniliforme and Fusarium proliferatum isolates from maize. Can. J. Microbiol. 41: 1063-1070.

Marín, S., V. Sanchis, F. Rull, A. J. Ramos, and N. Magan. 1998. Colonization of maize grain by Fusarium moniliforme and Fusarium proliferatum in the presence of competing fungi and their impact on fumonisin production. J. Food Protect. 61: 1489-1496.

Miller, N., A. Estoup, S. Toepfer, D. Bourguet, L. Lapchin, S. Derridj, K. Kim, P. Reynaud, L. Furlan, and T. Guillemaud. 2005. Multiple transatlantic introductions of the western corn rootworm. Science 310: 992.

Mogensen, J. M., K. F. Nielsen, R. A. Samson, J. C. Frisvad, and U. Thrane. 2009. Effect of temperature and water activity on the production of 
fumonisins by Aspergillus niger and different Fusarium species. BMC Microbiol. 9: 12.

Mouhoube, A., F. Schulthess, Y. D. Mawuena, K. F. Cardwell, and G. Cardwell. 2003. The effect of Fusarium verticilloides on oviposition behaviour and binomics of lepidopteran and coleopteran pests attacking the stem and cobs of maize in West Africa. Entomol. Exp. Appl. 106: 201-210.

Mulè, G., A. Susca, G. Stea, and A. Moretti. 2004. A species-specific PCR assay based on the calmodulin partial gene for identification of Fusarium verticillioides, F. proliferatum and F. Subglutinans. 110: 495-502.

Munkvold, G. P., D. C. McGee, and W. M. Carlton. 1996. Importance of different pathways for maize kernel infection by Fusarium verticilloides. Phytopathology 87: 209-217.

Munkvold, G. P., and W. M. Carlton. 1997. Influence of inoculation method on systemic Fusarium moniliforme infection of maize plants grown from infected seeds. Plant Dis. 81: 211-216.

Munkvold, G. P., and A. E. Desjardins. 1997. Fumonisins in maize - can we reduce their occurrence ? Plant Dis. 81: 556-565.

Munkvold, G. P., R. L. Hellmich, and L. G. Rice. 1999. Comparison of fumonisin concentration in kernels of transgenic bt maize hybrids and nontransgenic hybrids. Plant Dis. 83: 130-138.

Munkvold, G. P. 2003. Epidemiology of Fusarium diseases and their mycotoxinss in maize. Europ. J. Plant Pathol. 109: 705-713.

Murillo-Williams, A., and G. P. Munkvold. 2008. Systemic infection by Fusarium verticilloides in maize plants grown under three temperature regimes. Plant Dis. 92: 1695-1700.

Oren, I., S. Ezrati, D. Cohen, and A. Sharon. 2003. Early events in the Fusarium verticilloides-maize interaction characterized by using a green fluorescent protein-expressing transgenic isolate. Appl. Environ. Microb. 69: 16951701.

Palmer, L. T., and T. Kommedahl. 1969. Root-infecting fusarium species in relation to rootworm infestations in corn. Phytopathology 59: 1613-1617.

Peters, T. M., and P. Barbosa. 1977. Influence of population-density on size, fecundity, and developmental rate of insects in culture. Annu. Rev. Entomol. 22: 431-450. 
Rajeev, B., V. R. Ravishankar, and A. A. Karim. 2009. Mycotoxins in food and feed: present status and future concerns. Compr. Rev. Food Sci. F. 9: 5781.

Rice, M. E. 2004. Transgenic rootworm corn: assessing potential agronomic, economic, and environmental benefits. Plant Health Prog.: 1-10.

Schumann, M. 2008. Fungus colonization in relation to the subterranean feeding of the western corn rootworm (Coloeptera:Chrysomelidae) in conventional and transgenic Maize, pp. 74, Imperial College, London

Stutz, J. C., and K. T. Leath. 1981. Effects of root wounding on Fusarium roseum development in red clover. Phytopathology 71: 564-565.

Voss, K. A., P. C. Howard, R. T. Riley, R. P. Sharma, T. J. Bucci, and R. J. Lorentzen. 2002. Carcinogenicity and mechanism of action of fumonisin B-1: a mycotoxin produced by Fusarium moniliforme (= F. verticillioides). Cancer Detect. Prev. 26: 1-9.

Waes, J. G., L. Starr, J. Maddox, F. Aleman, K. A. Voss, J. Wilberding, and R. T. Riley. 2005. Maternal fumonisin exposure and risk for neural tube defects: mechanisms in an in vivo mouse model. Birth Defects Res. Part AClin. Mol. Teratol. 73: 487-497.

Weiss, M. J., K. P. Seevers, and Z. B. Mayo. 1985. Influence of western corn rootworm larval, densities and damage on corn rootworm survival, developmental time, size and sex ratio (Coleoptera, Chrysomelidae) J. Kans. Entomol. Soc. 58: 397-402.

Wesseler, J., and E. Fall. 2009. Benefits and costs of Diabrotica virgifera virgifera control in Europe, 23rd IWGO Conference \& 2nd International Conference of Diabrotica Genetics, Munich.

Wilke, A. L., C. R. Bronson, A. Tomas, and G. P. Munkvold. 2007. Seed transmission of Fusarium verticillioides in maize plants grown under three different temperature regimes. Plant Dis. 91: 1109-1115 


\title{
Chapter 4: Can western corn rootworm larvae orientate towards, transport and transmit root infecting Fusarium verticillioides?
}

\author{
B. Kurtz and S. Vidal
}

Georg-August University Göttingen, Department of Crop Science, Agricultural Entomology, Grisebachstrasse 6, 37077 Göttingen, phone:++49(0)551393728, Email: bkurtz@gwdg.de

Corresponding author: S. Vidal address as above, phone: +49(0)551-39 9744, fax:+49(0)551 -39 12105, Email: svidal@gwdg.de

\begin{abstract}
In this study it was investigated if the soil-dwelling maize pest western corn rootworm (WCR, Diabrotica virgifera virgifera LeConte) is a belowground vector of the root infecting plant pathogen Fusarium verticillioides (Saccardo) Nirenberg (synonym = Fusarium moniliforme Sheldon). Choice tests were performed to assess the preference of WCR larvae towards $F$. verticillioides colonized plants. In a "transmission experiment" WCR larvae were transferred from plants artificially inoculated with $F$. verticillioides to not-inoculated plants. Additionally WCR larvae were removed from the inoculated plants and were put on PDA media to check for fungus sticking to the larvae. Fungal colonies growing on the media were identified by qualitative PCR as $F$. verticillioides. The amount of $F$. verticillioides DNA in the roots of the inoculated and not-inoculated plants was measured by using real-time PCR. In choice tests larvae avoided F. verticillioides colonized plants. $23 \%$ of the larvae that had fed on colonized plants transported vital fungal material with them. $15 \%$ of the larvae transported $F$. verticillioides even after they had been surface sterilized. However larvae did not induce colonization of plants by $F$. verticillioides. This is the first study that addresses the orientation of western corn rootworm larvae to plants colonized by $F$. verticillioides, and that investigates the potential of western corn rootworm larvae to transport and to induce colonization by a plant pathogenic fungus.
\end{abstract}


KEYWORDS: Diabrotica virgifera virgifera, western corn rootworm, Fusarium verticillioides, transmission, belowground vector, choice test, orientation

\section{INTRODUCTION}

Since its first discovery in Europe in 1992, the invasive maize pest western corn rootworm (WCR, Diabrotica virgifera virgifera LeConte) has spread from Eastern to Central Europe (Kiss et al. 2005, Miller et al. 2005). Rootworms are responsible for losses of 1 billion $\$$ per year in the USA (Rice 2004) and 472 million $€$ per year are expected to occur in Europe (Wesseler and Fall 2009). The feeding of the WCR larvae on the roots weakens the plant and intensive feeding can result in lodging (Levine and Oloumi-Sadeghi 1991; Godfrey et al. 1993). Additionally the damage caused by rootworm feeding leads to an increase in root colonization by root pathogens (Palmer and Kommedahl 1969, Kurtz et al. 2010). F. verticillioides (Saccardo) Nirenberg (synonym = Fusarium moniliforme Sheldon) is one of the most wide-spread soil borne pathogens of maize that causes a variety of different diseases at different parts of the plant (Danielsen and Jensen 1998; Munkvold et al. 1999; Munkvold 2003). Moreover, upon colonization of plant tissues, the fungus produces fumonisins $\left(\mathrm{FB}_{1}, \mathrm{FB}_{2}\right)$ which have cancer promoting activity (Gelderblom et al. 1988; Nelson et al. 1993). The fumonisins have been associated with different diseases in animals (equine leukoencephalomalacia, porcine pulmonary edema) and humans (esophageal cancer) (Desjardins and Hohn 1997, Rajeev et al. 2009, Voss et al. 2002, Mouhoube et al. 2003). Palmer and Kommedahl, (1969) isolated different Fusarium spp. from Diabrotica longicornis (Say) northern corn rootworm (NCR) larvae, and found increased incidence of Fusarium rot root in fields where NCR was present. Palmer and Kommedahl (1969) concluded that northern corn rootworms acted as vectors of Fusarium spp., but did not test the mechanism underlying their observation. The increase in the incidence of Fusarium infections could be caused by the larvae creating wounds the fungus uses to enter (Schumann 2008, Kurtz et al. 2010), or by larvae transporting inoculum to previously uninfected plants. We focused on the second hypothesis asking the following questios:

(1) Do WCR larvae orientate towards F. verticillioides colonized plants? 
(2) Do WCR larvae transport $F$. verticillioides spores after having fed on colonized plants?

(3) Are WCR larvae able to induce infections on previously not colonized plants?

WCR larvae orientate towards a $\mathrm{CO}_{2}$ gradient to find the maize plant (Bernklau and Bjostad 1998), and additionally semiochemicals as 6-methoxy-2benzoxazolinone (MBOA) (Bjostad and Hibbard 1992) and long-chain free fattyacids (Hibbard et al. 1994) are also involved in the orientation process. Having found the root a blend of different sugars and fatty-acids act as feeding stimulants for WCR larvae (Bernklau and Bjostad 2008) while hydroxamic acids act as deterrent (Xie et al. 1992). The colonization of $F$. verticillioides might influence the release of relevant cues and the composition of present contact chemical cues influencing the attractiveness of maize roots for WCR larvae. As colonization of roots by $F$. verticillioides can influence WCR development (Kurtz et al. 2010), larvae would benefit if they could discriminate between colonized and not colonized plants.

Soil dwelling insects and mites carry fungal propagules with them, and can transmit plant pathogenic fungi like Fusarium oxysporum, Fusarium sp. vasinfectum, Verticillium sp. (Wiggins and Curl 1979). Dighton et al., (1997) suggested in his review that macro-arthropods could play a significant role in dispersing micro-organisms, but detailed information is still lacking. WCR larvae are able to move up to $100 \mathrm{~cm}$ from egg hatch until adult emergence (Suttle et al. 1967). After the initial movement of the neonates to the host plant, larval migration is not complete. As WCR larvae grow they redistribute not only in the root system they initially moved to, but also move to new host plants. Post-establishment movement of $46 \mathrm{~cm}$ and $61 \mathrm{~cm}$ has been reported in the literature (Hibbard et al.; 2003; Hibbard et al. 2004). The movement of the larvae however is strongly influenced by soil bulk density, pore size, soil moisture and soil compaction (Suttle et al. 1967; Short and Luedkte 1970; Macdonald and Ellis 1990). Summing up WCR larvae can cover relatively large distances, can move between plants, and can be present in high densities up to 45 larvae per plant (Suttle et al. 1967, Hibbard et al. 2003; Hibbard et al. 2004, Weiss et al. 1985).

Because of the growth of renewable energy fuelled by maize, it is expected that the intensity and the area of maize production will increase in the future ( $\mathrm{Holm}$ - 
Nielsen et al. 2006; Odling-Smee 2007). Especially in fields where maize is planted after maize for several years, favouring equally the occurrence of western corn rootworm and $F$. verticillioides, belowground transmission could have significant consequences.

\section{MATERIAL AND METHODS}

\section{Choice test}

\section{Maize cultivar}

Maize seeds of the cultivar Ricardinho (KWS, Einbeck, Germany) were surface sterilized following the procedure described by Benziri et al. (1994). Maize seeds were placed in Petri dishes on wet filter paper under sterile conditions at $20^{\circ} \mathrm{C}$ for two days to germinate, prior to inoculation with $F$. verticillioides (details see below). After inoculation plants were planted in the greenhouse in pots with mixture of potting soil and sand (1:1). After four weeks plants were transferred into the choice test and continued as described in the experimental setup.

\section{Cultivation and handling of Fusarium verticillioides}

We obtained the isolate FM 8114 from Prof. Dr. Petr Karlovsky (Molecular Phytopathology and Mycotoxin Research, Georg-August University Goettingen). The fungus was previously maintained on potato extract glucose agar (39 g/l) and upon receipt was transferred to "Spezieller Nährstoffarmer Agar" (SNA, Nirenberg 1976) modified as liquid culture. SNA liquid culture induces $F$. verticillioides to produce spores, which were used as inoculum in the experiment. The culture was maintained for 3 wks on a shaker at $100 \mathrm{rpm}$ and $25^{\circ} \mathrm{C}$ and spore concentration was determined by using a haemocytometer. For inoculation $10^{5}$ spores per germinated seed were applied in $100 \mu$ l of water (A. Ahmed pers. comm. 2009).

\section{Western corn rootworm}

Western corn rootworm eggs from the non-diapausing strain were obtained from USDA-ARS, Agricultural Research Laboratory, Brookings, USA (Branson 1976). The eggs were stored in Petri dishes in the fridge at $8^{\circ} \mathrm{C}$. Before the experiment 
was started, the timing of larval hatch was determined with a hatch test as follows: eggs were kept at $26{ }^{\circ} \mathrm{C}, 65 \%$ relative humidity, in $9 \mathrm{-cm}$ diameter Petri dishes (100 eggs per dish) with wet filter papers and were checked daily for larval hatching, which occurred after $13 \mathrm{~d}$ (data not shown).

Three days prior to hatching, the eggs were washed using a sieve (250 $\mu \mathrm{m})$ and transferred into a $0.15 \%$ agar solution. The eggs in the agar solution were applied into the choice test by using a manual hand dispenser (Multipette Plus, Eppendorf, Hamburg, Germany) as described below.

\section{Experimental setup}

The experiment was carried out in three separated repetitions, one for the control and two in which $F$. verticillioides was applied. The experiments were carried out in a choice test arena which consisted of two pots $\left(16^{\star} 20 \mathrm{~cm}\right)$ that were connected by a tube $(20 \mathrm{~cm}$, Photo1). The tube was filled with vermiculite $(3-6 \mathrm{~mm})$ while the plants growing in the pots were planted into Haplic Luvisoil mixed with potting soil (1:1, Tab. 1). Hundred eggs were applied three days prior to hatching into the middle of the tubes. At hatching time plants were about 30 days old (growth stage V4). After the start of larval hatch plants grew for another twenty days before harvest (growth stage V7). The soil from the pots and the vermiculite from the tubes were put into the Kempson apparatus (Kempson et al. 1968), and extracted larvae were counted. The whole setup was repeated in a slightly modified way. One week after hatch of the WCR larvae the tube connecting the two pots was removed. In this way it was prevented that larvae moved back from plants they initially had moved to.

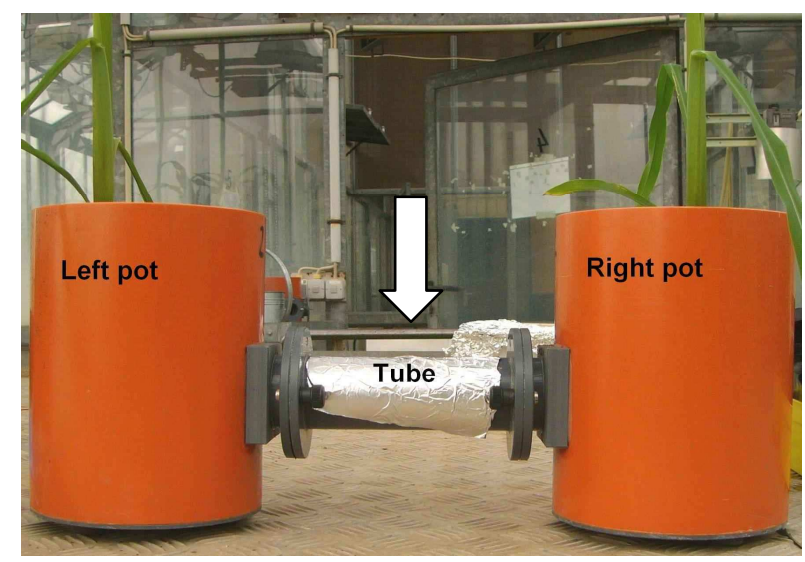

Photo 1 Choice test arena: The arrow marks the point where the eggs were applied. 
Tab. 1 Details of soil type used in the experiment. Nomenclature after Lt. FAO

World Soil Resources Report, Food and Agriculture Organization of the UN, 1990.

\begin{tabular}{lc}
\hline & $\begin{array}{c}\text { Haplic Luvisol } \\
\text { (silt loam) }\end{array}$ \\
\hline Coordinates & $5129 ` 52.88 \mathrm{~N}$ \\
& $9555^{\prime} 38.26 \mathrm{E}$ \\
Sand content $(\%)$ & 20.71 \\
Silt content $(\%)$ & 68.08 \\
Clay content $(\%)$ & 11.21 \\
pH $\left(\mathrm{H}_{2} \mathrm{O}\right)$ & 7.61 \\
$\mathrm{C} / \mathrm{N} \mathrm{Ratio}$ & 15.76 \\
\hline
\end{tabular}

\section{Data Analysis}

In the choice test experiment for each section (pot-left, pot-right, tube) the percentage of found larvae was calculated. Each of the three repetitions of the experiment was analyzed separately. The data was transformed into ranks (Conover and Iman 1981) and analyzed with an univariate ANOVA. The percentage of found larvae was used as dependent variable and the side where larvae were found as independent variable.

\section{Transmission experiment}

\section{Soil and plants}

For the experiments a flint $x$ dent maize cultivar (KWS14, KWS, Einbeck, Germany) was used. It is a medium early variety (maturity class 270 ). Before planting maize seeds were sterilized following the method described by Benziri et al. (1994). Maize plants were sown in plastic trays $\left(34 \mathrm{~cm}{ }^{*} 26 \mathrm{~cm}\right)$ in a mixture of potting soil and sand (1:1) and transplanted to pots (diameter=13 cm) 1 wk later. 


\section{Handling of western corn rootworm}

See above in the section choice test.

Trays $(34 \mathrm{~cm}$ * $26 \mathrm{~cm}$ ) with humid potting soil and sand (1:1) and 24 planted maize seeds (KWS 14, KWS, Einbeck, Germany) were prepared and placed in the quarantine laboratory under halogen mirror lamps (250W, E40, Lanzini, Italy) at $26^{\circ} \mathrm{C}$ and $65 \%$ r.h. WCR eggs were applied to 5 days o ld plants. Larvae hatched after another 5 days and were given one week to feed before they were used for the experiment (young second instar larvae).

\section{Cultivation and handling of Fusarium verticillioides}

The isolate of $F$. verticillioides was obtained from the German resource centre of biological material (DSMZ, Braunschweig, Germany, No. DSM62264).

F. verticillioides was maintained on "Spezieller Nährstoffarmer Agar" (SNA, Nirenberg 1976). Before the start of the experiment $F$. verticillioides was moved to PDA (39 g/l). Wheat straw was grinded $(4 \mathrm{~mm}) 12 \mathrm{~g}$ filled in a 1-I flask and filled up with $400 \mathrm{ml}$ distilled water. The flasks were left over night and autoclaved the following day. After two days the flasks were autoclaved a second time and a disc of mycelium from $F$. verticillioides was added. Flasks were transferred to a shaker at $20^{\circ} \mathrm{C}$ and $100 \mathrm{rpm}$ for four weeks. The spore conce ntration in the culture was assessed by using a haemocytometer to control successful colonization (data not shown). The straw was filtered and seven grams mixed with $100 \mathrm{~g}$ dry soil which was placed onto the top soil in the pot.

\section{Experimental setup}

The experiment was carried out twice in two separated repetitions of experiments. Maize was grown in the greenhouse under 16 hours of illumination by sodium lamps (400W, HS2000, Hortilux Schréder, Monster, Netherlands) for three wks before inoculation with $F$. verticillioides (as described above). Maize plants were watered daily and fertilized once a week using $2 \%$ Hakaphos blue solution (Compo, Münster, Germany). After the application of $F$. verticillioides, plants grew in the greenhouse for another four wks to allow the colonization of the plants. In the meantime larvae of WCR were reared in trays with young maize plants in the 
quarantine laboratory as described above. Three weeks after the application of the fungus young second instar larvae were picked out of the trays by hand with a fine brush and applied to six week old plants (growth stage V7). Thirty larvae were transferred from the trays to the pots with the infected maize plants where they were left for five days to pick up fungal material $(n=30)$. Following larvae were searched out of the soil by hand and individually put into small Petri dishes filled with wet soil for transport to un-inoculated plants. The un-inoculated plants were four weeks old at that time (growth stage V4). Four larvae from one infected plant were moved to one un-inoculated plant. This transfer of larvae to un-inoculated plants was performed for 12 replicates. Additionally 26 larvae were removed from 12 plants for analysis of contamination with $F$. verticillioides. Therefore larvae were put on PDA (39 $\mathrm{g} / \mathrm{l})$, turned and afterwards surface sterilized by placing them for one minute into $0.1 \% \mathrm{AgNO}_{3}$ solution following a washing step for one minute in sterile $0.85 \% \mathrm{NaCl}$ solution. After the surface sterilization, the larvae were placed on a second PDA plate. In that way it was detected if larvae transported the fungus at their surface. PDA plates were checked for growing fungal colonies and colonies that were assumed to be $F$. verticillioides were isolated. Root samples were taken (approx. $5 \mathrm{~g}$ of fresh weight) near the bottom of the pot for DNA extraction and quantification of $F$. verticillioides. The maize plants were moved to the quarantine laboratory and self made gauze bags (Voile, 100\% polyester, Alfatex, Goettingen, Germany) were attached between the stem and the edge of the pot. In that way the escape of emerging adults was prevented. Maize plants were grown for further four weeks in the quarantine laboratory with 16 hours of illumination. By then sufficient colonization of the roots by $F$. verticillioides should have been taken place. Finally the plants (growth stage V9) were harvested, root samples taken (approx. $5 \mathrm{~g}$ of fresh weight) near the bottom of the pots, DNA extracted and F. verticillioides DNA quantified.

\section{Qualitative PCR}

The colonies isolated from the PDA plates were transferred to falcon tubes $(15 \mathrm{ml})$ filled with $4 \mathrm{ml}$ malt extract agar (33.6 $\mathrm{g} / \mathrm{l})$. After one week the growing mycelium was collected with a sterile spatula, transferred into $2 \mathrm{ml}$ Eppendorf tubes, freeze dried and homogenized in a ball mill. The DNA was extracted from the pulverized 
mycelium by using the CTAB protocol described by Brandfass and Karlovsky (2008).

For the identification of $F$. verticillioides the DNA extracted from the mycelia was inserted into a classical qualitative PCR. PCR amplifications were carried out in 25- $\mu$ l reactions (10x Buffer Bioline, $\mathrm{MgCl}_{2}$ Buffer $2.5 \mathrm{mM}$, dNTP Bioline $100 \mu \mathrm{M}$, Taq Bioline 0.5 U, forward and reverse Primers VER1, VER2 0.3 $\mu \mathrm{M}$ ). Two different positive controls were used. One control was prepared from DNA of F. verticillioides FRC 8114 (Fusarium Research Centre, Penn State University, Pennsylvania, USA) which was purified and quantified as described by Brandfass and Karlovsky (2006). The second positive control was one sample from DSM 6224 grown on PDA, where the DNA was extracted as described and the sample included into the assay. Water and non infected maize samples were used as non template standards to ensure that no contamination occurred. Primers of F. verticillioides (VER1 and VER2) were designed as described by Mulè et al. (2004). Quality and quantity of DNA were assessed by electrophoresis in $0.8 \%$ (w/v) agarose gels (Biozym, Hess. Oldendorf, Germany) prepared in TAE buffer (40 mM Tris, $1 \mathrm{mM}$ EDTA, pH set to 8.5 with acetic acid). The electrophoresis was carried out at $4 \mathrm{~V} / \mathrm{cm}$ for $60 \mathrm{~min}$. Double-stranded DNA was stained with ethidium bromide $(2 \mathrm{mg} / \mathrm{l})$. Gels were documented with the help of a digital imaging system (Vilber Lourmat, Marne la Vallee, France).

\section{DNA extraction and real-time PCR}

The root samples (approx. $5 \mathrm{~g}$ fresh material) were wrapped in aluminium foil, freeze-dried for $72 \mathrm{~h}$ and ground by using a laboratory mill (Analysenmühle A10, IKA Labortechnik, Staufen, Germany). DNA was extracted from dry roots milled to a fine powder using a CTAB protocol described previously (Brandfass and Karlovsky 2008). Afterwards the quality and quantity of DNA was assessed by electrophoresis as decribed above. Real-time PCR for F. verticillioides DNA was performed using primers VER1 and VER2 and SYBR Green fluorescence monitoring according to a protocol adapted from qPCR assays for F. culmorum and F. graminearum (Mulè et al. 2004, Brandfass and Karlovsky 2008; Nutz pers. com. 2010). One microliter of 10-times diluted maize root DNA was used for each $25-\mu \mathrm{l}$ reaction. Standards were prepared from DNA of Fusarium verticillioides FRC 
8114 (Fusarium Research Centre, Penn State University, Pennsylvania, USA) as described in Brandfass and Karlovsky 2006. Two sets of standards ranging from $0.3 \mathrm{pg}$ to $100 \mathrm{pg}$, dissolved in 10-time diluted maize DNA matrix, were analyzed with each sample set.

\section{Data analysis}

The percentage of larvae on which $F$. verticillioides was identified was calculated. A semi quantitative analysis of the real-time PCR was carried out. Orientating on the Ct-values of the standards given by the CFX Manager software (C1000 Thermo Cycler, Biorad, Hercules, USA), classes of amounts of $F$. verticillioides colonization were built $(+++>0.3 p g / \mu l,++<0.3 p g / \mu l,+=$ positive but no quantification possible, $0=$ negative). In these classes the samples were sorted and percentages were calculated.

\section{RESULTS}

\section{Choice test}

The hatch rate lied at approximately $80 \%$. Around forty larvae were extracted from the control experiment and the experiment where larval movement was restricted by removal of the tubes. In the experiment where larvae could move between plants the number of extracted larvae was seventy. When two not-inoculated plants were offered in the choice test larvae moved into both pots without significant preference for one of the two sides $(n=6, d f=1, F=0.61, p=0.61)$. In both experiments where $F$. verticillioides was applied significantly more larvae moved to the control plants. If larvae had the possibility to move between plants during the whole experiment $61 \%$ of the larvae preferred to move to the un-inoculated plant $(\mathrm{n}=6, \mathrm{df}=1, \mathrm{~F}=20.6, \mathrm{p}<0.05$, Fig. 1). When larvae had no possibility to move back, $64 \%$ of the larvae were found on the un-inoculated plant $(n=5, d f=1, F=14.3$, $\mathrm{p}<0.05)$. 


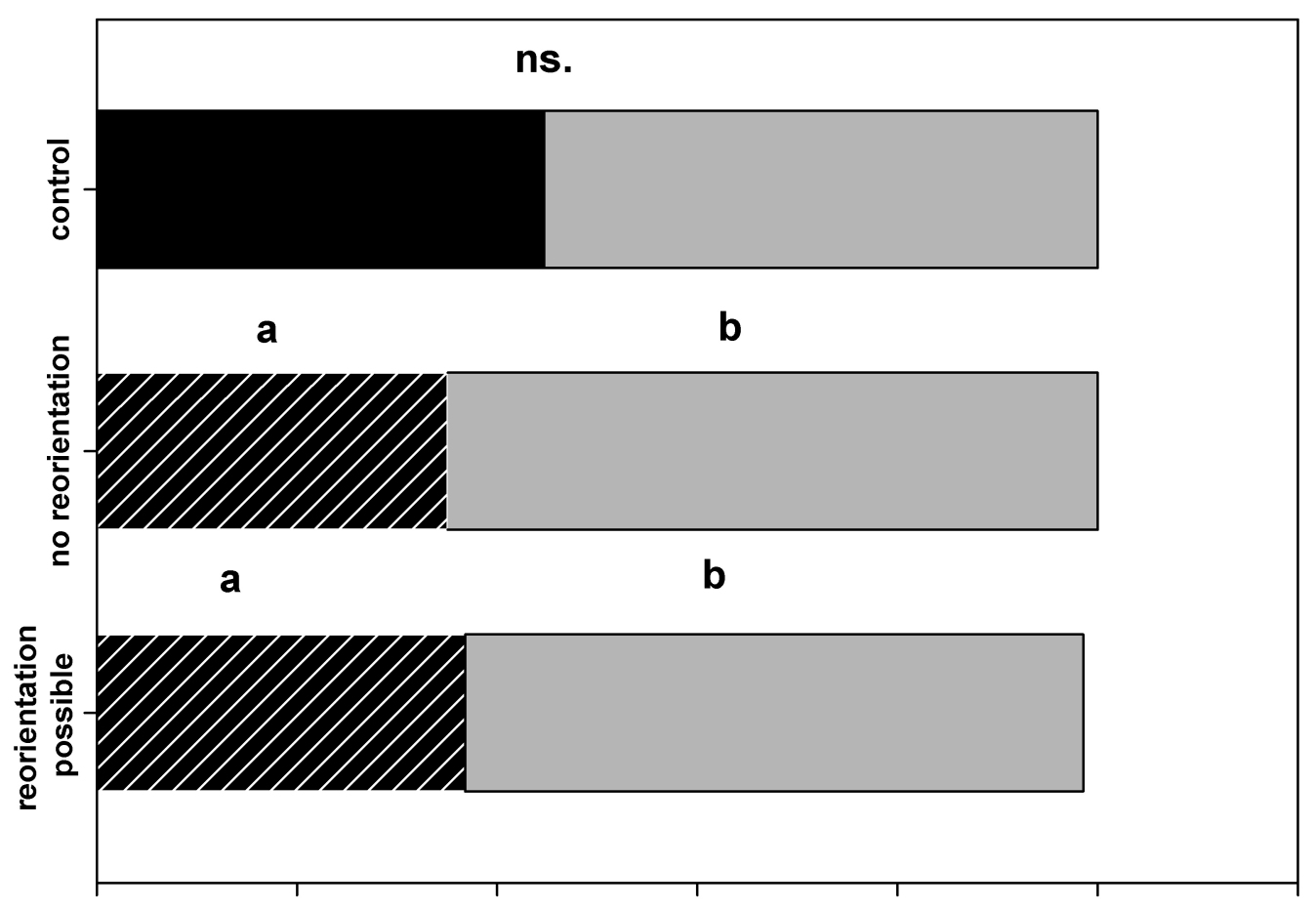

Fig. 1 Percentage of western corn rootworm larvae found in a choice test on plants inoculated with or without Fusarium verticillioides (lined= Fusarium applied, black and grey the two different pots of the choice test). Data is shown for three different experiments (control= no fungal application; "no reorientation"= larvae cannot move back from plants they initially moved to, "reorientation possible"=larvae can move between plants during the whole experiment). Data of tubes is not presented as only very few larvae were found (<2\%). Letters above columns indicate significance of difference according to ANOVA $<0.05$.

\section{Transmission experiment}

In $23 \%$ of the cases $F$. verticillioides was growing on PDA plates on which larvae had been turned. So in this cases the fungus had sticked to the surface of the larvae. In $15 \%$ of the cases $F$. verticillioides grew on PDA plates on which surface sterilized larvae moved (Photo 1). Maize plants where larvae from infected plants had been transferred to did not show an increased colonization of $F$. verticillioides 
(Fig. 2). A low colonization by $F$. verticillioides was noticeable in plants that had not been inoculated with $F$. verticillioides.

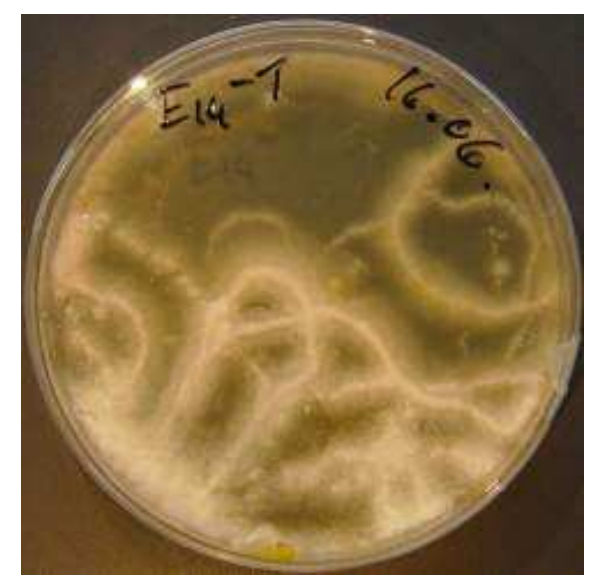

Photo 1 Fusarium verticillioides growing out of traces made by a western corn rootworm larvae on PDA media. The fungus was identified by using qualitative PCR.

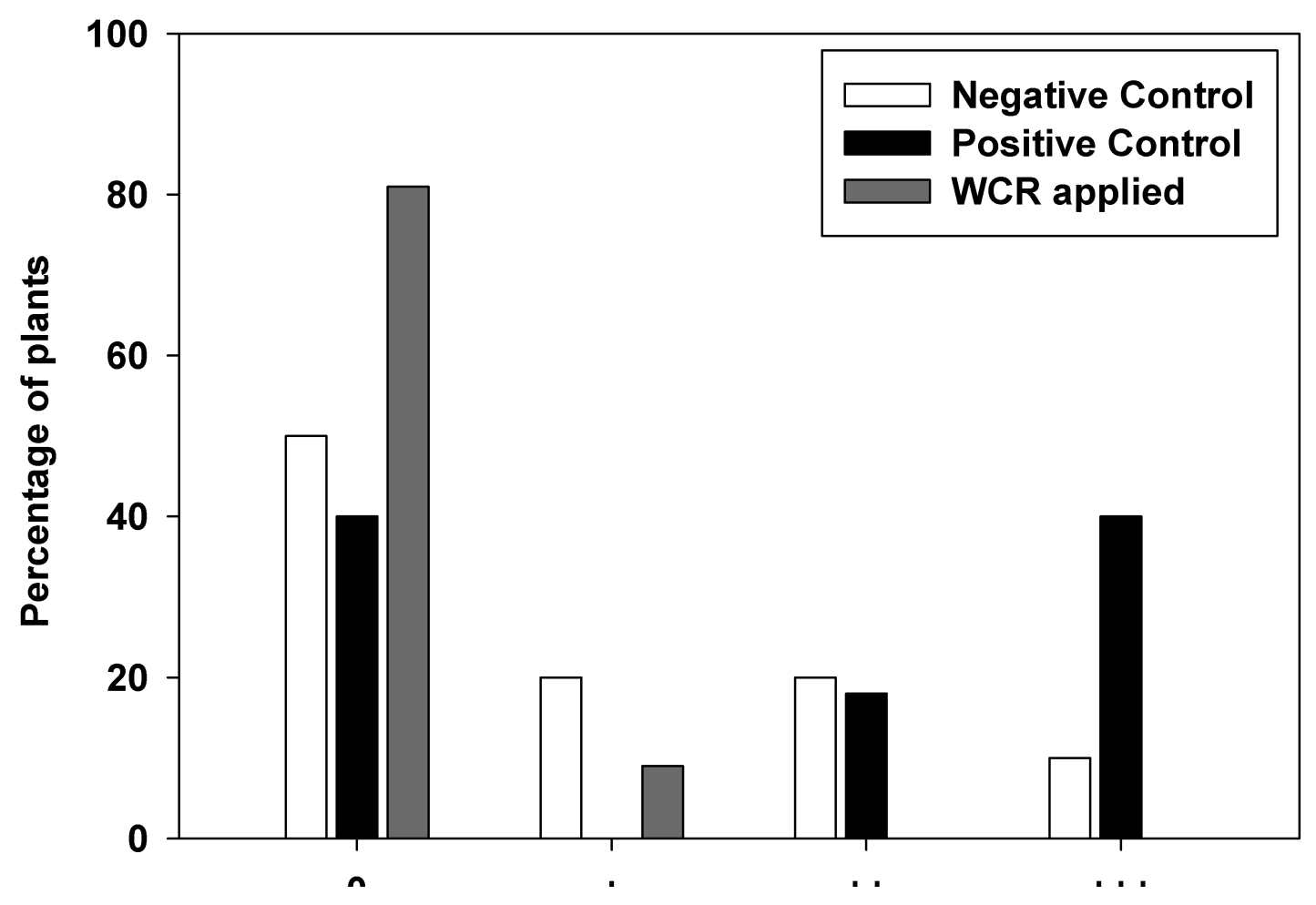

Fig. 2 Amount of $F$. verticillioides DNA found in roots of plants without application of Fusarium verticillioides (negative control), with application (positive control) and in the presence of western corn rootworm (WCR, amount of $F$. verticillioides DNA represented by $+++>0.3 \mathrm{pg} / \mu \mathrm{l},++<0.3 \mathrm{pg} / \mu \mathrm{l},+=$ positive but no quantification possible, $0=$ negative). 


\section{DISCUSSION}

We were able to demonstrate that western corn rootworm larvae avoided plants that were colonized by Fusarium verticillioides. About one quarter of western corn rootworm (WCR) larvae that had been feeding on F. verticillioides colonized plants, had vital stages of $F$. verticillioides attached, but larvae did not induce colonization on previously un-colonized plants.

Miller (2007) reported that increased root damage by Diabrotica undecimpunctata undecimpunctata howardi Barber western spotted cucumber beetle (WSCB) larvae, occurred at maize plants that were grown from $F$. verticillioides inoculated seeds. WSCB and WCR differ significantly in their biology as WSCB is multivoltine and larvae are generalist feeders (Branson and Krysan 1981). As previous results show WCR larval development was significantly delayed when feeding at F. verticillioides colonized plants (Kurtz et al.2010). Unfortunately similar data is not available for WSCB.

The restriction of larval movement did not influence the distribution of found larval numbers. So larvae did not move back again after having reached the colonized plant. This means that larvae were deterred by $F$. verticilloides colonized plants before reaching them. Yue et al., (1998) documented that $F$. verticillioides break down 6-methoxy-2-benzoxazolinone (MBOA) which is a semiochemical for host location by WCR (Bjostad and Hibbard 1992). In that way colonization of the plant by $F$. verticillioides could be perceptible for WCR. F. verticillioides may elicit an antixenotic behaviour and therefore contributes to the clumped distributions of WCR larvae that are observed under field conditions (Toepfer et al. 2007). For the transmission experiment the colonization by $F$. verticillioides was relatively low as compared to previous studies ( 3 pg/mg in comparison to $10 \mathrm{pg} / \mathrm{mg}$ in Kurtz et. al 2010), and larvae were only 5 days present at the infected plant. So it is seems to be that larvae can take up spores relatively fast as $25 \%$ of the larvae transported F. verticillioides on their surface. Even as no faeces could be spotted on the PDA plates, we suggest that WCR can excrete viable spores, as it is described for different insects and mites (Price 1976; Wiggins and Curl 1979; Williams et al. 1998). The $15 \%$ of the larvae that transported $F$. verticillioides after surface sterilization did not transport the fungus on the surface when they were tested before surface sterilization. So larvae must have excreted vital fungal spores. 
Different studies have shown that rootworm larvae take up Fusarium species into their gut and that the fungus is still vital (Palmer and Kommedahl 1969; Molnár et al. 2008, Venjakob 2009). Palmer and Kommedahl (1969) could isolate

F. verticillioides from frass including faeces of Diabrotica longicornis northern corn rootworm (NCR) larvae which also suggests that larvae might be able to excrete fungal spores.

The WCR larvae transported vital $F$. verticillioides, but our results showed that colonization of $F$. verticillioides has not to be induced on un-colonized plants. Results from other studies suggested that a minimum inoculum $(3 \mathrm{~g}$ colonized straw/plant in Schumann 2008, $10^{7}$ spores/plant in Kurtz et al. 2010) of

$F$. verticillioides was needed in the soil so that WCR damage could enhance F. verticillioides colonization. Furthermore the enhancement of colonization by $F$. verticillioides was higher when the fungus had time to colonize the root before the appearance of the insect (Kurtz et. al 2010). As the colonization on the control plants inoculated with $F$. verticillioides was rather weak, the reason that the transmission did not occur may lie in the low virulence of the isolate. Comparative virulence tests would be needed to find out if more virulent strains of F. verticillioides could be transmitted by WCR. Because of room limitations in the quarantine, plants were grown all together in one cabin so that infection via the air could not be ruled out. This might explain the low colonization levels of plants where no inoculum was applied.

The presented study documented for the first time that WCR larvae are deterred by $F$. verticillioides colonized plants.

The research has shown that western corn rootworm larvae are not efficient vectors of $F$. verticillioides as it was suggested by Palmer and Kommedahl (1969). Instead of transmitting $F$. verticillioides, larvae can enhance $F$. verticillioides colonization of maize plants as documented in other studies (Schumann 2008, Kurtz et al. 2010).

\section{ACKNOWLEDGEMENTS}

We thank Prof. Dr. Petr Karlovsky and Patricia Bartoschek for support with the real-time PCR and Wade French, (USDA-ARS, Brookings, SD) for providing the 
western corn rootworm eggs. This work was funded by the DFG (German Research Foundation).

\section{REFERENCES}

Benziri, E., A. Courtade, and A. Guckert. 1994. Fate of two microorganisms in maize simulated rhizosphere under hydroponic and sterile conditions. Soil Biol. Biochem. 27: 71-77.

Bernklau, E. J., and L. B. Bjostad. 1998. Reinvestigation of host location by western corn rootworm larvae (Coleoptera: Chrysomelidae): $\mathrm{CO}_{2}$ is the only volatile attractant. J. Econ. Entomol. 91: 1331-1340.

Bernklau, E. J., and L. B. Bjostad. 2008. Identification of feeding stimulants in corn roots for western corn rootworm (Coleoptera : Chrysomelidae) larvae. J. Econ. Entomol. 101: 341-351.

Bjostad, L. B., and B. E. Hibbard. 1992. 6-Methoxy-2-benzoxazolinone: A semiochemical for host location by western corn rootworm larvae. J. Chem. Ecol. 18: 931-944.

Brandfass, C., and P. Karlovsky. 2006. Simultaneous detection of Fusarium culmorum and F. graminearum in plant material by duplex PCR with melting curve analysis. BMC Microbiol. 6: 4.

Brandfass, C., and P. Karlovsky. 2008. Upscaled CTAB-based DNA extraction and real-time PCR assays for Fusarium culmorum and F. graminearum DNA in plant material with reduced sampling error. Int. J. Mol. Sci. 9: 23062321.

Branson, T. F. 1976. The selection of a non-diapause strain of Diabrotica virgifera (Coleoptera: Chrysomelidae). Entomol. exp. appl. 19: 148-154.

Branson, T. F., and J. L. Krysan. 1981. Feeding and oviposition behavior and life cycle strategies of Diabrotica: an evolutionary view with implications for pest management ${ }^{1,2}$. Environ. Entomol. 10: 826-831.

Conover, W.J., and Iman, R.L. 1981. Rank transformations as a bridge between parametric and nonparametric statistics. Am. Stat. 35, 124-129.

Danielsen, S., and D. F. Jensen. 1998. Relationships between seed germination, fumonisin content and Fusarium verticilloides infection in selected maize samples from different regions of Costa Rica. Plant Pathol. 47: 609-614. 
Desjardins, A. E., and T. M. Hohn. 1997. Mycotoxins in plant pathogenesis. Mol. Plant Microbe Interact. 10: 147-152.

Dighton, J., H. E. Jones, C. H. Robinson, and J. Beckett. 1997. The role of abiotic factors, cultivation practices and soil fauna in the dispersal of genetically modified microorganisms in soils. Appl. Soil. Ecol. 5: 109-131.

FAO, 1990. World Soil Resources Report 60, Food and Agriculture Organization of the United Nations, Rome, Italy.

Gelderblom, W. C., K. Jaskiewicz, W. F. Marasas, P. G. Thiel, R. M. Horak, R. Vleggaar, and N. P. Kriek. 1988. Fumonisins--novel mycotoxins with cancer-promoting activity produced by Fusarium moniliforme. Appl. Environ. Microbiol. 54: 1806-1811.

Godfrey, L. D., L. J. Meinke, and R. J. Wright. 1993. Vegetative and reproductive biomass accumulation in field corn: response to root injury by western corn rootworm (Coleoptera: Chrysomelidae). J. Econ. Entomol. 86: 1557-1573.

Hibbard, B. E., E. J. Bernklau, and L. B. Bjostad. 1994. Long-chain free fattyacids semiochemicals for host location by western corn rootworm larvae J. Chem. Ecol. 20: 3335-3344.

Hibbard, B. E., D. P. Duran, M. R. Ellersieck, and M. M. Ellsbury. 2003. Postestablishment movement of western corn rootworm larvae (Coleoptera: Chrysomelidae) in Central Missouri corn. J. Econ. Entomol. 96: 599-608.

Hibbard, B. E., M. L. Higdon, D. P. Duran, Y. M. Schweikert, and M. R. Ellersieck. 2004. Role of egg density on establishment and plant-to-plant movement by western corn rootworm larvae (Coleoptera:Chrysomelidae). J. Econ. Entomol. 97: 871-882.

Holm-Nielsen, J. B., M. Madsen, and P. O. Popiel. 2006. Predicted energy crop potentials for bioenergy, worldwide and for EU-25., World Bioenergy 2006 Conference on Biomass for Energy, Jönköping - Sweden

Kempson, D., M. Lloyd, and R. Ghelardy. 1968. A new extractor for woodland litter. Pedobiologia 3: 1-30.

Kiss, J., C. R. Edwards, H. K. Berger, P. Cate, M. Cean, S. Cheek, J. Derron, H. Festic, L. Furlan, J. Igrc-Barc ic', I. Ivanova, W. Lammers, V. Omelyuta, G. Princzinger, P. Reynaud, I. Sivcev, P. Sivicek, G. Urek, and O. Vahala. 2005. Monitoring of western corn rootworm (Diabrotica 
virgifera virgifera LeConte) in Europe 1992-2003, pp. 29-39. In U. K. S. Vidal, C. R. Edwards [ed.], Western Corn Rootworm: Ecology and Management, CABI, Wallingford.

Kurtz, B., Karlovsky P., and S. Vidal. 2010. Interaction between western corn rootworm (Coleoptera: Chrysomelidae) larvae and root-infecting Fusarium verticillioides. Environ. Entomol. (accepted for publication).

Levine, E., and H. Oloumi-Sadeghi. 1991. Management of Diabroticite rootworms in corn. Annu. Rev. Entomol. 36: 229-255.

Macdonald, P. J., and C. R. Ellis. 1990. Survival-time of unfed, 1st-Instar western corn-rootworm (Coleoptera, Chrysomelidae) and the effects of soil type, moisture, and compaction on their mobility in soil. Environ. Entomol. 19: 666-671.

Miller, N., A. Estoup, S. Toepfer, D. Bourguet, L. Lapchin, S. Derridj, K. Kim, P. Reynaud, L. Furlan, and T. Guillemaud. 2005. Multiple transatlantic introductions of the western corn rootworm. Science 310: 992.

Miller, N. 2007. Responses and relationships among Fusarium species, sweet corn, and western spotted cucumber beetles, Botany and Plant Pathology Department. Oregon State University.

Molnár, O., M. Wuczkowski, and H. Prillinger. 2008. Yeast biodiversity in the guts of several pests on maize; comparison of three methods: classical isolation, cloning and DGGE. Mycol. Prog. 7: 111-123.

Mouhoube, A., F. Schulthess, Y. D. Mawuena, K. F. Cardwell, and G. Cardwell. 2003. The effect of Fusarium verticilloides on oviposition behaviour and binomics of lepidopteran and coleopteran pests attacking the stem and cobs of maize in West Africa. Entomol. Exp. Appl. 106: 201-210.

Mulè, G., A. Susca, G. Stea, and A. Moretti. 2004. A species-specific PCR assay based on the calmodulin partial gene for identification of Fusarium verticillioides, F. proliferatum and F. subglutinans. Eur. J. Plant Pathol. 110: 495-502.

Munkvold, G. P. 2003. Epidemiology of Fusarium diseases and their mycotoxinss in maize. Europ. J. Plant Pathol. 109: 705-713.

Munkvold, G. P., R. L. Hellmich, and L. G. Rice. 1999. Comparison of fumonisin concentration in kernels of transgenic bt maize hybrids and nontransgenic hybrids. Plant Dis. 83: 130-138. 
Nelson, P. E., A. E. Desjardins, and D. Plattner. 1993. Fumonisins, mycotoxins produced by fusarium species: biology, chemnistry and significance. Annu. Rev. Phytopathol. 31: 233-252.

Nirenberg, H. I. 1976. Untersuchungen über die morphologische und biologische Differenzierung in der Fusarium-sektion Liseola. Mitt. Bundesforsch. 169: 1-117.

Odling-Smee, L. 2007. Biofuels bandwagon hits a rut. Nature 446: 483-483.

Palmer, L. T., and T. Kommedahl. 1969. Root-infecting fusarium species in relation to rootworm infestations in corn. Phytopathology 59: 1613-1617.

Price, D. W. 1976. Passage of Verticillium albo atrum propagules through alimentary canal of bulb mite Phytopathology 66: 46-50.

Rajeev, B., V. R. Ravishankar, and A. A. Karim. 2009. Mycotoxins in food and feed: present status and future concerns. Compr. Rev. Food Sci. F. 9: 57-81.

Rice, M. E. 2004. Transgenic rootworm corn: assessing potential agronomic, economic, and environmental benefits. Plant Health Prog.: 1-10.

Schumann, M. 2008. Fungus colonization in relation to the subterranean feeding of the western corn rootworm (Coloeptera:Chrysomelidae) in conventional and transgenic Maize, pp. 74, Imperial College, London

Short, D. E., and R. J. Luedkte. 1970. Larval migration of the western corn rootworm. J. Econ. Entomol. 63: 325 - 326.

Suttle, P. J., G. J. Musick, and M. L. Fairchild. 1967. Study of larval migration of the western corn rootwarm. J. Econ. Entomol. 60: 1226 - 1228.

Toepfer, S., M. M. Ellsbury, R. Eschen, and U. KuhImann. 2007. Spatial clustering of Diabrotica virgifera virgifera and Agriotes ustulatus in smallscale maize fields without topographic relief drift. Entomol. Exp. Appl. 124: 61-75.

Venjakob, C. 2009. Der Westliche Maiswurzelbohrer (Diabrotica virgifera virgifera LeConte) als Vektor von Pilzen der Rhizosphäre, pp. 48, Institut für Pflanzenpathologie und Pflanzenschutz. Georg-August Universität, Göttingen.

Voss, K. A., P. C. Howard, R. T. Riley, R. P. Sharma, T. J. Bucci, and R. J. Lorentzen. 2002. Carcinogenicity and mechanism of action of 
fumonisin B-1: a mycotoxin produced by Fusarium moniliforme (=F. verticillioides). Cancer Detect. Prev. 26: 1-9.

Weiss, M. J., K. P. Seevers, and Z. B. Mayo. 1985. Influence of western corn rootworm larval, densities and damage on corn rootworm survival, developmental time, size and sex ratio (Coleoptera, Chrysomelidae) J. Kans. Entomol. Soc. 58: 397-402.

Wesseler, J., and E. Fall. 2009. Benefits and costs of Diabrotica virgifera virgifera control in Europe, 23rd IWGO Conference \& 2nd International Conference of Diabrotica Genetics, Munich.

Wiggins, E. A., and E. A. Curl. 1979. Interaction of collembola and microflora of cotton rhizosphere. Phytopathology 69: 244-249.

Williams, R. H., J. M. Whipps, and R. C. Cooke. 1998. Role of soil mesofauna in dispersal of Coniothyrium minitans: Transmission to sclerotia of Sclerotinia sclerotiorum. Soil Biol. Biochem. 30: 1929-1935.

Xie, Y. S., J. T. Arnason, B. J. R. Philogene, J. Atkinson, and P. Morand. 1992. Behavioural-response of western corn rootworm larvae to naturallyoccurring and synthetic hydroxamic acids. J. Chem. Ecol. 18: 945-957.

Yue, Q., C. W. Bacon, and M. D. Richardson. 1998. Biotransformation of 2-benzoxazolinone and 6-methoxy-benzoxazolinone by Fusarium moniliforme. Phytochemistry 48: 451-454. 


\title{
Chapter 5: Interaction between western corn rootworm (Coleoptera; Chrysomelidae) and the mycorrhiza Glomus intraradices
}

\author{
B. Kurtz and S. Vidal
}

Georg-August University Göttingen, Department of Crop Science, Agricultural Entomology, Grisebachstrasse 6, 37077 Göttingen, phone:++49(0)551393728, Email: bkurtz@gwdg.de

Corresponding author: S. Vidal address as above, phone: +49(0)551-39 9744, fax: +49(0)551 -39 12105, Email: svidal@gwdg.de

\section{Abstract}

In greenhouse experiments we investigated the interaction between western corn rootworm Diabrotica v. virgifera LeConte larvae, the mycorrhiza Glomus intraradices (Smith \& Schenck), and Fusarium verticillioides (Saccardo). We analyzed western corn rootworm (WCR) development, mycorrhizal colonization and biomass production by maize plants. Maize plants were artificially inoculated with $G$. intraradices or $F$. verticillioides and planted in natural field soil in the greenhouse. WCR eggs were applied, larvae extracted from the plants and the development of the larvae was assessed by determining larval instar and third instar weight. Plant dry weight was measured and the colonization by G. intraradices was measured by using microscopical analysis of colonized root length. Glomus intraradices reduced third larval instar weight and increased the proportion of second instar larvae in comparison to the control. $F$ verticillioides did not affect third instar larval weight, but reduced the overall larval number and influenced larval instar composition. WCR larval damage did not affect mycorrhizal colonization. This study demonstrates that the colonization of the root by mycorrhizal fungi significantly influences the performance of western corn rootworm larvae. 
KEY WORDS Diabrotica virgifera virgifera, western corn rootworm, Glomus intraradices, Fusarium verticillioides, root colonization, larval development

\section{INTRODUCTION}

Supported by human transportation biological invasions can change ecosystem composition and causes biodiversity losses (Vitousek et al. 1996, Liebhold et al. 2006). The western corn rootworm Diabrotica virgifera virgifera LeConte (Coeloptera, Chrysomelidae) is an invasive maize pest in Europe that has spread from East to Central Europe in the last decade (Miller et al. 2005). Studies using microcosms with Tipula paludosa (Meigen) feeding on grassland plants (Agrostis capillaris, Trifolium repens) proved that insect root herbivores can change the composition of root colonizing micro-organisms (Grayston et al. 2001, Dawson et al. 2004). Grayston et al. (2001) suggested that changes in microbial community colonizing the root could lead to changes in nutrient and carbon cycling in the soil. In that way an invasive pest could have significant influence on ecosystem processes and performance of plants. Important micro-organisms that WCR larvae encounter are the mutualistic root colonizing arbuscular mycorrhiza (AM). Two third of the world flowering plants form associations with AM which form a group of approximately 150 different fungal species (Hodge 2000). AM built a hyphal network at the roots of their host through which they provide phosphorus and water and receive carbohydrates in return. Mycorrhiza can be found in nearly every terrestrial ecosystem and play an important role influencing soil structure, nutrient cycling, plant nutrition, plant growth and plant community structure (Ganade and Brown 1997, van der Heijden et al. 1998, Matthias C. Rillig 2006, van der Heijden and Horton 2009). AM influence water uptake, root morphology and function and can increase the productivity of maize plants especially in nutrient unbalanced or nutrient poor soils (Berta et al. 1992, Kothari et al. 1990, Sylvia et al. 1993). On the one side colonization by mycorrhiza might increase the nutritional value of the plant for the herbivore, but on the other side mycorrhizal colonization increases jasmonic acid (JA) concentrations in a variety of crop plants. High JA levels induce the activation of genes involved in plant defence response (Hunter 2000). Furthermore mycorrhiza are known to influence the production of defensive metabolites as alkaloids (Abu-Zeyad et al. 1999), monoterpenoids (Toussaint et al. 2008), diterpinoids, simple phenolics and 
glucosinolates (Vierheilig et al. 2000). Aboveground feeding of insects can have significant influence on mycorrhizal colonization (Gange et al. 2002) and even stronger effects can be expected by root feeders. However only very few studies have dealt with the interaction of insect root feeders and mycorrhizal colonization: (1) Brown and Gange (1990) speculated that root feeders might decrease the colonization of roots by mycorrhiza by feeding on colonized roots (2) Gange (2001) found no influence of Oitorynchus sulcatus (Fabricius) larvae feeding at strawberry roots on AM fungal colonization (3) Currie et al. (2006) documented that $T$. paludosa feeding increased colonization of AM fungi at Agrostis capillaris (L.). Apparently the outcome of the interaction is strongly dependent on the plant, insect and fungal species involved. Given the small number of studies that are available, it is not surprising that a consistent view has not yet been established. This work on WCR adds an interesting case study keeping in mind that WCR is invasive in Europe and is a pest of high economic importance.

\section{MATERIAL AND METHODS}

\section{Soil and plants}

We obtained Haplic Chernozem from a field close to Goettingen (for details see Tab. 1). The soil was collected to a depth of $25 \mathrm{~cm}$ from four different spots that were separated by $5 \mathrm{~m}$, and located on one transect. About $400 \mathrm{~kg}$ of soil was removed from the field and stored before use. Before the experiment began, each soil was homogenized using a "soil crusher" (Unifix 300, Moeschle, Ortenberg, Germany) and then passed through a $10-\mathrm{mm}$-mesh sieve. This procedure removed coarse material only and had minimal effect on soil composition. The whole amount of soil was mixed before starting of the experiment to ensure that the soil was as homogenous as possible. For the experiments a flint $x$ dent maize cultivar (KWS13, KWS, Einbeck, Germany) was used. Maize seeds were sterilized following the method described by Benziri et al. (1994). Sterile maize seeds were placed for three days in sterile Petri dishes with wet filter papers for germination. Finally the germinated seeds were singly planted into pots (diameter $=13 \mathrm{~cm}$ ) with Haplic Chernozem. 
Tab. 1 Characteristics of the soil used in this study. Nomenclature after Lt. FAO World Soil Resources Report, Food and Agriculture Organization of the UN, (1990)

\begin{tabular}{lc}
\hline Soil & $\begin{array}{c}\text { Haplic Chernozem } \\
(\text { silt })\end{array}$ \\
\hline Coordinates & $5130 ` 29.44 \mathrm{~N}$ \\
& 955 `38.26 E \\
Sand content (\%) & 3.7 \\
Silt content $(\%)$ & 83.8 \\
Clay content $(\%)$ & 12.6 \\
pH $\left(\mathrm{H}_{2} \mathrm{O}\right)$ & 7.6 \\
$\mathrm{C} / \mathrm{N}$ Ratio & 16.3 \\
\hline
\end{tabular}

\section{Cultivation of $\boldsymbol{F}$. verticillioides, handling of Glomus intraradices and handling of western corn rootworm}

The F. verticillioides strain FM8114 was obtained from Prof. Dr. Petr Karlovsky (Molecular Phytopathology and Mycotoxin Research, Georg August University Goettingen, Germany). F. verticillioides was cultured on Spezieller Nährstoffarmer Agar (Nirenberg 1976) before it was used for the experiment. Flask with $12 \mathrm{~g}$ of milled wheat straw and $400 \mathrm{ml}$ of bi-distilled water were prepared and autoclaved two times before use. F. verticillioides was moved from SNA to PDA (39 g/l) and from PDA to the flasks with straw. The flasks were placed for three weeks at a shaker with $100 \mathrm{rpm}$ and $25^{\circ} \mathrm{C}$. To control successful colonization of the culture, the concentration of spores was measured by using a haemocytometer (data not shown). The straw was filtered from the water by using a water jet vacuum pump. $6 \mathrm{~g}$ of wet Fusarium straw was mixed with $100 \mathrm{~g}$ of soil and applied onto the top of the soil.

Glomus intraradices (strain 501) was obtained in expanded clay material from Dr. Henning von Alten (Institute of Plant Disease and Plant Protection, University of Hannover, Germany). The inoculum was mixed as $5 \%$ of the volume into the soil before planting of the maize seeds (Dehne and Backhaus 1986). 
Diabrotica $v$. virgifera western corn rootworm eggs from the non-diapausing strain were obtained from USDA-ARS, North Central Agricultural Research Laboratory, Brookings, USA (Branson 1976). The eggs were stored in Petri dishes in the fridge at $8{ }^{\circ}$. Immediately before experiments were starte $d$, timing of larval hatch was determined using a hatch test as follows: eggs were kept at $26^{\circ} \mathrm{C}$ in $9-\mathrm{cm}$ diameter Petri dishes (100 eggs per dish) containing wet filter papers and were checked daily for larval hatching, which on average started after 14 days (data not shown).The eggs were incubated at $26^{\circ} \mathrm{C}$ and $65 \%$ rela tive humidity and checked using a dissecting microscope for visible larvae inside. After 12 days, which was 2 days before hatching, the eggs were washed on a sieve $(250 \mu \mathrm{m})$ and then transferred onto a $0.15 \%$ agar solution. Thereafter, 200 eggs where applied per plant in $2 \mathrm{ml}$ of liquid agar; these eggs were applied $5 \mathrm{~cm}$ deep in the soil with a manual hand dispenser (Multipette Plus, Eppendorf, Hamburg, Germany). Additional eggs were added to Petri dishes (ten dishes with 30 eggs per dish), as described for the hatch test above, to determine the hatch rate and to confirm that the neonates hatched on the date indicated by the initial hatch test.

\section{Experimental setup}

Six different treatments were prepared (1) with $G$. intraradices (2) with

G. intraradices and WCR (3) with WCR (4) with WCR and F. verticillioides (5) with $F$. verticillioides (6) without any inoculum $(n=12)$. $G$. intraradices was applied when the germinated seedlings were planted. From that time on the plants were kept in the greenhouse for six weeks (growth stage V7) before application of WCR eggs. Thereafter plants had twenty days to grow before the final sampling (growth stage VT). At the final sampling date plant aboveground biomass was harvested, dried at $60^{\circ} \mathrm{C}$ for five days, and weighted using a laboratory scale (TE 1502S, Sartorius, Goettingen, Germany). Additionally the roots of four plants per treatment were harvested and washed for the analysis of mycorrhizal colonization.

WCR larvae were extracted using high gradient Kempson extraction system (Kempson et al. 1968). Larvae were classified into larval stages by measuring head capsule width following Hammack et al. (2003). Additionally random subsamples of ten $3^{\text {rd }}$ instar larvae were taken from each plant for each treatment. The samples were put into a box $\left(22.5^{\star} 30 \mathrm{~cm}\right)$ with a numbered grid and larvae were taken by randomly drawing numbers. The sub-samples were put for three 
days into an incubator at $60^{\circ} \mathrm{C}$, and the dry weight of individual $3^{\text {rd }}$ instar larva was determined with a micro scale (MC5, Sartorius, Goettingen, Germany).

\section{Microscopical analysis of mycorrhizal colonization}

The complete washed roots were stained for $12 \mathrm{~h}$ in $0.1 \%$ cotton blue in $90 \%$ lactic acid. Afterwards 100 pieces of $1 \mathrm{~cm}$ length were randomly cut out of the stained root and washed for $2 \mathrm{~h}$ in $90 \%$ lactic acid. Finally the stained root pieces were analyzed under the microscope (BH2-Uma, Olympus, Tokyo, Japan) for the percentage of colonized root length according to Trouvelot et al. (1986). The following parameters were analyzed to assess mycorrhizal colonization: The colonization frequency $(\mathrm{F} \%)$ is a ratio between colonized root fragments and total number of root fragments observed. It gives an estimation of the root length colonized by the fungus. The colonization intensity (M\%) is an estimation of the amount of cortical cells occupied by AM fungal structures. The arbuscule abundance $(A \%)$ gives an estimation of the arbuscule richness in the root system. Four replicates per treatment were analyzed. All values were calculated using the program mycocalc (http://www.dijon.inra.fr/mychintec/Mycocalc$\mathrm{prg} /$ download.htm). Photos of the stained root pieces were made to document the observed colonization.

\section{Data analysis}

All statistical tests and transformations were performed using the software STATISTICA 8.0 (Statsoft, Tulsa, Oklahoma, USA). Log transformed plant dry biomass was analyzed in a multivariate ANOVA combined with a Tukey`s HSD test. The plant dry biomass served as dependent variable and the fungal treatments (Glomus, Fusarium) and treatments with and without WCR as independent variables. The overall larval number was log transformed and tested in an univariate ANOVA as dependent variable against the fungal treatments as independent variable. A Tukey`s HSD test was used to analyze the differences between the fungal treatments.

The mean values of the $3^{\text {rd }}$ instar weight were formed from the means of the subsamples per plant. These values were log transformed and applied in an univariate 
ANOVA. The $3^{\text {rd }}$ instar weight was applied as independent variable, the treatments as dependent variable and analyzed in combination with a Fisher LSD test. For the analyzes of the composition of larval instars the numbers of $2^{\text {nd }}$ and $3^{\text {rd }}$ instar larvae were transformed by using the formula (number $3^{\text {rd }}$ instar larvaenumber $2^{\text {nd }}$ instar larvae) $+\mathrm{K}$, where $\mathrm{K}$ is a constant used to avoid negative values. The calculated values were analyzed using univariate general linear models with the calculated value of $2^{\text {nd }}$ and $3^{\text {rd }}$ larval instar as a dependent variable and the treatment as independent variables. Differences among the fungal treatments were tested using the Tukey`s HSD test.

For the statistical analysis of mycorrhizal colonization the percentages of colonized root length were arcsin transformed. The transformed values were analyzed as dependent variables and the treatment (Glomus, Glomus \& WCR and Control) as independent variable in a univariate ANOVA.

\section{RESULTS}

\section{Maize dry weight}

The aboveground dry biomass did not differ between WCR ( $d f=1, F=3.14, p=0.08$ ) or fungal treatments $(d f=2, F=0.63, p=00.53$, Fig. 1 ).

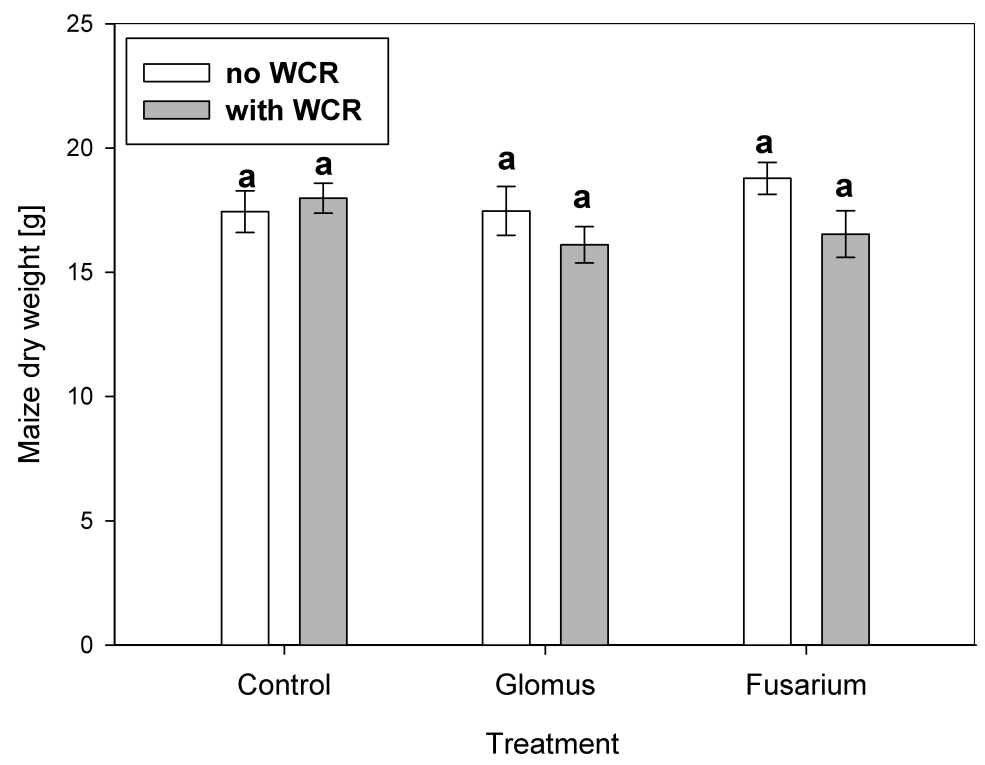

Fig. 1 Aboveground biomass of maize plants (mean $\pm S E, n=12$ ) treated with three different fungal treatments (Control= no fungus applied, Glomus=Glomus 
intraradices, Fusarium=Fusarium verticillioides) and western corn rootworm (WCR, with and without WCR). Letters above columns indicate significance of difference according to ANOVA $<0.05$.

\section{Western corn rootworm development}

The total number of larvae found in the Control treatment did not differ from the number found in the Glomus treatment, but numbers were significantly smaller in the Fusarium treatment (Fig. 2). The composition of larval instars significantly differed between the Control and the two fungal treatments (Control vs. Fusarium $d f=41, p<0.05$, Control vs. Glomus $d f=41, p<0.05$ ). The weight of $3^{\text {rd }}$ larval stage was significantly lower in the Glomus treatment in comparison to the Control $(d f=37, p<0.05)$, while no effect was found between Fusarium was found compared to the Control treatment $(d f=37, p=0.14$, Fig. 3 ).

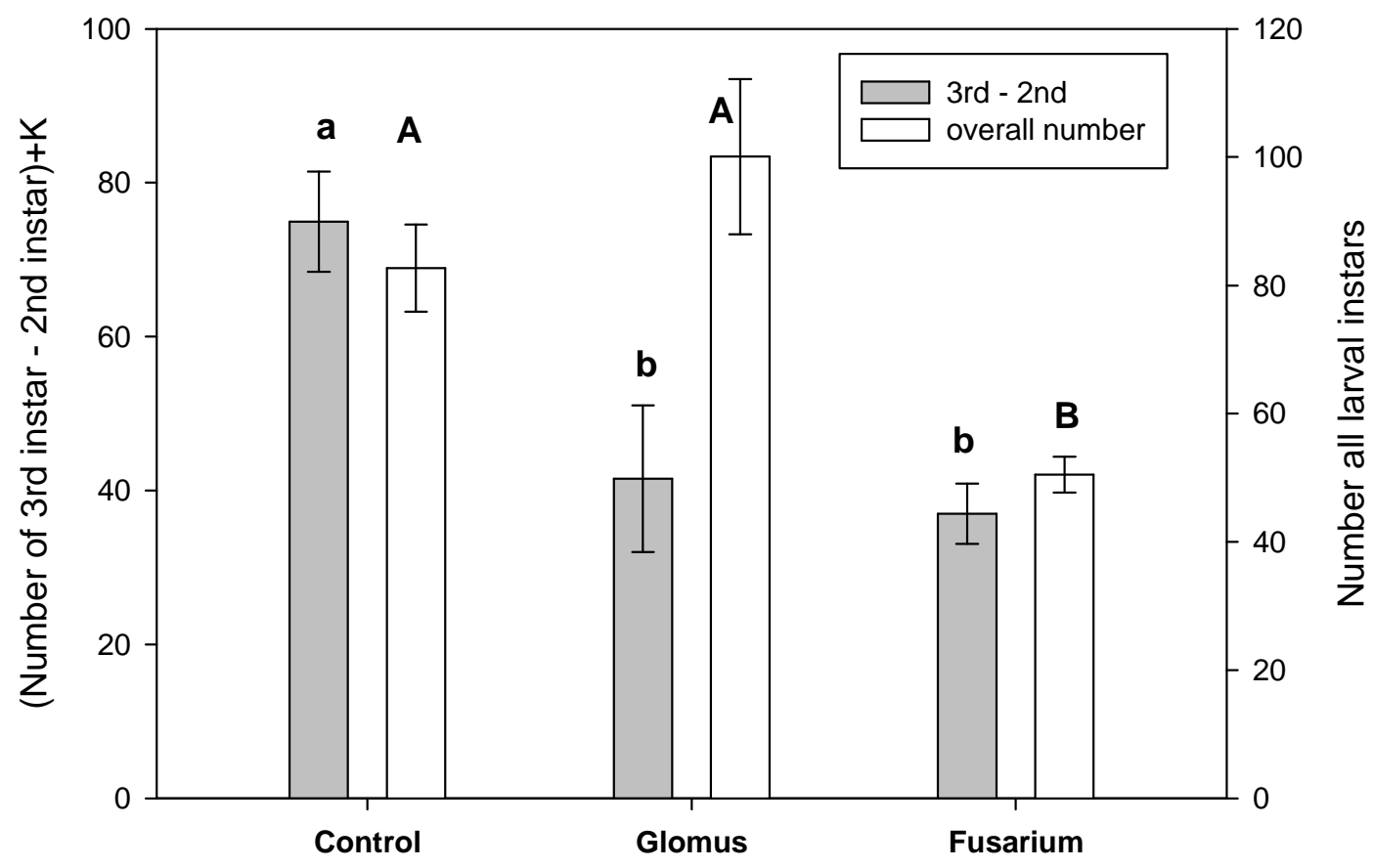

Treatment

Fig. 2 Composition of western corn rootworm second and third instar (mean \pm SE) and overall number of larvae (mean $\pm \mathrm{SE}$ ) as affected by different fungal treatments ( $n=12$, Control= no fungus applied, Glomus=Glomus intraradices, Fusarium=Fusarium verticillioides). Lowercase letters above columns indicate significance of difference between larval instar composition, while uppercase 
letters indicate significance of difference between overall larval number according to ANOVA $<0.05 . \mu$

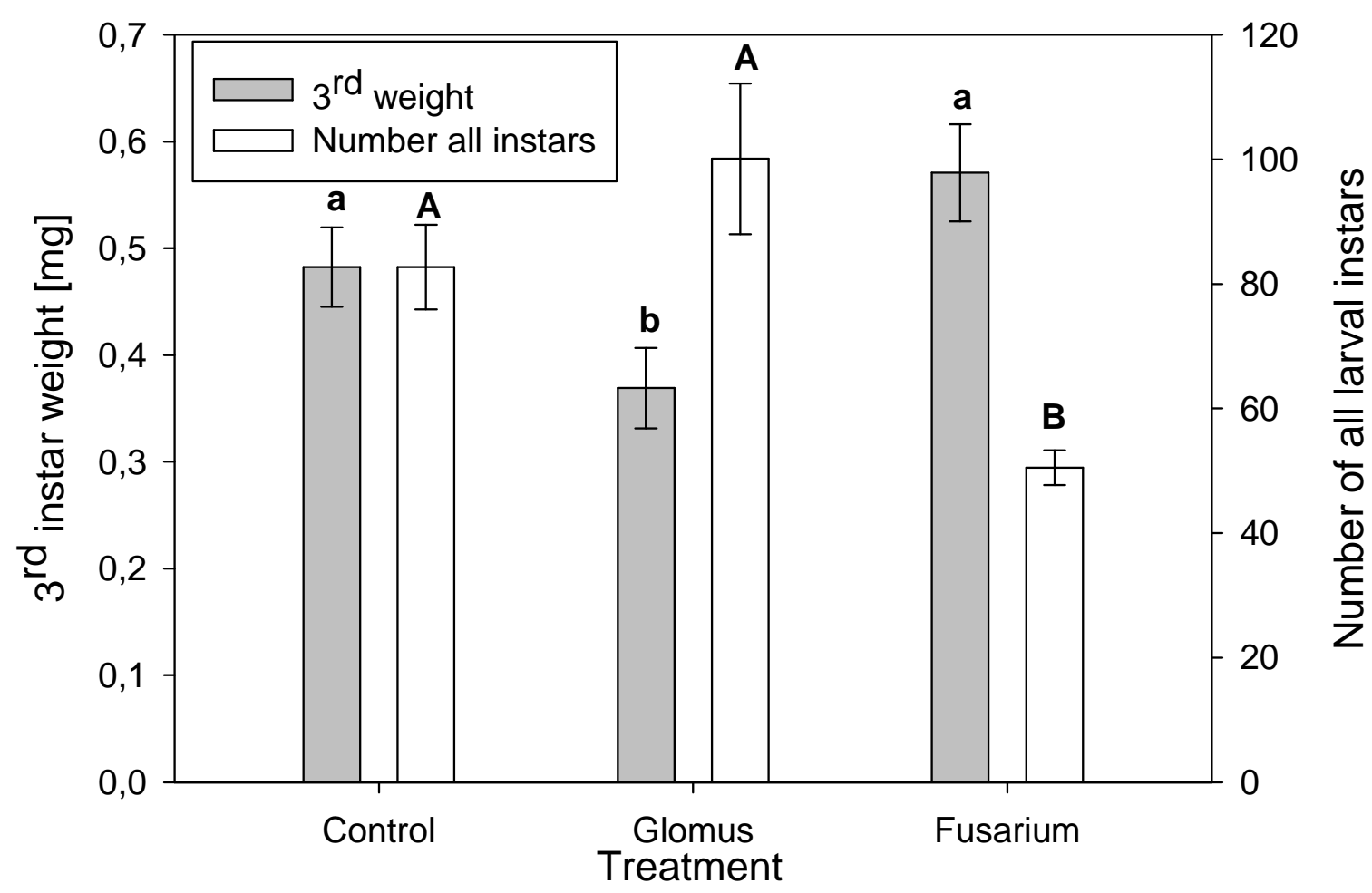

Fig. 3 Third instar weight (mean \pm SE) and overall number of western corn rootworm larvae (mean $\pm S E$ ) as affected by different fungal treatments $(n=12$, Control= no fungus applied, Glomus=Glomus intraradices, Fusarium=Fusarium verticillioides). Lowercase letters above columns indicate significance of difference between $3^{\text {rd }}$ instar weight, while uppercase letters indicate significance of difference between overall larval number according to ANOVA $<0.05$.

\section{Mycorrhizal colonization}

In the treatments were Glomus intraradices was applied the colonization frequency, colonization intensity and arbuscular abundance was significantly higher in comparison to the control $(\mathrm{df}=2, \mathrm{~F}=10.1, \mathrm{p}<0.05)$. However WCR larval presence did not affect any of the measured parameters characterizing mycorrhizal colonization (Fig.5). 


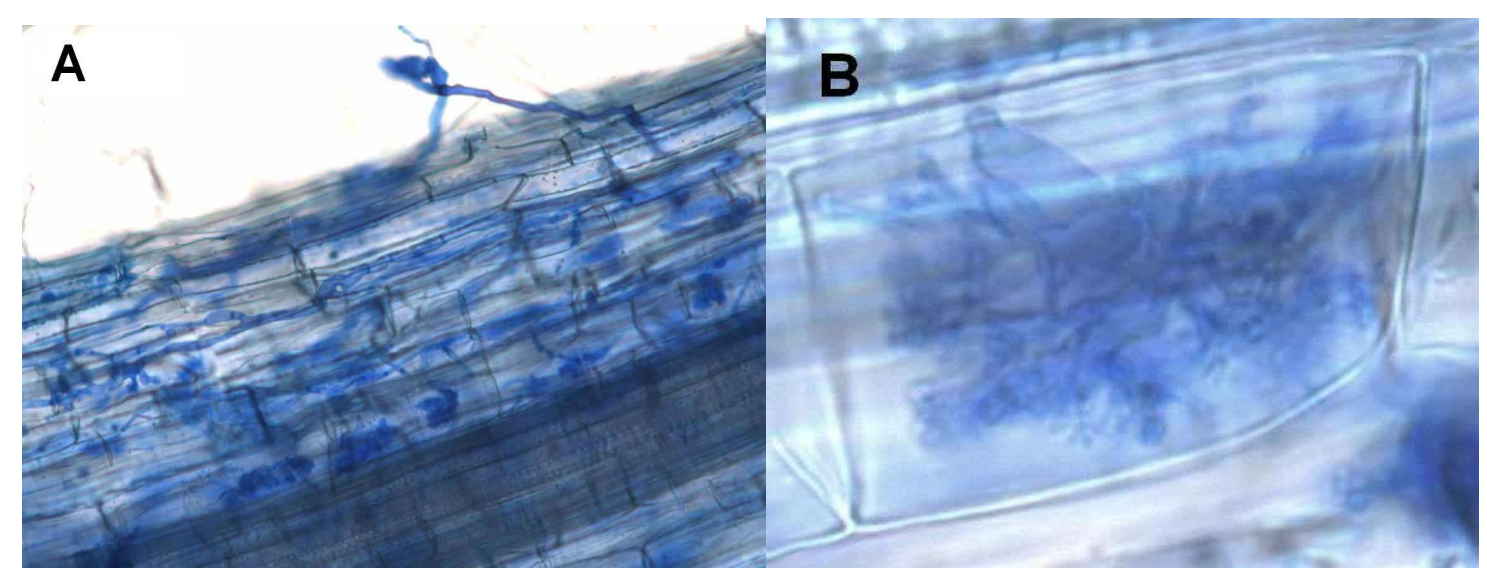

Fig. 4 (A) Mycorrhizal hyphae colonizing root and (B) rot cell with arbuscle after staining with cotton blue.

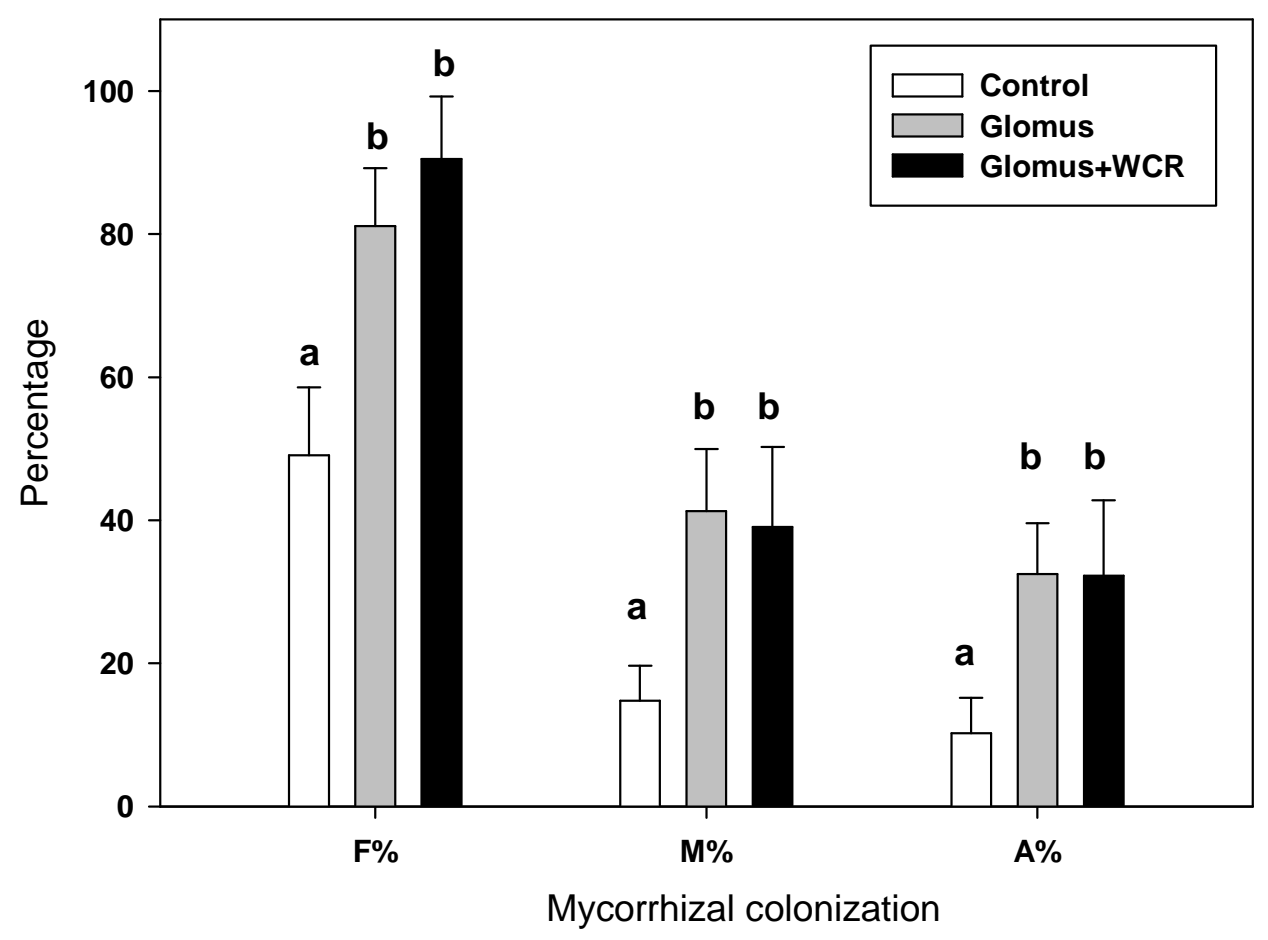

Fig. 5 Mycorrhizal colonization (mean+SE) of maize plants measured as F\% = frequency of mycorrhiza colonization in the root system, $\mathrm{M} \%=$ Intensity of root colonization and $A \%=$ arbuscle abundance in the root system, for plants treated with different treatments $(n=4$, Control=no application, Glomus=Glomus intraradices applied, Glomus+WCR=Glomus intraradices+western corn rootworm). Letters above columns indicate significance of difference according to ANOVA $<0.05$. 


\section{DISCUSSION}

The presented research documented that Glomus intraradices and Fusarium verticillioides colonizing the root signififcantly influences western corn rootworm larval development. The influence and the interaction between fungus and WCR larvae however vary depending on the specific fungus. F. verticillioides increased proportion of $2^{\text {nd }}$ larval instars and increased the mortality of WCR larvae, whereas no influence on $3^{\text {rd }}$ larval instar weight occured. In contrast $G$. intraradices had no influence on WCR mortality but increased the proportion of $2^{\text {nd }}$ larval instars and decreased $3^{\text {rd }}$ larval instars weight. This finding is consistent with results by Joachim Moeser (unpublished data), who demonstrated that WCR larval weight gain was reduced when feeding on $G$. intraradices colonized roots. Gange et al. (1994) reported decreased survival of Oitorhynchus sulcatus (Fabricius) black vine weevil larvae, which had fed on dandelion roots colonized by Glomus mossae (Nicol and Gerd). In study by Gange (2001) it was documented that $G$. intraradices when colonizing the root alone had a negative effect on $O$. sulcatus larval survival and biomass, while this effect was not present when $G$. intraradices and $G$. mossae colonized the root together. In a meta-analysis Koricheva et al. (2009) documented that studies on the effects of mycorrhiza on insect herbivores that used $G$. intraradices, showed a clear negative effect of this fungus on insect performance.

In general, roots can contain defensive compounds similarly as shoots do. Alkaloids, phenolics, terpenoids, furanocoumarins and cardenolidas have been found in roots (Zangerl and Rutledge 1996, Bezemer et al. 2004, Kaplan et al. 2008, Rasmann et al. 2009). Stevenson et al. (2009) documented that the survival of African sweetpotato weevil was significantly reduced when feeding on an artificial diet, which had been enriched with phenolic esters from a root of a resistant sweet potato variety. Mycorrhiza can alter the production of defensive compounds as already mentioned (review by van Dam 2009).

It was demonstrated that the colonization of maize roots by $G$. intraradices induced an increase in the content of abscisic acid (ABA) in the root and shoot (Danneberg et al. 1992). An increase in ABA content in root and shoot of maize plants was also reported when WCR larvae were feeding at the maize roots (Erb 
et al. 2009). So the early induction of plant defence by the mycorrhiza through increased ABA levels could retard WCR development.

Mycorrhiza in natural soils is spatially heterogeneous (Allen 1991). In case WCR larvae are deterred by AM colonized plants as they are by $F$. verticillioides colonized plants (Chapter 4., Kurtz and Vidal 2010, in prep.), this would support clumped distribution of WCR larvae as it is found in the natural field situation (Toepfer et al. 2007).

The produced biomass was not significantly different in the various treatments. Our results support the observations from other studies that the quantity of plant biomass is not a crucial factor influencing WCR larval development (Branson et al. 1982, Allee and Davis 1996, Kurtz et al. 2010).

In addition to the results of Kurtz et al. (2010) where a reduced development of larvae was found, this time increased mortality was observed. Here we used a different strain (FM8114 vs. DSM6224), which might have been more virulent and differed in the production of mycotoxins.

If mortality is increased by the influence of $F$. verticillioides, competition is reduced and the surviving larvae occupy the best spots in the root system and are therefore well developed. Intra-specific competition can have significant influence on the fitness of WCR as it was documented by Branson and Sutter (1985) in a study that investigated the influence of different egg densities on adult survival, fecundity and longevity. This might be the reason why no influence of F. verticillioides application on $3^{\text {rd }}$ instar weight was observed.

Field soils harbour a community of different mycorrhiza (Siddiqui et al. 2008) so it is not suprising that without application of $G$. intraradices, $49 \%$ of the root length (F\%) of control plants was colonized. The application of $G$. intraradices enhanced the colonized root length ( $81 \%$ Glomus only) but larval feeding did not significantly affect colonization ( $90 \%$ Glomus and WCR).

Rodriguez-Echeverria et al. (2009) documented that root feeding by nematodes (Pratylenchus penetrans and $P$. dunensis) on Ammophila arenaria did not change the total percentage and composition of exterior AM colonization. In a study by Gange (2001) it was reported that feeding by $O$. sulcatus larvae on strawberry roots did not influence colonization by Glomus intararadices and or Glomus mosseae. Mycorrhiza do not enter plant roots through wounds so this would not 
have been a possible way of interaction (Hayman 1983). WCR larvae can induce physiological changes in the plant, which could have been a possible way to affect mycorrhizal colonization. WCR larvae can reduce $\mathrm{CO}_{2}$ assimilation and plant growth but the effects depend on the phenological stage of the attacked plant and cultivars differ in their susceptibility (Godfrey et al. 1993, Hou et al. 1997, Riedell and Reese 1999). Under well-watered conditions as in the presented study, WCR larvae neither reduce stomatal conductance or net photosynthetic rate (Dunn and Frommelt 1998). So under water stress an influence on mycorrhizal colonization might have been more probable.

This study demonstrated that mycorrhiza delay the development of western corn rootworm larvae and that western corn rootworm larval feeding does not affect mycorrhizal colonization of maize roots.

\section{ACKNOWLEDGEMENTS}

We thank Flavia Dematheis for support working with the mycorrhiza, Patricia Bartoschek for help carrying out the real-time PCR and Wade French, (USDAARS, Brookings, SD) for providing the western corn rootworm eggs. The soil was analyzed by Karin Schmidt from the Institute of Soil Science (Georg-August University, Goettingen). This work was funded by the DFG (German Research Foundation).

\section{REFERENCES}

Allen, M. F. 1991. The ecology of mycorrhizae. University Press, Cambridge. Abu-Zeyad, R., A. G. Khan, and C. Khoo. 1999. Occurrence of arbuscular mycorrhiza in Castanospermum australe A. Cunn. \& C. Fraser and effects on growth and production of castanospermine. Mycorrhiza 9: 111-117.

Allee, L. L., and P. M. Davis. 1996. Effect of manure and corn hybrid on survival of western corn rootworm (Coleoptera: Chrysomelidae). Environ. Entomol. 25: 801-809. 
Benziri, E., A. Courtade, and A. Guckert. 1994. Fate of two microorganisms in maize simulated rhizosphere under hydroponic and sterile conditions. Soil Biol. Biochem. 27: 71-77.

Berta, G., A. Fusconi, and A. Trotta. 1992. VA mycorrhizal infection and the morphology and function of root systems. Environ. Exp. Bot. 33: 159-173.

Bezemer, T. M., R. Wagenaar, N. M. Van Dam, W. H. Van Der Putten, and F. L. Wackers. 2004. Above- and below-ground terpenoid aldehyde induction in cotton, Gossypium herbaceum, following root and leaf injury. J. Chem. Ecol. 30: 53-67.

Branson, T. F. 1976. The selection of a non-diapause strain of Diabrotica virgifera (Coleoptera: Chrysomelidae). Entomol. exp. appl. 19: 148-154.

Branson, T. F., and G. R. Sutter. 1985. Influence of Population Density of Immatures on Size, Longevity, and Fecundity of Adult Diabrotica virgifera virgifera (Coleoptera: Chrysomelidae). Environ. Entomol. 14: 687-690.

Branson, T. F., G. R. Sutter, and J. R. Fisher. 1982. Comparison of a tolerant and a susceptible maize inbred under artificial infestations of Diabrotica virgifera virgifera: Yield and adult emergence. Environ. Entomol. 11: 371372.

Brown, V. K., and A. C. Gange. 1990. Insect herbivory below ground. Adv. Ecol. Res. 20: 1-59.

Currie, A. F., P. J. Murray, and A. C. Gange. 2006. Root herbivory by Tipula paludosa larvae increases colonization of Agriostis capillaris by arbuscular mycorrhizal fungi. Soil Biol. Biochem. 38: 1994-1997.

Danneberg, G., C. Latus, W. Zimmer, B. Hundeshagen, H. SchneiderPoetsch, and H. Bothe. 1992. Influence of vesicular-arbuscular mycorrhiza on phytohormone balances in maize (Zea mays L.). J. Plant Physiol. 141: 33-39.

Dawson, L. A., S. J. Grayston, P. J. Murray, J. Ross, E. J. Reid, and A. M. Treonis. 2004. Impact of Tipula paludosa larvae on plant growth and soil microbial community. Appl. Soil Ecol. 25: 51-61.

Dehne, H.-W., and G. F. Backhaus. 1986. The use of vesicular-arbuscular mycorrhizal fungi in plant production. Z. PflKrankh. Pflanzenschutz 93: 415424. 
Dunn, J. P., and K. Frommelt. 1998. Effects of below-ground herbivory by Diabrotica virgifera virgifera (Col., Chrysomelidea) and soil moisture on leaf gas exchange of maize. Appl. Soil Ecol. 122: 179-183.

Erb, M., V. Flors, D. Karlen, E. d. Lange, C. Planchamp, M. D'Alessandro, T. C. J. Turlings, and J. Ton. 2009. Signal signature of aboveground-induced resistance upon belowground herbivory in maize. Plant J. 59: 292-302.

FAO, 1990. World Soil Resources Report 60, Food and Agriculture Organization of the United Nations, Rome, Italy

Ganade, G., and V. K. Brown. 1997. Effects of below-ground insects, mycorrhizal fungi and soil fertility on the establishment of Vicia in grassland communities. Oecologia 109: 374-381.

Gange, A. 2001. Species-specific responses of a root- and shoot-feeding insect to arbuscular mycorrhizal colonization of its host plant. New Phytol. 150: 611618.

Gange, A., V. K. Brown, and G. S. Sinclair. 1994. Reduction of black vine weevil larval growth by vesicular-arbuscular mycorrhizal infection. Entomol. exp. appl. 70: 115-119.

Gange, A. C., E. Bower, and V. K. Brown. 2002. Differential effects of insect herbivory on arbuscular mycorrhizal colonization. Oecologia 131: 103-112.

Grayston, S. J., L. A. Dawson, A. M. Treonis, P. J. Murray, J. Ross, E. J. Reid, and R. MacDougall. 2001. Impact of root herbivory by insect larvae on soil microbial communities. Eur. J. Soil Biol. 37: 277-280.

Godfrey, L. D., L. J. Meinke, and R. J. Wright. 1993. Vegetative and reproductive biomass accumulation in field corn: response to root injury by western corn rootworm (Coleoptera: Chrysomelidae). J. Econ. Entomol. 86: 1557-1573.

Hammack, L., M. M. Ellsbury, R. L. Roehrdanz, and J. L. Pikul, Jr. 2003. Larval sampling and instar determination in field populations of northern and western corn rootworm (Coleoptera: Chrysomelidae). J. Econ. Entomol. 96: 1153-1159.

Hayman, D. S. 1983. The physiology of vesicular-arbuscular endomycorrhizal symbiosis. Can. J. Bot. 61: 944-963.

Hodge, A. 2000. Microbial ecology of the arbuscular mycorrhiza. FEMS Microbiol. Ecol. 32: 91-96. 
Hou, X., L. J. Meinke, and T. J. Arkebauer. 1997. Soil moisture and larval western corn rootworm injury: Influence on gas exchange parameters in corn. Agron. J. 89: 709-717.

Hunter, M. D. 2000. Mixed signals and cross-talk: interactions between plants, insect herbivores and plant pathogens. Agr. Forest Entomol. 2: 155-160.

Kaplan, I., R. Halitschke, A. Kessler, S. Sardanelli, and R. F. Denno. 2008. Constitutive and induced defenses to herbivory in above- and belowground plant tissues. Ecology 89: 392-406.

Kempson, D., M. Lloyd, and R. Ghelardy. 1968. A new extractor for woodland litter. Pedobiologia 3: 1-30.

Koricheva, J., A. C. Gange, and T. Jones. 2009. Effects of mycorrhizal fungi on insect herbivores: a meta-analysis. Ecology 90: 2088-2097.

Kothari, S. K., H. Marschner, and E. George. 1990. Effect of Va Mycorrhizal Fungi and Rhizosphere Microorganisms on Root and Shoot Morphology, Growth and Water Relations in Maize. New Phytol. 116: 303-311.

Kurtz, B., Karlovsky P., and S. Vidal. 2010. Interaction between western corn rootworm (Coleoptera: Chrysomelidae) larvae and root-infecting Fusarium verticillioides. Environ. Entomol. (accepted for publication).

Liebhold, A. M., T. T. Work, D. G. Mccullough, and J. F. Cavey. 2006. Airline baggage as a pathway for alien insect species invading the United States. Am. Entomol. 52: 48-54.

Matthias C. Rillig, D. L. M. 2006. Mycorrhizas and soil structure. New Phytol. 171: 41-53.

Miller, N., A. Estoup, S. Toepfer, D. Bourguet, L. Lapchin, S. Derridj, K. Kim, P. Reynaud, L. Furlan, and T. Guillemaud. 2005. Multiple transatlantic introductions of the western corn rootworm. Science 310: 992.

Nirenberg, H. I. 1976. Untersuchungen über die morphologische und biologische Differenzierung in der Fusarium-sektion Liseola. Mitt. Bundesforsch. 169: 1-117.

Rasmann, S., A. A. Agrawal, S. C. Cook, and A. C. Erwin. 2009. Cardenolides, induced responses, and interactions between above- and belowground herbivores of milkweed (Asclepias spp.). Ecology 90: 2393-2404. 
Riedell, W. E., and R. N. Reese. 1999. Maize morphology and shoot CO2 assimilation after root damage by western corn rootworm larvae. Crop Sci. 39: $1332-1340$.

Rillig, M. C., and D. L. Mummey. 2006. Mycorrhizas and soil structure. New Phytol. 171: 41-53.

Rodriguez-Echeverria, S., E. de la Pena, M. Moens, H. Freitas, and W. H. van der Putten. 2009. Can root-feeders alter the composition of AMF communities? Experimental evidence from the dune grass Ammophila arenaria. Basic Appl. Ecol. 10: 131-140.

Siddiqui, Z. A., M. S. Akthar, and F. Kazuyoshi. 2008. Mycorrhiza: Sustainable Agriculture and Forestry. Springer, Dordrecht, The Netherlands.

Stevenson, P. C., H. Muyinza, D. R. Hall, E. A. Porter, D. I. Farman, H. Talwana, and R. O. M. Mwanga. 2009. Chemical basis for resistance in sweetpotato Ipomoea batatas to the sweetpotato weevil Cylas puncticollis. Pure Appl. Chem. 81: 141-151.

Sylvia, D. M., L. C. Hammond, J. M. Bennett, J. H. Haas, and S. B. Linda. 1993. Field response of maize to a Vam fungus and water management. Agron. J. 85: 193-198.

Toepfer, S., M. M. Ellsbury, R. Eschen, and U. KuhImann. 2007. Spatial clustering of Diabrotica virgifera virgifera and Agriotes ustulatus in smallscale maize fields without topographic relief drift. Entomol. Exp. Appl. 124: 61-75.

Toussaint, J. P., M. Kraml, M. Nell, S. E. Smith, F. A. Smith, S. Steinkellner, C. Schmiderer, H. Vierheilig, and J. Novak. 2008. Effect of Glomus mosseae on concentrations of rosmarinic and caffeic acids and essential oil compounds in basil inoculated with Fusarium oxysporum f.sp basilici. Plant Pathol. 57: 1109-1116.

Trouvelot, A., J. L. Kough, and V. Gianinazzi-Pearson. 1986. Mesure du taux de mycorhization VA d'un syste 'me radiculaire. Recherche de me'thodes d'estimation ayant une signification fonctionnelle., pp. 217-221. In V.

Gianinazzi-Pearson and S. Gianinazzi [eds.], Physiological and Genetical Aspects of Mycorrhizae. INRA Press, Paris.

van Dam, N. M. 2009. Belowground Herbivory and Plant Defenses. Annu. Rev. Ecol. Evol. Syst. 40: 373-391. 
van der Heijden, M. G. A., and T. R. Horton. 2009. Socialism in soil? The importance of mycorrhizal fungal networks for facilitation in natural ecosystems. J. Ecol. 97: 1139-1150.

van der Heijden, M. G. A., T. Boller, A. Wiemken, and I. R. Sanders. 1998.

Different arbuscular mycorrhizal fungal species are potential determinants of plant community structure Ecology 79: 2082-2091.

Vierheilig, H., R. Bennett, G. Kiddle, M. Kaldorf, and J. Ludwig-Muller. 2000. Differences in glucosinolate patterns and arbuscular mycorrhizal status of glucosinolate-containing plant species. New Phytol. 146: 343-352.

Vitousek, M., C. Dantonio, L. Loope, and R. Westbrooks. 1996. Biological Invasions as Global Environmental Change. Am. Sci. 84: 468-478.

Zangerl, A. R., and C. E. Rutledge. 1996. The probability of attack and patterns of constitutive and induced defense: A test of optimal defense theory. Am. Nat. 147: 599-608. 


\section{General Discussion}

The rhizosphere is a centre of high biological, chemical and physical activity surrounding the plant root, distinguishing it from the bulk soil. It is colonized by a diverse community of archea, bacteria, actinomycetes, protists and fungi influencing each other across spatial and temporal scales. The exchange of organic carbon, mineral nutrients and water by this microbial community is a driver of energy flow and ecosystem processes (Cardon and Whitbeck 2007). The microbial community can be divided into functional subsets such as plant growth promoting bacteria (Dalmastri et al. 2003), nitrifiers (Priha et al. 1999) and mycorrhizal fungi (Hodge 2000). Root feeding insects must compulsorily come into contact with these organisms; however, there is not much information available on the interactions taking place between these organisms.

These interactions are of special interest with regard to invasive root feeding insect species spreading into a new area of distribution. An interesting example of such a case is the western corn rootworm (WCR, Diabrotica $v$. virgifera LeConte). It is the most important maize pest in the USA that has been introduced into Europe and has spread since then to many countries on the continent (Meinke et al. 2009). We concentrated on the interaction between WCR larvae, a plant pathogenic fungus (Fusarium verticillioides (Saccardo) Nirenberg (synonym $=F$. moniliforme)) and a mutualistic mycorrhiza (Glomus intraradices Schenck and Smith).

The mechanisms by which root colonizing fungi and root feeding insects influence each other may be regarded as direct ones, either the production of toxic metabolites by the fungus or active removal of fungal structures by the insect. Fusaric acids, picolinic acids or beauvericin are mycotoxins that are produced by Fusarium spp. and inhibit defensive enzymes in insects and plants (Dowd 1999). On the other hand, WCR larvae might remove fungal structures when feeding on maize roots.

A second way of influencing each other is related to the indirect change of the physiological state of the plant and plant's exudates. For example, mycorrhiza change the physiological state of a plant, influencing water and nutrient uptake (Smith and Reed 2008), root morphology (Kaldorf 2000), plant defensive 
metabolites (Bi et al. 2007) and plant hormones (Shaul-Keinan et al. 2002, Hause et al. 2007). Mycorrhizal growth also induces an increase in jasmonic acid levels resulting in the activation of genes involved in plant defence responses (Hunter 2000, Hause et al. 2007). WCR larval feeding induces an increase in abscisic acid levels in roots and shoots (Erb et al. 2009). Especially under water stress conditions WCR larval damage reduces the photosynthetic rate and stomatal conductance in maize plants (Godfrey et al. 1993, Hou et al. 1997, Riedell and Reese 1999).

\section{Influence of soil type and maize cultivar on western corn rootworm development}

The influence of soil type and maize cultivar on WCR development was included into the study as different soil types harbour different fungal communities (Singh 2007), which might interact with WCR larvae. Our cooperation partners Flavia Dematheis and Prof Dr. Kornelia Smalla (Institute of Epidemiology and Pathogen Diagnostics, Julius-Kühn Institute, Braunschweig) investgated the structure of fungal communities colonizing the root with denaturing gradient gel electrophoresis (DGAAE). Their results show that fungal communities differed between soil types and that in Haplic Chernozem no effect of WCR larval feeding on fungal community structure occurred. For the two other soil types no final results are available yet. In combination with our own results this finding show that fungal community structure had neither a strong effect on WCR larval development nor did it influence the suitability of maize cultivars for WCR development. Because susceptible cultivars significantly differ in their suitability to support WCR development, selecting the least suitable cultivar can already help to delay WCR population built up.

\section{Interaction of western corn rootworm with the root infecting plant pathogen Fusarium verticillioides}

We quantified the increase in $F$. verticillioides root colonization caused by WCR larval feeding, and were able to demonstrate that especially when the fungus is given time to colonize the roots before insect damage, root colonization is increased up to 50 -fold. This may be due to the longer time the fungus is able to spread into the root system entering the wounds as early as they are created. 
These experiments also showed that the fungus did not benefit from older wounds. When the fungus was applied later than the insect, fungal colonization was not enhanced.

Different studies have shown that the fungus is able to move from the colonized root up to the kernels of the plant (Kedera et al. 1994, Munkvold et al. 1996, Munkvold and Carlton 1997, Bacon et al. 2001). Different studies by Munkvold (Munkvold et al. 1996, Munkvold and Carlton 1997) demonstrated that the limiting step in this movement appear from the crown to the stalk and much less from stalk to ear. In this work we demonstrated for the first time that WCR larval feeding causes increased systemic colonization in lower stalk parts, bridging this gap. For that reason we expect that WCR larval damage also increases the colonization of upper parts of the plant and may therefore enhance mycotoxin conatminations. So far systemic infections were thought to be caused primarily by early infection of the seeds (Foley 1962, Oren et al. 2003). Systemic infections can contribute to mycotoxin contaminations in maize (Desjardins and Plattner 2000, Desjardins et al. 2002), but root feeders have not been considered in risk assessment models for fumonisin contamination (Maiorano et al. 2009).

We conclude that in areas with intensive maize production where WCR and F. verticillioides are present, an effective control of WCR larvae reduces systemic F. verticillioides colonization. Comparing our results with data from Schumann (2008), no acceleration of $F$. verticillioides colonization by WCR occurs in Bt maize at low to medium fungal inoculum densities in the soil. However, as Schumann (2008) reported, at high $F$. verticillioides inoculum densities in the soil, enhancement of root colonization can be even higher in Bt maize than in conventional cultivars. To our knowledge no data on the quantification of natural spore densities of $F$. verticillioides in field soils is available. Nevertheless we would expect that as the inoculum used in the experiment was cultured under optimized conditions, with competing fungi being excluded and placed close to the plant, these are rather optimal conditions in comparison to the field situation. This means that in general, under natural conditions Bt maize might be able to reduce Fusarium colonization due to WCR larval damage. Maize production will increase due to the growing production of renewable energy (Holm-Nielsen et al. 2006, Odling-Smee 2007) and an increase in temperatures going along with the climate change is observed (Annette et al. 2006). F. verticillioides is the most common 
Fusarium species in maize in Southern Europe (Miraglia et al. 2009) and this fungus is favoured by hot and dry conditions (Doohan et al. 2003). Fumonisin production by $F$. verticillioides has been associated with dry weather during grain filling and late season rains (Munkvold et al. 1997). Consequently the predicted climate change will favour $F$. verticillioides infections and fumonisin contamination in maize (Miraglia et al. 2009). In Europe WCR as well will benefit from increasing temperatures. Bernardi (2001) carried out a mapping of WCR to analyze the potential areas in Europe where WCR could become establish. In parts of Europe that are currently on the edge of the European WCR distribution (e.g. United Kingdom), because of climatic limitations for WCR development, increasing temperatures will met the requirements for WCR population buildup (Baker et al. 2003). Thus, future increase in maize production and climate change will promote both the spread of WCR in Europe and the occurrence of $F$. verticillioides infections. Therefore it is necessary to analyze the potential risk for plant and animal health ariseing from these interactions.

Based on the results of Palmer and Kommedahl (1969) who found Fusarium spp. to be transported by Diabrotic longicornis (Say) northern corn rootworm larvae, we tested the ability of WCR larvae to orientate towards plants colonized by $F$. verticillioides and to transmit $F$. verticillioides to non colonized plants. We were able to demonstrate that WCR larvae are deterred by $F$. verticillioides colonized plants. F. verticillioides may elicit an antixenotic behaviour and therefore contributes to the clumped distributions observed under field conditions (Toepfer et al. 2007). Yue et al. (1998) documented that $F$. verticillioides can break down 6-methoxy-2-benzoxazolinone (MBOA), a semiochemical involved in host location by WCR (Bjostad and Hibbard 1992). This mechanism would be a possible explanation for our observation, but more detailed studies are needed to test this hypothesis.

As WCR larval development is delayed by $F$. verticillioides root colonization, larvae benefit from their avoidance behaviour. Although larvae were able to passively carry $F$. verticillioides with them, they did not induce colonization in previously not colonized plants. Therefore we rejected our hypothesis that WCR larvae act as belowground vectors of $F$. verticillioides.

It would have been a possible mechanism for $F$. verticillioides to influences WCR development by changing the nutritional quality of the root. However as we have 
been able to demonstrate that $F$. verticillioides influences WCR development acutely, this mechanism becomes less probable. Instead $F$. verticillioides is known to produce several mycotoxins (Nelson 1992) which may influence WCR development. Specifically fusaric acid and beauvericin are inhibitors of phenoloxidase, an enzyme responsible for wound healing and pathogen encapsulation in insects (Dowd 1999).

\section{Interaction of western corn rootworm with the mutualistic mycorrhiza}

\section{Glomus intraradices}

In contrast to the results on the interaction with $F$. verticillioides, WCR larval feeding had no influence on the colonization of the roots by the mycorrhizal fungus G. intraradices. Because mycorrhiza do not enter plant roots via wounds this way of interaction was less likely to occur (Hayman1983). Comparably, Gange (2001) documented no influence of $O$. sulcatus larvae feeding on strawberry roots colonized by Glomus intararadices (Schenk \& Smith) and or Glomus mosseae (Nicol. \& Gerd.). WCR larvae are reported to induce physiological changes in damaged plants (Hou et al. 1997, Riedell and Reese 1999, Erb et al. 2009) thereby possibly influencing mycorrhizal colonization. WCR larvae are able to reduce $\mathrm{CO}_{2}$ assimilation and plant growth; however the effects depend on the phenological stage of the attacked plant and cultivars differ in their susceptibility (Godfrey et al. 1993, Hou et al. 1997, Riedell and Reese 1999). Under well watered conditions as in the presented study, WCR larvae neither reduce stomatal conductance nor net photosynthetic rate (Dunn and Frommelt 1998). Therefore an influence on mycorrhizal colonization under water stress might have been more probable.

Glomus intraradices had a negative effect on WCR development. This has been reported in other studies investigating interactions between root feeding insects and mycorrhiza (Moeser pers. comm., Gange et al. 1994, Koricheva et al. 2009). In our experiments no secondary compounds or quality parameters of the plants were measured, being of importance for the development of root feeding insects (e.g. $\mathrm{C} / \mathrm{N}$ ratio, phytosterol content). We can only speculate on the underlying mechanisms causing the observed effects. In general roots contain defensive compounds in a similar way shoots do. Defensive compounds found in roots comprise alkaloids, phenolics, terpenoids, furanocoumarins and cardenolidas 
(Zangerl and Rutledge 1996, Bezemer et al. 2004, Kaplan et al. 2008, Rasmann et al. 2009). Different allocation patterns are reported for different groups of defensive compounds. While alkaloids tend to be higher in aboveground parts, phenolics and terpenoids are evenly distributed and glucosinolates tend to be higher in roots (van Dam 2009). Mycorrhiza can alter the quantity of defensive compounds as alkaloids (Abu-Zeyad et al. 1999), monoterpenoids (Toussaint et al. 2008), diterpinoids, simple phenolics and glucosinolates (Vierheilig et al. 2000) in plants. In this way mycorrhiza might increase the resistance of plants against herbivorous insects. Stevenson et al. (2009) reported that the survival of the African sweet potato weevil was significantly reduced when feeding on an artificial diet which had been enriched by phenolic esters from a root of a resistant sweet potato variety.

The colonization of maize roots by $G$. intraradices induces an increase in the content of abscisic acid (ABA) in the root and shoot (Danneberg et al. 1992). An increase in $A B A$ content in maize plants was also reported when WCR larvae were feeding on maize roots (Erb et al. 2009). Early induction of plant defences by mycorrhiza through increased ABA levels may be regarded as the parameter negatively influencing WCR development. The biomass produced was not significantly different in the various treatments supporting the observations from different studies (Branson et al. 1982, Allee et al. 1996, Kurtz et al. 2010) that root biomass is not a decisive factor for WCR development.

As mentioned previously our cooperating partners Flavia Dematheis and Prof. Dr. Kornelia Smalla analyzed the fungal community of the roots also in this experiment.

The fungal community colonizing the roots was neither influenced by WCR presence nor fungal application (Flavia Dematheis, $\mathrm{PhD}$ thesis 2010 in prep.). These findings are in contrast to results from other studies reporting an influence of $T$. paludosa feeding on microbial community composition and mycorrhizal colonization (Denton et al. 1998, Dawson et al. 2004, Currie et al. 2006). showed that feeding by the nematode species Pratylenchus penetrans (Cobb 1917) Filipjev \& Schuurmans, Stekhoven and $P$. dunensis de la Peña, Moens, van Aelst \& Karssen, on the dune grass Ammophila arenaria (L.) Link did not change the mycorrhizal colonization or species composition on the root. So far only few studies have been published investigating the interactions between microbial 
communities or mycorrhiza and insect feeding on the roots. The outcome of these interactions probably depends on the species involved. To get a better understanding of these interactions more knowledge on the physiological changes of the plants induced by the species and their influence on micro-organisms and insects is needed.

Changes in soil nutrient cycling that are suggested by Grayston et al. (2001) because of induced changes in the microbial communities are not likely to appear because of WCR larval damage. Fungal communities and mycorrhizal colonization are relatively consant and independent of invasive WCR larvae.

Given the background of increasing maize production and climate change, future research should investigate the potential of western corn rootworm larvae to interact with the fumonisin levels in maize. The influence $F$. verticillioides may have on the orientation of WCR larvae could be a promising approach for understanding the orientation and sensibility of WCR larvae towards specific olfactory cues. Using the new visualisation techniques that have been developed by Mario Schumann (PhD thesis in prep.), these questions whether larvae discriminate in the root system of a colonized plant between fungal colonized, and non colonized parts may be answered.

In addition, further research efforts should aimed at understanding the mechanism how mycorrhiza influences western corn rootworm larval development and whether larvae are able to discriminate between differentially mycorrhized plants. 


\section{References cited in general introduction and discussion}

Abu-Zeyad, R., A. G. Khan, and C. Khoo. 1999. Occurrence of arbuscular mycorrhiza in Castanospermum australe A. Cunn. \& C. Fraser and effects on growth and production of castanospermine. Mycorrhiza 9: 111-117.

Agrios, G. N. 2004. Transmission of plant disease by insects, pp. 2290-2317. In J. L. Capinera [ed.], Encyclopedia of Entomology. Kluwer Academic, Dordrecht.

Allee, L. L., and P. M. Davis. 1996. Effect of manure and corn hybrid on survival of western corn rootworm (Coleoptera: Chrysomelidae). Environ. Entomol. 25: 801-809.

Annette, M., S. Tim H, E. Nicole, K. Elisabeth, A. Anto, A. Rein, A. L. M. K. Kerstin, B. Peter, B. Ol'Ga, B. Agrita, C. Frank M, C. Zalika, C. Yannick, D. ÅsıöG, D. Claudio, D. Alison, F. Yolanda, J. Katarzyna, M. Finn, M. Antonio, N. ØYvind, P. Josep, P. Pentti, R. O. Viera, S. Helfried, S. Martin, S. Andreja, V. Arnold J. H. Van, W. Frans-Emil, Z. Susanne, and Z. Ana. 2006. European phenological response to climate change matches the warming pattern. Glob. Change Biol. 12: 1969-1976.

Bacon, C. W., I. E. Yates, D. M. Hinton, and F. Meredith. 2001. Biological control of Fusarium moniliforme in maize. Environ. Health Perspect. 109: 325-332.

Baker, R. H. A., R. J. C. Cannon, and A. MacLeod. 2003. Predicting the potential distribution of alien pests in the UK under global climate change, pp. 12011208., The BCPC Conference - Pests \& Diseases 2003. British Crop Protection Council, Glasgow, Scotland.

Behmer, S. T., and W. D. Nes. 2003. Insect sterol nutrition and physiology: A global overview, pp. 1-72, Advances in Insect Physiology, Vol 31. Academic Press Ltd, London.

Bernardi, M. 2001. Linkages between FAO agroclimatic data resources and the development of GIS models for control of vector-borne diseases. Acta Trop. 79: 21-34.

Berta, G., A. Fusconi, and A. Trotta. 1992. VA mycorrhizal infection and the morphology and function of root systems. Environ. Exp. Bot. 33: 159-173. 
Bezemer, T. M., R. Wagenaar, N. M. Van Dam, W. H. Van Der Putten, and F. L. Wackers. 2004. Above- and below-ground terpenoid aldehyde induction in cotton, Gossypium herbaceum, following root and leaf injury. J. Chem. Ecol. 30: 53-67

Bi, H. H., Y. Y. Song, and R. S. Zeng. 2007. Biochemical and molecular responses of host plants to mycorrhizal infection and their roles in plant defence. Allelopathy J. 20: 15-27.

Bjostad, L. B., and B. E. Hibbard. 1992. 6-Methoxy-2-benzoxazolinone: A semiochemical for host location by western corn rootworm larvae. J. Chem. Ecol. 18: 931-944.

Blossey, B., and R. H. J. Tamaru. 2003. Belowground herbivory by insects: influence on plants and aboveground herbivores. Annu. Rev. Entomol. 48: 521-47.

Branson, T. F., G. R. Sutter, and J. R. Fisher. 1982. Comparison of a tolerant and a susceptible maize inbred under artificial infestations of Diabrotica virgifera virgifera: Yield and adult emergence. Environ. Entomol. 11: 371372.

Branson, T. F., V. A. Welch, G. R. Sutter, and J. R. Fisher. 1983. Resistance to larvae of Diabrotica virgifera virgifera in three experimental maize hybrids. Environ. Entomol. 12: 1509-1512.

Brown, V. K., and A. C. Gange. 1990. Insect herbivory below ground. Adv. Ecol. Res. 20: 1-59.

Cardon, Z. G., and J. L. Whitbeck [eds.]. 2007. The Rhizosphere an ecological perspective. Elsvier Academic Press, San Diego.

Currie, A. F., P. J. Murray, and A. C. Gange. 2006. Root herbivory by Tipula paludosa larvae increases colonization of Agriostis capillaris by arbuscular mycorrhizal fungi. Soil Biol. Biochem. 38: 1994-1997.

Danneberg, G., C. Latus, W. Zimmer, B. Hundeshagen, H. SchneiderPoetsch, and H. Bothe. 1992. Influence of vesicular-arbuscular mycorrhiza on phytohormone balances in maize (Zea mays L.). J. Plant Physiol. 141: 33-39.

Dalmastri, C., A. Fiore, C. Alisi, A. Bevivino, S. Tabacchioni, G. Giuliano, A. R. Sprocati, L. Segre, E. Mahenthiralingam, L. Chiarini, and P. Vandamme. 2003. A rhizospheric Burkholderia cepacia complex 
population: genotypic and phenotypic diversity of Burkholderia cenocepacia and Burkholderia ambifaria. FEMS Microbiol. Ecol. 46: 179-187.

Danielsen, S., and D. F. Jensen. 1998. Relationships between seed germination, fumonisin content and Fusarium verticilloides infection in selected maize samples from different regions of Costa Rica. Plant Pathol. 47: 609-614.

Dawson, L. A., S. J. Grayston, P. J. Murray, J. Ross, E. J. Reid, and A. M. Treonis. 2004. Impact of Tipula paludosa larvae on plant growth and soil microbial community. Appl. Soil Ecol. 25: 51-61.

Desjardins, A. E., and R. D. Plattner. 2000. Fumonisin B-1-nonproducing strains of Fusarium verticillioides cause maize (Zea mays) ear infection and ear rot. J. Agric. Food Chem. 48: 5773-5780.

Desjardins, A. E., G. P. Munkvold, R. D. Plattner, and R. H. Proctor. 2002. FUM1 - A gene required for fumonisin biosynthesis but not for maize ear rot and ear infection by Gibberella moniliformis in field tests. Mol. PlantMicrobe Interact. 15: 1157-1164.

Denton, C. S., R. D. Bardgett, R. Cook, and P. J. Hobbs. 1998. Low amounts of root herbivory positively influence the rhizosphere microbial community in a temperate grassland soil. Soil Biol. Biochem. 31: 155-165.

Doohan, F. M., J. Brennan, and B. M. Cooke. 2003. Influence of climatic factors on Fusarium species pathogenic to cereals. Eur. J. Plant Pathol. 109: 755768.

Dowd, P. F. 1999. Relative inhibition of insect phenoloxidase by cyclic fungal metabolites from insect and plant pathogens. Nat. Toxins 7: 337-341.

Dunn, J. P., and K. Frommelt. 1998. Effects of below-ground herbivory by Diabrotica virgifera virgifera (Col., Chrysomelidea) and soil moisture on leaf gas exchange of maize. J. Appl. Entomol. 122: 179-183.

Erb, M., C. Lenk, J. Degenhardt, and T. C. J. Turlings. 2009. The underestimated role of roots in defence against leaf attackers. Trends Plant Sci. 14: 653-659.

Foley, D. C. 1962. Systemic infection of corn by Fusarium moniliforme. Phytopathology 52: 870-872.

Fontaine, J., A. Grandmougin-Ferjani, M. A. Hartmann, and M. Sancholle. 2001. Sterol biosynthesis by the arbuscular mycorrhizal fungus Glomus intraradices. Lipids 36: 1357-1363. 
Gange, A., V. K. Brown, and G. S. Sinclair. 1994. Reduction of black vine weevil larval growth by vesicular-arbuscular mycorrhizal infection. Entomol. exp. appl. 70: 115-119.

Gange, A. 2001. Species-specific responses of a root- and shoot-feeding insect to arbuscular mycorrhizal colonization of its host plant. New Phytol. 150: 611618.

Gerber, E., H. L. Hinz, and B. Blossey. 2007. Interaction of specialist root and shoot herbivores of Alliaria petiolata and their impact on plant performance and reproduction. Ecol. Entomol. 32: 357-365.

Godfrey, L. D., L. J. Meinke, and R. J. Wright. 1993. Vegetative and reproductive biomass accumulation in field corn: response to root injury by western corn rootworm (Coleoptera: Chrysomelidae). J. Econ. Entomol. 86: 1557-1573.

Goverde, M., H. van der, M. v. d. Heijden, A. Wiemken, Sanders, I. Sanders, and A. Erhardt. 2000. Arbuscular mycorrhizal fungi influence life history traits of a lepidopteran herbivore. Oecologia 125: 362-369.

Gray, M. E., T. W. Sappington, N. J. Miller, J. Moeser, and M. O. Bohn. 2009. Adaptation and invasiveness of western corn rootworm: intensifying research on a worsening pest*. Annu. Rev. Entomol. 54: 303-321.

Grayston, S. J., L. A. Dawson, A. M. Treonis, P. J. Murray, J. Ross, E. J. Reid, and R. MacDougall. 2001. Impact of root herbivory by insect larvae on soil microbial communities. Eur. J. Soil Biol. 37: 277-280.

Gustin, R. D., and T. E. Schumacer. 1989. Relationship of some soil pore parameters to movement of first-instar western corn rootworm (Coleoptera: Chrysomelidae). Environ. Entomol. 18: 343-346.

Hause, B., C. Mrosk, S. Isayenkov, and D. Strack. 2007. Jasmonates in arbuscular mycorrhizal interactions. Phytochemistry 68: 101-110.

Hayman, D. S. 1983. The physiology of vesicular-arbuscular endomycorrhizal symbiosis. Can. J. Bot. 61: 944-963.

Hodge, A. 2000. Microbial ecology of the arbuscular mycorrhiza. FEMS Microbiol. Ecol. 32: 91-96.

Holm-Nielsen, J. B., M. Madsen, and P. O. Popiel. 2006. Predicted energy crop potentials for bioenergy, worldwide and for EU-25., World Bioenergy 2006 Conference on Biomass for Energy, Jönköping - Sweden 
Hou, X., L. J. Meinke, and T. J. Arkebauer. 1997. Soil moisture and larval western corn rootworm injury: Influence on gas exchange parameters in corn. Agron. J. 89: 709-717.

Hunter, M. D. 2000. Mixed signals and cross-talk: interactions between plants, insect herbivores and plant pathogens. Agr. Forest Entomol. 2: 155-160.

Hunter, M. D. 2001. Out of sight out of mind: the impacts of root feeding insects in natural and managed systems. Agr. Forest Entomol. 2001: 3-9.

Jeffries, P. 1987. Use of mycorrhizae in agriculture. CRC Cr. Rev. Biotechn. 5: 319-357.

Johnson, S. N., and P. J. Murray. 2009. Root Feeders: An Ecosystem Perspective. CABI, Wallingford.

Kalb, D. W., G. C. Bergstrom, and E. J. Shields. 1994. Prevalence, severity and association of fungal crown and root rots with injury by the clover root curculio in New York alfalfa. Plant Dis. 78: 491-495.

Kaldorf, M., and J. Ludwig-Müller. 2000. AM fungi might affect the root morphology of maize by increasing indole-3-butyric acid biosynthesis. Physiol. Plantarum 109: 58-67.

Kaplan, I., R. Halitschke, A. Kessler, S. Sardanelli, and R. F. Denno. 2008. Constitutive and induced defenses to herbivory in above- and belowground plant tissues. Ecology 89: 392-406.

Kedera, C. J., J. F. Leslie, and L. E. Claflin. 1994. Genetic diversity of Fusarium section liseola (Gibberella-Fujikuro) in individual maize stalks. Phytopathology 84: 603-607.

Kiss, J., C. R. Edwards, H. K. Berger, P. Cate, M. Cean, S. Cheek, J. Derron, H. Festic, L. Furlan, J. Igrc-Barc 'ic', I. Ivanova, W. Lammers, V. Omelyuta, G. Princzinger, P. Reynaud, I. Sivcev, P. Sivicek, G. Urek, and O. Vahala. 2005. Monitoring of western corn rootworm (Diabrotica virgifera virgifera LeConte) in Europe 1992-2003, pp. 29-39. In U. K. S. Vidal, C. R. Edwards [ed.], Western Corn Rootworm: Ecology and Management, CABI, Wallingford.

Kogan, M. 1998. Integrated pest management: Historical perspectives and contemporary developments. Annu. Rev. Entomol. 43: 243-270.

Koricheva, J., A. C. Gange, and T. Jones. 2009. Effects of mycorrhizal fungi on insect herbivores: a meta-analysis. Ecology 90: 2088-2097. 
Kothari, S. K., H. Marschner, and E. George. 1990. Effect of Va mycorrhizal fungi and rhizosphere microorganisms on root and shoot morphology, growth and water relations in maize. New Phytol. 116: 303-311.

Kurtz, B., Karlovsky P., and S. Vidal. 2010. Interaction between western corn rootworm (Coleoptera: Chrysomelidae) larvae and root-infecting Fusarium verticillioides. Environ. Entomol. (accepted for publication).

Leath, K. T., and A. A. Hower. 1993. Interaction of Fusarium oxysporum f. sp. medicaginis with feeding activity of clover root larvae in alfalfa. Plant Dis. 77: 799-802.

LeConte, J. 1868. New Coleoptera collected on the survey for the extension of the Union Pacific Railway, E.D. from Kansas to Fort Craig, New Mexico. T. Am. Entomol. Soc. 2: 49-59.

Levine, E., and H. Oloumi-Sadeghi. 1991. Management of Diabroticite rootworms in corn. Annu. Rev. Entomol. 36: 229-255.

Maiorano, A., A. Reyneri, D. Sacco, A. Magni, and C. Ramponi. 2009. A dynamic risk assessment model (FUMAgrain) of fumonisin synthesis by Fusarium verticillioides in maize grain in Italy. Crop Prot. 28: 243-256.

Miraglia, M., H. J. P. Marvin, G. A. Kleter, P. Battilani, C. Brera, E. Coni, F. Cubadda, L. Croci, B. De Santis, S. Dekkers, L. Filippi, R. W. A. Hutjes, M. Y. Noordam, M. Pisante, G. Piva, A. Prandini, L. Toti, G. J. van den Born, and A. Vespermann. 2009. Climate change and food safety: An emerging issue with special focus on Europe. Food Chem. Toxicol. 47: 1009-1021.

Meinke, L. J., T. W. Sappington, D. W. Onstad, T. Guillemaud, N. J. Miller, K. Judith, L. Nora, L. Furlan, K. Jozsef, and T. Ferenc. 2009. Western corn rootworm (Diabrotica virgifera virgifera LeConte) population dynamics. Agric. For. Entomol. 11: 29-46.

Moeser, J., and S. Vidal. 2004. Do alternative host plants enhance the invasion of the maize pest Diabrotica virgifera virgifera (Coleoptera: Chrysomelidae) in Europe? Environ. Entomol. 33: 1169-177.

Moeser, J., and T. Guillemaud. 2009. International cooperation on western corn rootworm ecology research: state-of-the-art and future research. Agric. For. Entomol. 11: 3-7. 
Mondy, N., and M.-F. Corio-Costet. 2004. Feeding insects with a phytopathogenic fungus influences their diapause and population dynamics. Ecol. Entomol. 29: 711-717.

Mouhoube, A., F. Schulthess, Y. D. Mawuena, K. F. Cardwell, and G. Cardwell. 2003. The effect of Fusarium verticilloides on oviposition behaviour and binomics of lepidopteran and coleopteran pests attacking the stem and cobs of maize in West Africa. Entomol. Exp. Appl. 106: 201-210.

Munkvold, G. P., D. C. McGee, and W. M. Carlton. 1996. Importance of different pathways for maize kernel infection by Fusarium verticilloides. Phytopathology 87: 209-217.

Munkvold, G. P., and W. M. Carlton. 1997. Influence of inoculation method on systemic Fusarium moniliforme infection of maize plants grown from infected seeds. Plant Dis. 81: 211-216.

Munkvold, G. P., and A. E. Desjardins. 1997. Fumonisins in maize - can we reduce their occurrence ? Plant Dis. 81: 556-565.

Munkvold, G. P., R. L. Hellmich, and L. G. Rice. 1999. Comparison of Fumonisin concentration in Kernels of transgenic bt maize hybrids and nontransgenic hybrids. Plant Dis. 83: 130-138.

Munkvold, G. P. 2003. Epidemiology of Fusarium diseases and their mycotoxinss in maize. Europ. J. Plant Pathol. 109: 705-713.

Murillo-Williams, A., and G. P. Munkvold. 2008. Systemic infection by Fusarium verticilloides in maize plants grown under three temperature regimes. Plant Dis. 92: 1695-1700.

Nelson, P. E. 1992. Taxonomy and biology of Fusarium moniliforme. Mycopathologia 117: 29-36.

Odling-Smee, L. 2007. Biofuels bandwagon hits a rut. Nature 446: 483-483.

Oren, I., S. Ezrati, D. Cohen, and A. Sharon. 2003. Early events in the Fusarium verticilloides-maize interaction characterized by using a green fluorescent protein-expressing transgenic isolate. Appl. Environ. Microb. 69: 16951701.

Palmer, L. T., and T. Kommedahl. 1969. Root-infecting fusarium species in relation to rootworm infestations in corn. Phytopathology 59: 1613-1617.

Priha, O., T. Hallantie, and A. Smolander. 1999. Comparing microbial biomass, denitrification enzyme activity, and numbers of nitrifiers in the rhizospheres 
of Pinus sylvestris, Picea abies and Betula pendula seedlings by microscale methods. Biol. Fertil. Soils 30: 14-19.

Prischmann, D. A., K. E. Dashiell, D. J. Schneider, and B. E. Hibbard. 2007. Field screening maize germplasm for resistance and tolerance to western corn rootworms (Col.: Chrysomelidae). J. Appl. Entomol. 131: 406-415.

Rasmann, S., T. G. Köllner, J. Degenhardt, I. Hiltpold, S. Toepfer, U. Kuhlmann, J. Gershenzon, and T. C. J. Turlings. 2005. Recruitment of entomopathogenic nematodes by insect-damaged maize roots. Nature 434 : 732-737.

Rasmann, S., A. A. Agrawal, S. C. Cook, and A. C. Erwin. 2009. Cardenolides, induced responses, and interactions between above- and belowground herbivores of milkweed (Asclepias spp.). Ecology 90: 2393-2404.

Rice, M. E. 2004. Transgenic rootworm corn: assessing potential agronomic, economic, and environmental benefits. Plant Health Prog.: 1-10.

Riedell, W. E., and R. N. Reese. 1999. Maize morphology and shoot CO2 assimilation after root damage by western corn rootworm larvae. Crop Sci. 39: 1332-1340.

Röder, G., M. Rahier, and R. E. Naisbit. 2007. Coping with an antagonist: the impact of a phytopathogenic fungus on the development and behaviour of two species of alpine leaf beetle. Oikos 116: 1514-1523.

Rodriguez-Echeverria, S., E. de la Pena, M. Moens, H. Freitas, and W. H. van der Putten. 2009. Can root-feeders alter the composition of AMF communities? Experimental evidence from the dune grass Ammophila arenaria. Basic Appl. Ecol. 10: 131-140.

Rostas, M., M. Simon, and M. Hilker. 2003. Ecological cross-effects of induced plant responses towards herbivores and phytopathogenic fungi. Basic Appl. Ecol. 4: 43-62.

Sappington, T. W., B. D. Siegfried, and T. Guillemaud. 2006. Coordinated Diabrotica genetics research: accelerating progress on an urgent insect pest problem. Am. Entomol. 52: 90-97.

Schumann, M. 2008. Fungus Colonization in relation to the subterranean feeding of the western corn rootworm (Coloeptera:Chrysomelidae) in conventional and transgenic maize, pp. 74. Imperial College, London. 
Shaul-Keinan, O., V. Gadkar, I. Ginzberg, J. M. Grunzweig, I. Chet, Y. Elad, S. Wininger, E. Belausov, Y. Eshed, N. Arzmon, Y. Ben-Tal, and Y. Kapulnik. 2002. Hormone concentrations in tobacco roots change during arbuscular mycorrhizal colonization with Glomus intraradices. New Phytol. 154: 501-507.

Singh, B. K., S. Munro, J. M. Potts, and P. Millard. 2007. Influence of grass species and soil type on rhizosphere microbial community structure in grassland soils. Appl. Soil. Ecol. 36: 147-155.

Smith, S. E., and D. J. Reed. 2008. Mycorrhizal Symbiosis. Academic Press, San Diego.

Spencer, J. L., B. E. Hibbard, J. Moeser, and D. W. Onstad. 2009. Behaviour and ecology of the western corn rootworm (Diabrotica virgifera virgifera LeConte). Agr. Forest Entomol. 11: 9-27.

Steinger, T., and H. Mullerscharer. 1992. Physiological and growth-responses of Centaurea maculosa (Asteraceae) to root herbivory under varying levels of interspecific plant competition and soil-nitrogen availability. Oecologia 91: 141-149.

Stevenson, P. C., H. Muyinza, D. R. Hall, E. A. Porter, D. I. Farman, H. Talwana, and R. O. M. Mwanga. 2009. Chemical basis for resistance in sweetpotato Ipomoea batatas to the sweetpotato weevil Cylas puncticollis. Pure Appl. Chem. 81: 141-151.

Strnad, S. P., and M. K. Bergman. 1987a. Movement of first-instar western corn rootworms (Coleoptera: Chrysomelidae) in soil. Environ. Entomol. 16: 975978.

Strnad, S. P., and M. K. Bergman. 1987b. Distribution and orientation of western corn rootworm (Coleoptera: Chrysomelidae) larvae in corn roots. Environ. Entomol. 16: 1193-1198.

Sylvia, D. M., L. C. Hammond, J. M. Bennett, J. H. Haas, and S. B. Linda. 1993. Field Response of Maize to a Vam Fungus and Water Management. Agron. J. 85: 193-198

Thimm, T., A. Hoffmann, H. Borkott, J. Charles Munch, and C. C. Tebbe. 1998. The gut of the soil microarthropod Folsomia candida (Collembola) is a frequently changeable but selective habitat and a vector for microorganisms, Appl. Eviron. Entomol. 64: 2660-2669. 
Toepfer, S., M. M. Ellsbury, R. Eschen, and U. KuhImann. 2007. Spatial clustering of Diabrotica virgifera virgifera and Agriotes ustulatus in smallscale maize fields without topographic relief drift. Entomol. Exp. Appl. 124: 61-75.

Tollefson, J. J. 2007. Evaluating maize for resistance to Diabrotica virgifera virgifera LeConte (Coleoptera: Chrysomelidae). Maydica 52: 311-318.

Toussaint, J. P., M. Kraml, M. Nell, S. E. Smith, F. A. Smith, S. Steinkellner, C. Schmiderer, H. Vierheilig, and J. Novak. 2008. Effect of Glomus mosseae on concentrations of rosmarinic and caffeic acids and essential oil compounds in basil inoculated with Fusarium oxysporum f.sp basilici. Plant Pathol. 57: 1109-1116.

van Dam, N. M. 2009. Belowground herbivory and plant defences. Annu. Rev. Ecol. Evol. Syst. 40: 373-391.

Vicari, M., P. E. Hatcher, and P. G. Ayres. 2002. Combined effect of foliar and mycorrhizal endophytes on an insect herbivore. Ecology 83: 2452-2464.

Vierheilig, H., R. Bennett, G. Kiddle, M. Kaldorf, and J. Ludwig-Muller. 2000. Differences in glucosinolate patterns and arbuscular mycorrhizal status of glucosinolate-containing plant species. New Phytol. 146: 343-352.

Visser, S., D. Parkinson, and M. Hassall. 1987. Fungi associated with Onyxhiurus-subtenuis (Collembola) in an aspen woodland. Can. J. Bot.Rev. Can. Bot. 65: 635-642.

Voss, K. A., P. C. Howard, R. T. Riley, R. P. Sharma, T. J. Bucci, and R. J. Lorentzen. 2002. Carcinogenicity and mechanism of action of fumonisin B-1: a mycotoxin produced by Fusarium moniliforme (= F. verticillioides). Cancer Detect. Prev. 26: 1-9.

Wesseler, J., and E. Fall. 2009. Benefits and costs of Diabrotica virgifera virgifera control in Europe, 23rd IWGO Conference \& 2nd International Conference of Diabrotica Genetics, Munich.

Whipps, J. M., and S. P. Budge. 1993. Transmission of the mycoparasite Coniothyrium minitans by collembolan Folsomia candida (Collembola, Entomobyridae) and glasshouse Sciarid Bradysia sp (Diptera, Sciaridae) Ann. Appl. Biol. 123: 165-171. 
Williams, R. H., J. M. Whipps, and R. C. Cooke. 1998. Role of soil mesofauna in dispersal of Coniothyrium minitans: Transmission to sclerotia of Sclerotinia sclerotiorum. Soil Biol. Biochem. 30: 1929-1935.

Yue, Q., C. W. Bacon, and M. D. Richardson. 1998. Biotransformation of 2-benzoxazolinone and 6-methoxy-benzoxazolinone by Fusarium moniliforme. Phytochemistry 48: 451-454.

Zangerl, A. R., and C. E. Rutledge. 1996. The probability of attack and patterns of constitutive and induced defense: A test of optimal defense theory. Am. Nat. 147: 599-608. 


\section{Publications}

\section{Articles}

Kurtz, B. and S. Vidal. 2010 Can western corn rootworm larvae orientate towards, transport and transmit root infecting Fusarium verticillioides? In preparation for submission

Kurtz, B., Karlovsky, P. and S. Vidal. 2010 Below ground feeding of western corn rootworm larvae increases above ground Fusarium verticillioides colonization in maize. In preparation for submission

Kurtz, B. and S. Vidal. 2010 Soil type and maize cultivar effects on western corn rootworm development. Submitted for publication

Kurtz, B., Karlovsky, P. and S. Vidal. 2010 Interaction between western corn rootworm (Coleoptera: Chrysomelidae) larvae and root-infecting Fusarium verticillioides. Accepted for publication in Environ. Entomol.

Kurtz, B., Schumann, M., Vidal, S., Moeser, J. and P. Karlovsky. 2008 Does Western Corn Rootworm larval feeding increase Fusarium verticilloides colonization in maize? Mitteilungen aus dem Julius Kühn-Institut 417, 224

\section{Presentations at conferences or workshops}

Kurtz, B. and S. Vidal. 2008 Der Maiswurzelbohrer, ein neuer Maisschädling erreicht Europa. Vorlesungsfrühling, Fachhochschule Osnabrück , Osnabrück, Germany

Kurtz, B. and S. Vidal. 2008 Does Western Corn Rootworm larval feeding increase Fusarium verticillioides colonization in maize? $56^{\text {th }}$ Conference of the German Plant Protectionl Society, Kiel, Germany 
Kurtz, B. and S. Vidal. 2009 Does chronological order matter? Western corn rootworm larvae and their interaction with root infecting Fusarium verticillioides. Deutsche Gesellschaft für allgemeine und angewandte Entomologie, Göttingen, Germany

Kurtz, B. and S. Vidal. 2009 Does chronological order matter? Western corn rootworm larvae and their interaction with root infecting Fusarium verticillioides $23^{\text {rd }}$ IWGO Conference $\& 2^{\text {nd }}$ International Conference of Diabrotica Genetics, Munich, Germany

\section{Posters at conferences or workshops}

Kurtz, B., Dematheis, F., Moeser, J., Smalla, K. and S. Vidal. 2008 Interactions of maize root-associated fungal communities and Western Corn Rootworm larvae._DIABR-ACT Symposium "Harmonise the strategies for fighting Diabrotica virgifera virgifera", Goettingen, Germany

Kurtz, B., Dematheis, F., Venjakob, C., Smalla, K. and S. Vidal. 2009 Incorporated from the rhizosphere - Fungal communities in the gut of western corn rootworm larvae. $23^{\text {rd }}$ IWGO Conference $\& 2^{\text {nd }}$ International Conference of Diabrotica Genetics, Munich, Germany

Kurtz, B. and S. Vidal. 2010 Belowground transmission and transportation of root infecting fungi by western corn rootworm larvae. Workshop Multitrophic Interactions, Goettingen, Germany 


\section{Acknowledgements/ Danksagungen}

Prof. Dr. Stefan Vidal danke ich für das interessante Thema, Vertrauen, Freiraum, Unterstützung der Arbeit sowie Durchsicht der Manuskripte.

Prof. Dr. Kornelia Smalla und Flavia Dematheis für die gute Kooperation.

Dr. Joachim Möser für sein offenes Ohr, Ideen, Ratschläge und das Korrekturlesen dieser Arbeit.

Prof. Dr. Petr Karlovsky für gute Ratschläge und Hilfe bei allem, was mit DNSExtraktion und real-time PCR zu tun hatte.

Patricia Bartoschek für Ihren Einsatz und die praktische Unterstützung bei der Durchführung der real-time PCR.

Dr. Christian Ahl für die Hilfe bei der Auswahl der Bodentypen.

Dr. Christian Scherber für die Unterstützung bei der statistischen Auswertung.

Christine Venjakob, Magdolna Weller und Bianca Tappe für Anregungen, Diskussionen und die gute Zusammenarbeit.

Meinen weiteren Korrekturlesern: Lana Dobrindt, Anne Wilstermann und Mario Schumann.

Meiner Familie und Freunden, welche mich immer unterstüzt haben.

Besonders meinen lieben Eltern, ohne die ich nie so weit gekommen wäre! 


\section{Curriculum vitae}

1999

Abitur

2000-2001

Zivildienst, Vogelzivi im Nationalpark Niedersächsisches

Wattenmeer

2001

Beginn Biologiestudium an der Christian Albrechts

Universität zu Kiel

2003

Auslandssemester mittels Erasmus Stipendium an der

University of Aberdeen

2004

Forschungsarbeit am Institut für Phytopathologie über

die Wintersterblichkeit von Weizengallmücken

2005

Abschluss des Biologiestudiums mit Diplom,

Thema der Diplomarbeit:" Curative and preventive use of entomopathogenic nematodes against Diabrotica v. virgifera".

2006

6-monatige Beschäftigung bei Commonwealth Agriculture

Bureux International (CABI) in Hodmezovarshahely, Ungarn und in Delémont, Schweiz

seit 2007

Promotion im Fachbereich für Pflanzenkrankheiten in der

Abteilung Agrarentomologie an der Georg-August Universität Göttingen, Thema: "Interactions between maize root associated fungi and the western corn rootworm". 


\section{Eidesstattliche Erklärung}

Hiermit erkläre ich eidesstattlich, dass diese Dissertation selbständig und ohne unerlaubte Hilfe angefertigt wurde.

Göttingen, Mai 2010 